\title{
Flammable Gas Project Topical Report
}

G. D. Johnson

DE\&S Hanford, Inc.

W. B. Barton

R. C. Hill Lockheed Martin Hanford Corporation

J. W. Brothers

S. A. Bryan

P. A. Gauglitz

L. R. Pederson

C. W. Stewart

Pacific Northwest National Laboratory

\section{H. Stock}

Date Published

January 1997

Prepared for the U.S. Department of Energy

Assistant Secretary for Environmental Management 
THE PA T NTONALA ANK 


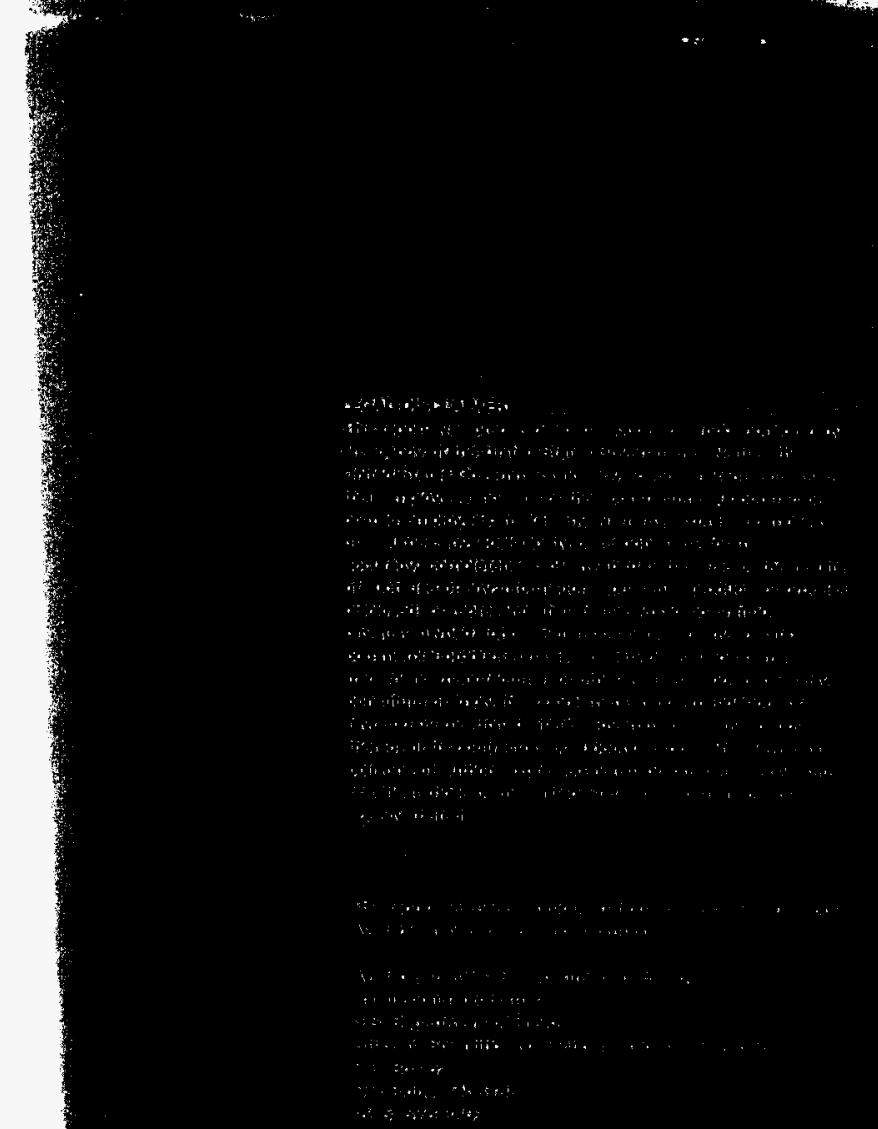


THIS PACE TNTENTTONALIY

LI: T BLANK 


\section{RELEASE AUTHORIZATION}

Document Number: HNF-SP-1193, Rev. 2

Document Title: Flammable Gas Project Topical Report

Release Date: $\quad 1 / 29 / 97$

This document was reviewed following the procedures described in WHC-CM-3-4 and is:

APPROVED FOR PUBLIC RELEASE

WHC Information Release Administration Specialist:

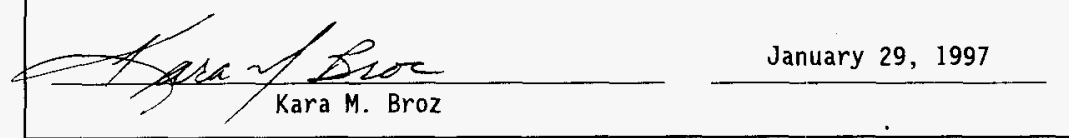




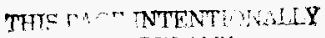
TlindN. 
HNF-SP-1193, Rev. 2

This page intentionally left blank. 
TH." IAGR INTENTIONALLY

LiW" BLWNK 


\begin{abstract}
The flammable gas safety issue was recognized in 1990 with the declaration of an unreviewed safety question (USQ) by the U. S. Department of Energy as a result of the behavior of the Hanford Site high-level waste tank 241-SY-101. This tank exhibited episodic releases of flammable gas that on a couple of occasions exceeded the lower flammability limit of hydrogen in air.

Over the past six years there has been a considerable amount of knowledge gained about the chemical and physical processes that govern the behavior of tank 241-SY-101 and other tanks associated with the flammable gas safety issue. This report was prepared to provide an overview of that knowledge and to provide a description of the key information still needed to resolve the issue.
\end{abstract}

Items covered by this report include summaries of the understanding of gas generation, retention and release mechanisms, the composition and flammability behavior of the gas mixture, the amounts of stored gas, and estimated gas release fractions for spontaneous releases. The report also discusses methods being developed for evaluating the 177 tanks at the Hanford Site and the problems associated with these methods.

Means for measuring the gases emitted from the waste are described along with laboratory experiments designed to gain more information regarding rates of generation, species of gases emitted and modes of gas storage and release. Finally, the process for closing the USQ is outlined as are the information requirements to understand and resolve the flammable gas issue. 
HNF-SP-1 193, Rev. 2

This page intentionally left blank. 


\section{PREFACE}

This report was prepared to satisfy the DNFSB Recommendation 93-5 Implementation Plan (DOE-RL 1996), Milestone 5.4.3.5.h, which requires a "Letter reporting completion of supporting technical document on Flammable Gas Safety Issue (this topical report will describe the current understanding of the issue and future work for resolution)." The text of the Recommendation 93-5 Implementation Plan states:

The flammable gas hazard will continue to exist until the wastes are retrieved from the tanks. However, DOE plans to resolve the Flammable Gas Safety Issue on a tank-by-tank basis when the following steps are completed: a) determination of the amount and composition of gas retained in the wastes; b) establishment of an adequate understanding of the mechanisms for gas generation, retention and release; and c) updating the Authorization Basis for the Manage Tank Waste Function.

The major emphasis of this report is to put the flammable gas hazard into perspective based on our current understanding of the mechanisms driving generation, retention and release of flammable gas mixtures in high-level waste tanks. It provides an overview of what has been learned and what needs to be learned about the phenomena, how the Unreviewed Safety Question will be closed, and the strategy for closing the flammable gas safety issue itself. Section 1 of this report provides an overview of the understanding and needs of the Flammable Gas Safety Issue and Sections 2-7 provide additional details to the information provided in Section 1.

The information in this report represents the status of what is known or being done as of the latter part of 1996. As additional information is obtained from the characterization of tanks, analyses of data, and development of models and analysis methods, the information in this report will need to be updated. 
HNF-SP-1193, Rev. 2

This page intentionally left blank. 
HNF-SP-1193, Rev. 2

\section{CONTENTS}

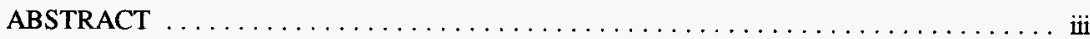

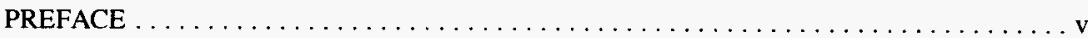

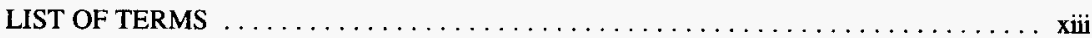

1.0 THE FLAMMABLE GAS SAFETY ISSUE $\ldots \ldots \ldots \ldots \ldots \ldots \ldots \ldots \ldots \ldots \ldots \ldots \ldots$

1.1 CURRENT VIEW OF THE FLAMMABLE GAS HAZARD $\ldots \ldots \ldots \ldots \ldots 1-1$

1.2 CURRENT UNDERSTANDING OF FLAMMABLE GAS GENERATION, RETENTION, AND RELEASE $\ldots \ldots \ldots \ldots \ldots \ldots \ldots \ldots \ldots \ldots$

1.2.1 Understanding of Gas Generation $\ldots \ldots \ldots \ldots \ldots \ldots \ldots \ldots \ldots \ldots$

1.2.2 Understanding of Gas Retention . . . . . . . . . . . . . . . . 1-4

1.2.3 Understanding of Gas Release ...................... 1-6

1.3 STATUS OF OPERATIONAL CONTROLS AND EVALUATION

METHODOLOGY ............................ 1-8

1.4 CLOSING THE FLAMMABLE GAS USQ AND RESOLVING THE

SAFETY ISSUE . . . . . . . . . . . . . . . . . . . . . . . . 1-11

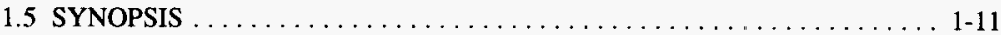

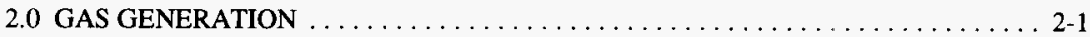

2.1 STUDIES USING SIMULATED WASTES $\ldots \ldots \ldots \ldots \ldots \ldots \ldots \ldots \ldots 2-1$

2.1.1 Thermal Generation $\ldots \ldots \ldots \ldots \ldots \ldots \ldots \ldots \ldots \ldots \ldots \ldots \ldots \ldots, 2-2$

2.1.2 Radiolytic Reactions .......................... 2-5

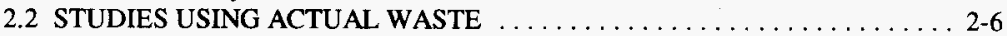

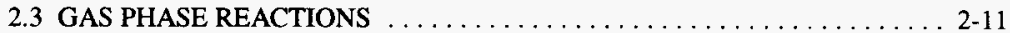

2.4 GAS SOLUBILITIES .......................... 2-11

2.5 DETERMINATION OF IN-TANK GAS COMPOSITION . . . . . . . . . 2-13

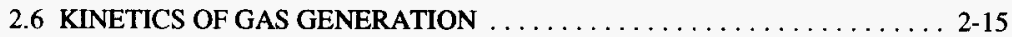

2.7 ACTIVITIES REMAINING TO UNDERSTAND GAS GENERATION . . . . . 2-16

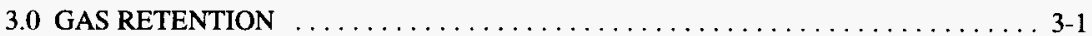

3.1 GAS BUBBLE RETENTION MECHANISMS $\ldots \ldots \ldots \ldots \ldots \ldots \ldots \ldots$. $\ldots \ldots \ldots$

3.2 RESULTS FOR BUBBLE RETENTION IN ACTUAL WASTES $\ldots \ldots \ldots \ldots 3-5$

3.2.1 Mechanism of Retention and Maximum Retention . . . . . . . . . . . 3-9

3.2.2 Effect of Liquid Removal on Maximum Retention . . . . . . . . . . 3-11

3.3 ESTIMATION OF RETAINED GAS VOLUME $\ldots \ldots \ldots \ldots \ldots \ldots \ldots \ldots . . \ldots \ldots$

3.3.1 Void Fraction Instrument . . . . . . . . . . . . . . . . . 3-12

3.3.2 Retained Gas Sampler ...................... 3-13

3.3.3 Assessment of the BPE and VFI Gas Volumes ............. 3-15

3.4 ACTIVITIES REMAINING TO UNDERSTAND GAS RETENTION . . . . . 3-15

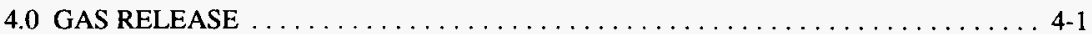




\section{CONTENTS (Continued)}

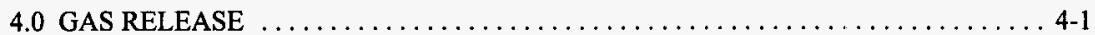

4.1 RELEASE MECHANISMS: UNDISSOLVED GAS $\ldots \ldots \ldots \ldots \ldots \ldots \ldots 4-1$

4.1.1 Buoyant Displacement .......................... 4-1

4.1.2 Percolation of Dendritic Bubbles .................... 4-4

4.1.3 Local Disruptions ............................. 4-6

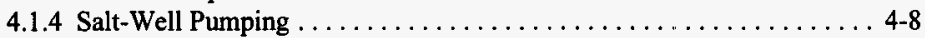

4.1.5 Earthquakes $\ldots \ldots \ldots \ldots \ldots \ldots \ldots \ldots \ldots \ldots \ldots \ldots, 4,11$

4.1.6 Observed Gas Releases ...................... 4-13

4.2 RELEASE MECHANISMS: DISSOLVED GAS $\ldots \ldots \ldots \ldots \ldots \ldots \ldots \ldots 4-15$

4.3 GAS MIXING IN THE HEAD SPACE $\ldots \ldots \ldots \ldots \ldots \ldots \ldots \ldots \ldots \ldots, 4-15$

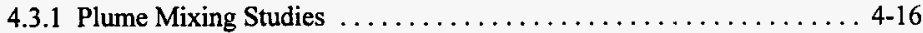

4.3.2 Ventilation Rate Studies ........................ 4-16

4.4 LEAN COMBUSTION OF GAS MIXTURES IN AIR ............. 4-19

4.5 ACTIVITIES REMAINING TO UNDERSTAND GAS RELEASE $\ldots \ldots \ldots$ 4-20

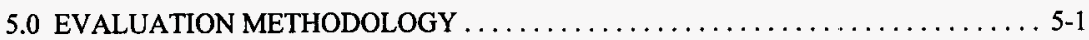

5.1 DEVELOPMENT OF THE EVALUATION METHODOLOGY ......... $5-1$

5.2 DISCUSSION ON APPLICATION OF THE METHODOLOGY $\ldots \ldots \ldots \ldots .5-2$

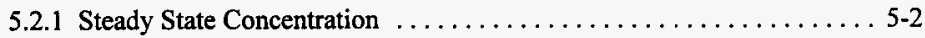

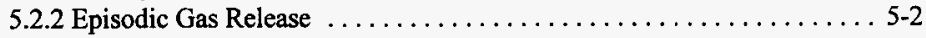

5.2.2.1 Surface Level Rise Method .................. 5-3

5.2.2.2 Barometric Pressure Effect Method ............. 5-3

5.3 REVIEW OF THE METHODOLOGY $\ldots \ldots \ldots \ldots \ldots \ldots \ldots \ldots \ldots \ldots, 5-4$

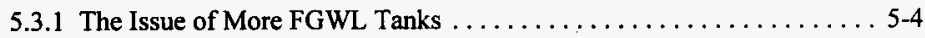

5.3.2 Critical Review Results ....................... 5-5

5.4 APPROACH FOR UPDATING THE METHODOLOGY $\ldots \ldots \ldots \ldots \ldots, 5-6$

6.0 WASTE CHARACTERIZATION $\ldots \ldots \ldots \ldots \ldots \ldots \ldots \ldots \ldots \ldots \ldots \ldots, 6,1$

6.1 MEASUREMENT OF STORED GAS VOLUME $\ldots \ldots \ldots \ldots \ldots \ldots \ldots \ldots, 6,1$

6.2 MEASUREMENT OF HEAD SPACE GASES $\ldots \ldots \ldots \ldots \ldots \ldots \ldots \ldots \ldots-1$

6.2.1 Tank Groupings and Data $\ldots \ldots \ldots \ldots \ldots \ldots \ldots \ldots \ldots \ldots \ldots, 6,2$

6.2.2 Gas Monitoring Priority and Criteria Methodology $\ldots \ldots \ldots \ldots \ldots 6-6$

6.2 .3 Prioritization Results $\ldots \ldots \ldots \ldots \ldots \ldots \ldots \ldots \ldots \ldots \ldots \ldots, 6,7$

6.2.4 Summary $\ldots \ldots \ldots \ldots \ldots \ldots \ldots \ldots \ldots \ldots \ldots \ldots \ldots \ldots \ldots, 6,8$

6.3 WASTE SURFACE LEVEL MEASUREMENTS $\ldots \ldots \ldots \ldots \ldots \ldots \ldots, 6-8$

6.4 LABORATORY TESTING OF SELECTED WASTE SAMPLES $\ldots \ldots \ldots \ldots 6-8$

7.0 CLOSURE OF THE FLAMMABLE GAS USQ AND SAFETY ISSUE $\ldots \ldots \ldots \ldots \ldots$ 7-1

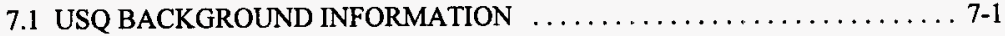

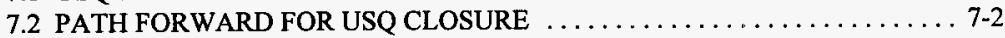

7.3 EVALUATION OF TANKS FOR REMOVAL FROM THE WATCH LIST $\ldots$ 7-3

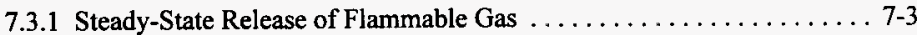

7.3.2 Episodic Gas Release Events $\ldots \ldots \ldots \ldots \ldots \ldots \ldots \ldots \ldots \ldots, 7-4$ 
HNF-SP-1193, Rev. 2

\section{CONTENTS (Continued)}

8.0 SUMMARY $\ldots \ldots \ldots \ldots \ldots \ldots \ldots \ldots \ldots \ldots \ldots \ldots \ldots \ldots \ldots \ldots \ldots, \ldots \ldots \ldots \ldots, 1$

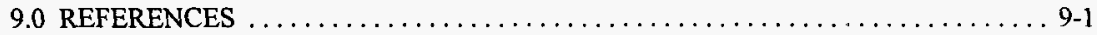

APPENDIX A - WATCH LIST TANKS $\ldots \ldots \ldots \ldots \ldots \ldots \ldots \ldots \ldots \ldots \ldots \ldots \ldots \ldots \ldots \ldots \ldots \ldots$

APPENDIX B -RESULTS OF VAPOR PHASE SAMPLING OF HANFORD SITE

PASSIVELY VENTILATED SINGLE-SHELL TANKS ............ B-1 


\section{LIST OF FIGURES}

2-1 Thermal Consumption of HEDTA and Appearance of Fragments as a Function of Time $\ldots \ldots \ldots \ldots \ldots \ldots \ldots \ldots \ldots \ldots \ldots \ldots \ldots \ldots \ldots \ldots \ldots \ldots \ldots \ldots \ldots \ldots, 2$

2-2 Thermal Generation of Hydrogen, Nitrogen, Nitrous Oxide, and Ammonia as a

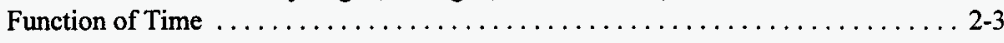

2-3 Hydrogen Yield in Thermal Reactions per Molecule HEDTA Consumed Versus Time for Tests with Air and with Argon as Cover Gases at $90^{\circ} \mathrm{C} \ldots \ldots \ldots \ldots .4$

2-4 Molar Efficiency of Hydrogen Generation for Chelators Using Simulated Tank

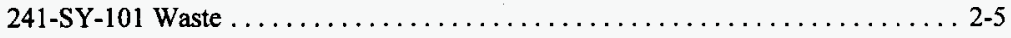

2-5 Composition of Major Products as a Function of Temperature from Gas Generation

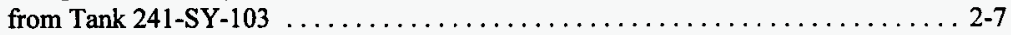

2-6 Arrhenius Plot of Total Gas Generation Rates for Convective Layer of Tank 241-SY-103 in Thermal Reactions . . . . . . . . . . . . . . . . . . .

2-7 Comparison of Total Gas Generation from a Tank 241-SY-101 Core Composite and a Tank 241-SY-103 Convective Layer Sample ................ 2-10

3-1 Schematic of Bubble Displacing Particles and a Dendritic Bubble Fingering Between Waste Particles . . . . . . . . . . . . . . . . . . . . . . . . . . 3

3-2 Bubbles Displacing Waste When Surface Tension Dominates $\left(\tau_{s} D_{\text {bubble }} / \gamma \ll 1\right)$ and When Waste Strength Dominates $\left(\tau_{s} D_{\text {buble }} / \gamma>>1\right) \ldots \ldots \ldots \ldots \ldots \ldots .4$

3-3 Location of Different Bubble Retention Regimes $\ldots \ldots \ldots \ldots \ldots \ldots \ldots \ldots . . \ldots \ldots$

3-4 Bubble Growth and the Formation of a Connected Pathway of Bubbles ........ 3-6

3-5 Gas Bubble Retention Mechanisms . . . . . . . . . . . . . . . . . . 3-7

3-6 Comparison of the Maximum Retention in Actual Waste Samples with Results for Bentonite Clay Simulants $\ldots \ldots \ldots \ldots \ldots \ldots \ldots \ldots \ldots \ldots \ldots \ldots \ldots \ldots \ldots \ldots \ldots, 10$

3-7 Void Fraction Instrument Deployed in a Tank $\ldots \ldots \ldots \ldots \ldots \ldots \ldots \ldots \ldots \ldots \ldots \ldots \ldots$

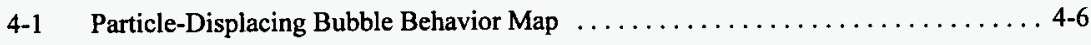

4-2 Percent of Gas Released as a Result of Disruption $\ldots \ldots \ldots \ldots \ldots \ldots \ldots \ldots \ldots$ 
HNF-SP-1 193, Rev. 2

\section{LIST OF FIGURES (Continued)}

4-3 Yield Energy Limit $-640-\mathrm{cm}$ Height, Horizontal $\ldots \ldots \ldots \ldots \ldots \ldots \ldots \ldots \ldots$ 4-12

4-4 Possible Gas Release Fraction Versus Earthquake Severity $\ldots \ldots \ldots \ldots \ldots \ldots$ 4-13 


\section{LIST OF TABLES}

2-1 Comparison of Yields from Reaction of HEDTA in Simulated Waste $\ldots \ldots \ldots \ldots$ 2-4

2-2 Pre-Exponential Factors and Activation Energies for Thermal Gas Generation Corrected for Gas Generation from Self-Radiolysis . . . . . . . . . . . . . 2-8

2-3 G-Values in Radiolytic Reactions of Waste from Tank 241-SY-103 at 5300 R/h . . . 2-9

2-4 Comparison of Hydrogen Generation Rates Estimated from Laboratory Studies Using Small Test Samples with Rates Estimated from Tank 241-SY-103 Observations . . . 2-10

2-5 Henry's Law Constants for Mother Liquor of Tank 241-SY-101 Calculated Using Schumpe Model with Modified Gas Interaction Constants ............ 2-12

2-6 Estimated Quantity of Gas Dissolved in Entire Tank 241-SY-101 Wastes ....... 2-13

2-7 Estimates of the Composition of Gases at $46^{\circ} \mathrm{C}$ in Tank 241-SY-101 ........ 2-13

2-8 Hydrogen-to-Nitrous-Oxide Ratios Calculated from Mass Spectrometry

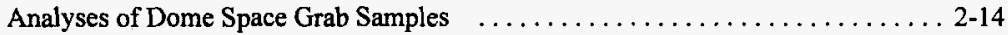

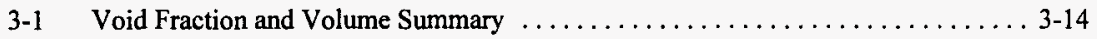

3-2 Barometric Response Comparison ........................... 3.15

4-1 Summary of GRE Behavior in Flammable Gas DSTs ................ 4-14

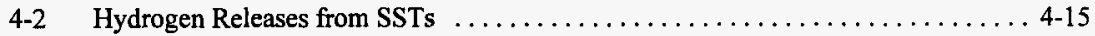

4-3 Summary of Ventilation Rates $\ldots \ldots \ldots \ldots \ldots \ldots \ldots \ldots \ldots \ldots \ldots \ldots, 4,18$

6-1 Waste Tank and Gas Monitor Prioritization $\ldots \ldots \ldots \ldots \ldots \ldots \ldots \ldots, 6 \ldots \ldots$ 


\section{LIST OF TERMS}

$\begin{array}{ll}\text { BIO } & \text { Basis for Interim Operations } \\ \text { BPE } & \text { barometric pressure effect } \\ \text { BPR } & \text { barometric pressure response } \\ \text { cfm } & \text { cubic feet per minute } \\ \text { DBE } & \text { design basis earthquake } \\ \text { DNFSB } & \text { Defense Nuclear Facilities Safety Board } \\ \text { DOE-HQ } & \text { U.S. Department of Energy - Headquarters } \\ \text { DOE-RL } & \text { U.S. Department of Energy - Richland Operations Office } \\ \text { DST } & \text { double-shell tank } \\ \text { FGWL } & \text { Flammable Gas Watch List } \\ \text { FSAR } & \text { Final Safety Assessment Report } \\ \text { FY } & \text { fiscal year } \\ \text { GIT } & \text { Georgia Institute of Technology } \\ \text { GRE } & \text { gas release event } \\ \text { HEPA } & \text { high efficiency particulate air (filter) } \\ \text { JCO } & \text { Justification for Continued Operation } \\ \text { LANL } & \text { Los Alamos National Laboratory } \\ \text { LFL } & \text { lower flammability limit } \\ \text { LOW } & \text { liquid observation well } \\ \text { MOU } & \text { memorandum of understanding } \\ \text { PNNL } & \text { Pacific Northwest National Laboratory } \\ \text { RGS } & \text { retained gas sampler } \\ \text { SHMS } & \text { standard hydrogen monitoring system } \\ \text { SCF } & \text { standard cubic feet } \\ \text { SCOPE } & \text { Safety Control Optimization by Performance Evaluation } \\ \text { SST } & \text { single-shell tank } \\ \text { STP } & \text { standard temperature and pressure } \\ \text { TMACS } & \text { Temperature Monitoring and Control System } \\ \text { TOC } & \text { total organic carbon } \\ \text { TWRS } & \text { Tank Waste Remediation System } \\ \text { USQ } & \text { Unreviewed Safety Question } \\ \text { VFI } & \text { void fraction instrument } \\ \text { WHC } & \text { Westinghouse Hanford Company } \\ & \\ \end{array}$


HNF-SP-1193, Rev. 2

This page intentionally left blank. 


\subsection{THE FLAMMABLE GAS SAFETY ISSUE}

Essentially all radioactive waste slowly generates flammable gas (mainly hydrogen, nitrogen, and nitrous oxide, with smaller amounts of ammonia and traces of methane and other hydrocarbons) by complex chemical reactions resulting from the thermal and radiological decomposition of organic compounds, radiolysis of water, and corrosion reactions with the metal tank walls. The rate due to water radiolysis can be estimated from the radiation dose, while the radiochemical reaction path requires more knowledge of the waste conditions. The generation rate is so low that ventilation is able to keep the flammable gas far below the concentration necessary for ignition. Thus flammable gas generation in itself is not a safety issue in any tank in which the flammable gas generated in the waste is continuously released to the tank head space. However, many tanks have stored enough gas in the waste to cause worker injury or damage to equipment if a significant fraction of it were suddenly released into the head space and ignited. Gas releases may be spontaneous or induced by external forces (e.g., earthquakes, salt-well pumping, barometric pressure swings) or waste intrusion (e.g., core sampling, equipment installation). The potential for such releases and their undesirable consequences constitutes the flammable gas safety issue.

This potential depends on the concentration and volume of flammable gases in the tank head space following a release. If the peak concentration remains everywhere below the lower flammability limit (LFL), the gas cannot be ignited. If the concentration locally exceeds the LFL and a source of ignition is present at that location, a portion or all of the flammable gas could burn. Damage caused by the elevated pressures in the head space or other inclosed spaces in and around the tank could result from such a burn; however, very few tanks are subject to sudden gas releases of a size sufficient to offer a significant potential for damage. Section 1.1 describes the flammable gas hazard.

\subsection{CURRENT VIEW OF THE FLAMMABLE GAS HAZARD}

The flammability hazard in Hanford waste tanks was first recognized in the double-shell tank 241-SY-101 (SY-101). The waste level in this tank began periodically rising and suddenly dropping shortly after it was filled in 1980. The large, "sawtooth" level drops were taken as an indication of episodic gas releases that might pose a safety hazard. A period of intense study of this tank's behavior in 1990-1992 revealed that these releases were, in fact, hazardous; the gas was indeed flammable, and the releases were quite large. Some of them had sufficient volume to exceed the LFL in the head space and would probably have damaged the tank if the gas had been ignited.

The major concern in SY-101 was mitigated in late 1993 with the installation of a mixer pump that has prevented gas retention (Brewster et al. 1995). But the experience with SY-101 created anxiety that other tanks might be having similar large gas releases or the potential to do so, thus associating a perception of imminent danger with all 177 waste tanks. We know now that this perception was not correct. 
The studies carried out in the past three years have shown that the large episodic gas release behavior of SY-101 was truly unique, that no other tanks have exhibited releases approaching this magnitude and that none appear to have the potential to do so. The level data show only five other tanks currently exhibiting periodic level drops associated with gas release, and these are much smaller than those of SY-101. Theory, experiment, and experience indicate that only the waste configuration found in double-shell tanks (DSTs) has the potential for significant episodic gas releases.

The historic gas releases in SY-101 were buoyancy-induced displacement events (Allemann et al. 1994). Prior to a buoyant displacement, a portion of the settled solids layer accumulates gas until it becomes sufficiently buoyant to overcome the weight and strength of material restraining it. At that point it suddenly breaks away and rises through the liquid. The stored gas expands as it rises, breaks up the retaining matrix and thus allows a portion of the gas to escape into the head space. Such gas release events (GREs) are clearly reflected in the axial waste temperature profiles, where the high-temperature "bulge" characteristic of nonconvective waste near the tank bottom suddenly cooled as the temperatures in the upper, convective portion increased. The violence of the rollover motion was also dramatically portrayed on in-tank video.

For a large gas release to occur by buoyant displacement, there must be a settled solids layer that traps gas, and sufficient potential energy must be released to free the trapped gas from the rising waste. The potential energy available for release depends on the depth of supernatant liquid above the gas-bearing solids layer. Experiments, thermodynamics, and tank experience all show that a relatively deep layer (more than about one meter) of supernatant is required to provide sufficient energy for a significant gas release (Stewart et al. 1996b). This is discussed in detail in Section 4.1.

Only the DSTs that have a waste configuration similar to SY-101 have enough potential energy to release a significant amount of gas in a buoyant displacement. Only five of these tanks (SY-103, AW-101, AN-103, AN-104, and AN-105) actually exhibit buoyant displacements, but their releases are typically less than 1,000 cubic feet, whereas those in SY-101 were typically several thousand cubic feet (Stewart et al. 1996a). Level drops in these tanks are generally less than 3 inches; those associated with the major GREs in SY-101 were in the range of 6-12 inches (see Section 4.1).

None of the single-shell tanks (SSTs) have a deep (greater than about one meter) supernatant liquid layer and thus are probably not subject to gas release by a buoyant displacement event. In fact, all release mechanisms believed plausible have been studied, and there are none by which SSTs can experience large, sudden, spontaneous gas releases (see Section 4.1). No large gas releases are seen in the head space gas monitoring data currently available (Wilkins et al. 1996), and only a few SSTs show isolated surface level breaks that might be evidence of small gas releases (Whitney et al. 1996). Otherwise, surface level changes in SSTs are only on the order of a few tenths of an inch and, in general, are related to changes in atmospheric pressure. Most of the SSTs show little evidence of stored gas (by head space monitoring, barometric pressure response, or surface level rise) (Hodgson et al. 1996; Whitney 1995). A major portion of the free liquid has been removed from over 100 SSTs. This action has eliminated their ability to release large 
volumes of gas except possibly during a severe earthquake. However, sufficiently severe seismic events are rare; only those with estimated return frequencies of 1000 years are expected to fluidize the waste and thereby release a large fraction of stored gas in SSTs, while a 100-year event might do so in DSTs (Stewart et al. 1996b). Earthquake-induced releases are discussed further in Section 4.1.

Based on recent technical work, the potential for large episodic gas releases in tanks other than SY-101 is not nearly as great a concern as once believed. However, flammable gas remains a potential operational hazard. Most tanks potentially contain some flammable gas, and small releases can be induced by local intrusions (e.g., core sampling). Also, small releases of tens of cubic feet over hours are observed on gas monitoring data in a few SSTs. Flammable gas from these very small releases can collect in equipment to create a real hazard to workers performing operations that penetrate the waste. Hence, some flammability controls will always be needed in all of the tanks to ensure safe operation. But controls need to be applied in a graded manner based on tank condition and type of activity. An adequate understanding of the processes and mechanisms for flammable gas generation, retention, and release is necessary to provide the proper controls for the appropriate tanks. A methodology consistent with the phenomenon is desired to evaluate the hazard in every tank.

\subsection{CURRENT UNDERSTANDING OF FLAMMABLE GAS GENERATION, RETENTION, AND RELEASE}

Analysis of the chemistry and physics of the flammable gas safety issue must embody the causeand-effect relationship of generation, retention, and release. Gas generation is the ultimate source of the hazard; gas retention is a measure of the potential hazard; and gas release represents the actual hazard. The need for understanding each of the three facets is described below.

Gas generation processes must be understood well enough to estimate the generation rate and relative gas composition. The generation rates of the major fuel and diluent species determine the minimum tank ventilation rate required to prevent a flammable mixture buildup in the head space.

The volume and composition of gas trapped in the waste is a direct measure of the potential flammable gas hazard. Each mechanism of gas retention has a complementary gas release mechanism; therefore, an understanding of gas retention is necessary to understand gas release, including its likelihood, rate, and amount.

The flammable gas hazard of a tank depends on the possible consequences of a gas release. Flammable gas cannot create consequences until it is actually released in a closed volume at a concentration that can be ignited and burn, elevating the pressure. Understanding gas release mechanisms sufficiently to estimate release rate, volume, and frequency and to relate each of these to the tank waste configuration and properties is necessary to evaluate the probable consequences. 


\subsubsection{Understanding of Gas Generation}

A review of the current understanding of the mechanisms for gas generation is provided in Section 2.0. In brief, the three most important mechanisms for gas generation are 1) radiolytic decomposition of water and some organic species; 2) chemical reactions, mainly involving organic complexants and solvents; and 3) chemical decomposition of the steel tank walls. The first two clearly dominate, and the yield from radiolysis of the organic compounds is especially important.

Recent studies on gas evolution from tank waste samples and prior mechanistic studies with simulants have advanced our understanding of gas generation processes significantly (Meisel et al. 1991, 1992, 1993; Barefield et al. 1996; Bryan et al. 1996; Pederson and Bryan 1996). Activation energies for overall gas generation as well as for hydrogen, nitrogen, and nitrous oxide are now well established for the waste from tank SY-103. The relative magnitude of the thermal and radiolytic components of gas generation are known as a function of temperature for wastes from SY-101 and SY-103 and a predictive model for gas generation based on the behavior of SY-103 waste is being developed.

Both head space gas concentration measurements and predictions show that gas generation of itself does not create a flammable gas hazard if ventilation is adequate. In the majority of tanks, passive natural convective ventilation provides enough dilution for the gases generated in the waste (see Section 4.3). In some tanks, however, the generation rate is high enough that active mechanical ventilation is required to prevent flammable gas buildup.

Though we know how to study gas generation effectively, and we understand the gas generation behavior of SY-101 and SY-103 waste reasonably well, we cannot yet extrapolate to other waste types with confidence and precision. We must be able to do this to predict the long-term behavior of the tanks and to understand what factors affect the composition of gas in the waste.

To make the step to prediction, the current laboratory methods need to be applied to core samples from several additional, carefully selected waste types. Based on earlier gas generation tests completed on tanks SY-101 and SY-103, tanks S-102, AW-101, and AN-105 were selected to best meet the needs of the Flammable Gas Project. We also recommend testing a second tank from the S or SX tank farm with composition dissimilar to S-102.

\subsubsection{Understanding of Gas Retention}

Studies have shown that some tanks store significant volumes of gas in the waste. In some, the waste surface level has gradually risen several inches since the last addition of waste, indicating a gas buildup. Other tanks show a correlation of small waste surface level fluctuations with barometric pressure changes that can only be due to compression and expansion of stored gas. Fewer than 60 tanks contain measurable gas volumes (Whitney 1995). It is important to accurately measure the volume of gas stored in these tanks and to understand the mechanisms by which it is stored to assess the magnitude of the hazard. 
The volumes of gas stored in the DSTs on the Flammable Gas Watch List (FGWL) are known to within 10-25\% from direct measurement with the void fraction instrument (VFI) and Retained Gas Sampler (RGS). Much of the uncertainty results from the rough estimates of the volume stored in the floating crust layer where no direct measurement is possible (see Table 3.1 and Section 3.3.3). Only one tank (AN-103) contains a volume comparable to that stored in SY-101 before installation of the mixer pump; the rest contain only $25-30 \%$ of that amount. The volume of gas stored in these DSTs is not sufficient to exceed the 3-bar tank pressure limit at $99 \%$ confidence even if $70 \%$ of the stored gas were released and burned (Stewart et al. 1996a). The RGS will be used in selected SSTs to measure gas volumes directly and to validate the previous conclusions.

Sufficiently accurate and frequent measurements are available in the majority of tanks on the FGWL to estimate the in-situ gas volume with fair accuracy (within -50\%) from the response of the waste level changes to barometric pressure. This method also gives a positive indication that a significant quantity of gas is present even in cases where the actual volume cannot be calculated. This method has been extensively evaluated in DSTs and will be applied to SSTs. All tanks have been screened for trapped gas with this method (Whitney 1995; Hodgson et al. 1996) and the results have undergone a very thorough critical review (Johnson 1996). Only 58 of the 177 tanks indicated trapped gas and, of these, only 20-25 tanks, including the six DSTs, stored relatively large volumes of gas. About 50 tanks have so little waste that gas retention is of no concern because of the large dome space dilution factor. The chronologies of these determinations and the operational issues associated with them are discussed in Section 1.3.

Free gas can accumulate only in submerged solids lying beneath the free liquid level as discussed in Section 3.5; gas escapes from unsubmerged solid layers by diffusion. Convective fluid layers cannot retain gas because bubbles rise through a liquid much faster than they are generated. The configuration, limiting size, and maximum volume fraction of gas bubbles can now be predicted with some confidence as a function of surface tension, particle size, yield stress, and waste depth (Gauglitz et al. 1996). While most submerged waste is capable of holding gas fractions on the order of $30 \%$, the size of individual bubbles (both round and dendritic) is quite limited, so a local disturbance does not trigger a general, large-scale gas release (Stewart et al. 1996b).

Soluble gases (mainly ammonia, with a small amount nitrous oxide) are also dissolved in the liquid waste. Based on preliminary RGS measurements, a typical tank might contain a large amount of dissolved ammonia. If all of it were to evaporate, on the order of 140 to 1400 cubic meters of ammonia might be liberated at standard conditions. However, evaporation of dissolved gas is a concern only when a free liquid surface is freshly exposed and/or agitated by some other disturbance such as seismic event or when liquid waste is transferred to another tank.

The needs remaining in understanding gas retention center around confirming the current model through additional experiment and actual measurements. The following list summarizes the discussion given in Section 3.8.

- Conduct bubble retention experiments on selected additional waste samples that cover the range of waste types important to the flammable gas safety issue. 
- Conduct a large scale, long-term experiment to validate the current model of gas retention.

- Install Enraf ${ }^{\infty}$ level gauges on all high-priority tanks, and ensure all of them record level automatically, to accurately monitor stored gas volume.

- $\quad$ Aggressively operate the RGS to provide

- the retained gas volume, composition, and distribution in high-priority SSTs

- the retained gas volume, composition, and distribution before and after salt-well pumping in representative tanks

- the concentration of dissolved ammonia in the liquid.

\subsubsection{Understanding of Gas Release}

Much of our knowledge about gas release has come from studying GREs in DSTs because significant GREs have occurred only in DSTs. They are characterized by "sawtooth" waste level drops with occasional concurrent changes in temperature profiles and, more recently, hydrogen concentration spikes in the head space from the standard hydrogen monitoring system (SHMS) data. No such sudden level drops associated with gas release are seen in SSTs though small gas releases have been noted from the SHMS data.

Through evaluations of the gas monitoring data, waste level history, dome space pressure response and ventilation rates, the distribution of gas release volumes and rates have been estimated for the six DSTs on the FGWL (Stewart et al. 1996a; Wilkins et al. 1996). These studies indicate that the large releases that occurred in SY-101 before the mixer pump was installed were unique in size and frequency. None of the gas releases in the other DSTs have created flammable mixtures in the tank head space nor are they expected to do so. The buoyant displacement gas release mechanism is quite well understood and explains the episodic gas release process in all the DSTs. We understand the dynamics of the buoyant displacement process and the conditions necessary for it to cause a large gas release. A method to predict the size, frequency, and gas release volume of buoyant displacements is under development.

Experiments, thermodynamics, and tank experience all show that gas releases do not occur via the buoyant displacement mechanism in the SSTs because they have insufficient supernatant liquid for the dynamics of the process to take place. The ongoing study of gas retention behavior of SST waste forms has narrowed the number of plausible spontaneous release mechanisms to only a few possibilities that are capable of only small releases (less than $10 \mathrm{~m}^{3}$ as opposed to $100-200 \mathrm{~m}^{3}$ in SY-101 (Stewart et al. 1996b).

Based on field experience and analysis, local waste disruptions do not suddenly trigger releases of large volumes (tens of cubic meters) of gas. A thorough study of 49 core sampling events and 38 liquid observation well (LOW) insertions in SSTs (LANL 1996), and over 50 waste penetrations 
with the VFI and ball rheometer in DSTs (Stewart et al. 1996a) revealed no bonafide gas releases in SSTs and only one instance of a small release in a DST. Gas is released only from the volume of waste actually disturbed. The limited extent of individual bubbles prevents a local penetration from triggering a large general release.

The general disruption of liquid removal by salt-well pumping is expected to release a relatively large volume of gas but slowly, as a series of small releases over many months. No large gas releases were observed in the limited gas monitoring data available for recent pumping campaigns (Caley et al. 1996), although preliminary analysis indicates relatively large ammonia releases are possible (Peurrung et al. 1996). In tanks with sufficiently permeable waste to allow most of the liquid to be removed by salt-well pumping, the combination of decreasing the volume of wet solids available to store gas, reducing hydrostatic head on that remaining, and increasing tank head space volume are expected to effectively eliminate the flammable gas hazard in the head space. Over 100 of the 149 SSTs have been interim-stabilized, but the data on the volume of wet solids are unclear, and additional measurements of the interstitial liquid level may be needed.

The needs remaining to understand gas release deal less with the large, catastrophic releases and focus more on the common, small releases that are of operational concern. The list below summarizes the discussion in Section 4.5. The data provided by the RGS, as stated above, also aid directly in understanding gas release.

- Develop the capability to predict whether buoyant displacement will occur in a "new" tank created by transfer of existing waste.

- Relate the small gas releases from SSTs observed in SHMS data to waste configuration and properties in the context of the gas retention and release mechanisms.

- Develop a predictive parametric model for the volume of a small, plume-type release that is actually flammable as a function of elapsed time after release.

- Continue head space tracer studies and analysis of concentration decay transients from SHMS data to understand the effects of diurnal, meteorological, and seasonal temperature variations on passive ventilation.

- Continue modeling and experimental studies of salt-well pumping focused on understanding ammonia (soluble gas) release. Interpret data from appropriately monitored tanks during pumping.

- Decide whether the earthquake-induced gas release hazard is applicable to the "safe storage" category.

- Continue developing knowledge of the combustion process in lean mixtures to aid in assessing the probability for deflagration and detonation in the head space and potential for flammable gas burns beneath the waste surface. 


\subsection{STATUS OF OPERATIONAL CONTROLS AND EVALUATION METHODOLOGY}

A methodology consistent with the flammable gas phenomenon is required to place every tank in the proper category according to its relative hazard level, with controls tailored to fit each category. The development of such a methodology also provides a collateral service by forcing integration of all necessary knowledge. This ensures consistency and completeness and helps prioritize future work. The current controls and evaluation methodology have evolved through a series of developments that will be summarized here as the basis for understanding what changes might be needed.

In 1990, the apparent release of large quantities of flammable gases in SY-101 waste was recognized as a situation requiring special attention and control. In April 1990, administrative controls were implemented to control activities in SY-101 and in other tanks that potentially had similar behavior (Bracken 1990) (see Appendix A). In May 1990, the U.S. Department of Energy-Richland Operations Office (DOE-RL) determined that hydrogen and nitrous oxide evolution in certain waste tanks and the possibility of its ignition constituted an unreviewed safety question (USQ) (Lawrence 1990). The USQ was applied to tanks previously identified as tanks of concern in Bracken (1990).

In November 1990, the National Defense Authorization Act for Fiscal Year 1991 (Public Law101-510, Section 3137, "Safety Measures for Waste Tanks at the Hanford Nuclear Reservation," (the Wyden Amendment) was passed. It required the Secretary of Energy to identify within 90 days high-level nuclear waste tanks that could have a "serious potential for release of high-level waste due to uncontrolled increases in temperature or pressure." The identified tanks contained flammable gas, ferrocyanide ions, organic chemicals, and high radioactive decay heat.

In January 1991, the Westinghouse Hanford Company (WHC) formally submitted a Watch List of tanks subject to the law (Harmon 1991a). In February 1991, WHC submitted a method for selecting flammable gas tanks (Harmon 1991b). The 1991 Watch List identified 23 tanks. In 1992 and 1993, two additional tanks were added, for a total of 25 . These six DSTs and 19 SSTs are listed in Appendix A. At this time the Watch List and the USQ identified the same tanks.

Over the next few years, additional evaluations indicated that a number of other tanks were retaining flammable gas in the waste and might present a "serious potential for release." Accordingly, a goal was set to screen all 177 tanks for flammable gas risk and potential addition to the FGWL.

By early 1995, Pacific Northwest National Laboratory (PNNL) completed an initial screening of all 177 tanks using the barometric pressure response method (Whitney 1995). The results indicated that 58 tanks retained detectable volumes of gas, but the actual volumes were not estimated. Twenty-one of these tanks were already on the FGWL. The Tank Waste Remediation System (TWRS) Plant Review Committee issued standing orders to place flammable gas work controls on the remaining 37 suspect tanks. 
A more detailed, formal methodology was developed to evaluate tanks for inclusion on the FGWL in late 1995 (Hopkins 1995); it used the barometric pressure response method along with surface level rise to calculate the volume of gas trapped in the waste. All 177 tanks were evaluated in accordance with this methodology by early 1996 (Hodgson et al. 1996). Fifty-three tanks failed the evaluation criteria, and 21 of these were already on the FGWL. Four of the original 25 tanks passed the evaluation and are therefore suggested as potential candidates for removal from the FGWL. In November 1995, flammability controls (ignition sources, ventilation requirements, and monitoring for flammable gases) were established in all 177 tanks.

Twenty five of the remaining 32 tanks (only three of which are DSTs) were placed under the flammable gas USQ in February 1996 and recommended for the FGWL. The recommendation was withdrawn in July 1996 after the Chemical Reactions SubPanel and DOE-HQ raised questions about the assumptions used in the methodology and the quality of the data on which the evaluation was based (Johnson 1996a). A major finding of the review team was that the methodology was not sufficiently definitive for recommending the addition or removal of tanks from the FGWL. However, all of the additional tanks remained under the USQ. The remaining seven tanks were added to the USQ in July 1996.

WHC updated the original USQ and consolidated previous determinations into one overall USQ determination that was adopted by DOE-RL on November 1, 1996. This expanded the USQ in flammable gas composition; applicability to additional structures; methods of gas generation, retention, and release; location of hazard; and energetics and characteristics of burns (see Section 7.1). The USQ now applies to 176 tanks. It is noteworthy that SY-101, the tank that initiated the entire process, was dropped from the USQ as having an adequate authorization basis.

A justification for continued operation (JCO) was submitted concurrent with the expanded USQ. The JCO provides detailed descriptions and data for the flammable gas hazards identified in the USQ. Work controls and equipment requirements were developed and documented. The controls and requirements include adaptations, expansions, and refinements to existing Authorization Basis controls and other administrative practices used to manage the flammable gas hazard. The JCO is under review by DOE-RL; however, standing orders have been approved that provide the controls outlined in the JCO (Wagoner 1996b) for ventilation, ignition source, and monitoring controls to be applied to the tanks on a graded basis for both waste- and non-waste-disturbing operations.

A revised criteria document for selecting FGWL tanks was submitted to DOE in 1996 (Bacon 1996a) to bring it more into line with the original intent of the Wyden amendment. The proposed criteria would select tanks for the FGWL in which the entire head space could reach $100 \%$ of the LFL, or in which a plume, if ignited, would cause containment damage. Tanks can be removed from the list when tank conditions meeting FGWL criteria are known to no longer be present. These revised criteria are currently being finalized by DOE. 
The evaluation methodology is being revised to accommodate the recommendations of the DOE review. New understanding of gas retention and release mechanisms will be incorporated as will an improved treatment of uncertainties. In the DOE review (Johnson 1996a) important conclusions were

Models used are elementary and do not represent the physical situation with the waste in the tanks. The calculational bases established by the models need to be validated before they can be relied upon for reliable gas volume estimates.

When they apply, the models currently available afford the ability to estimate the volume of gas trapped; however, no independent measurements have been made in the FGWL tanks to confirm that the volume calculated is actually present. The (contractor) should acquire appropriate data (retained gas and void fractions) to allow validation of the models and the assumptions associated with them.

The Barometric Pressure Effect method appears to have the best potential, of the methods available, for detecting the presence and estimating the volumes of trapped gas. ... it still is not fully satisfactory because of intrinsic errors (model short comings) and information uncertainties. It is possible to reduce these errors and an effort to systematically do so should be considered. Improved surface level measurement equipment, such as the Enraf gauge, will have a direct benefit to this method.

Given these conclusions, efforts for improving the methodology will be directed at improving the barometric pressure effect (BPE) model with an emphasis on using the data from the VFI and RGS efforts. These data will provide information on the distribution and total amount of stored gas, which in turn, will permit establishing the proper effective pressure at which the gas is stored. Waste level monitoring improvements (Enraf gauges and automatic recording) will improve the BPE method by allowing for the hysteresis effect that has been observed in the measurements, as well as improving the basic statistics of the data.

Better information is needed to assign release fractions to the various waste and tank types. This can be done with additional monitoring of releases and more laboratory studies. Results can then be used to update the parameters used in the methodology, with an emphasis on improving the basis for gas release in SSTs.

Finally, the long-term surface level rise method will be used only to indicate, not to measure, retained gas, in accordance with the report of the team that reviewed the methodology (Johnson 1996a). 


\subsection{CLOSING THE FLAMMABLE GAS USQ AND RESOLVING THE SAFETY ISSUE}

A brief overview of the flammable gas unreviewed safety question (USQ) was given in Section 1.3. The USQ has been closed for tank 241-SY-101, a process that took two years. During this time there was a wide variety of views on what constituted closure, especially from the point of what was the acceptable technical basis. The redefinition of the USQ in July 1996 encompassed a wider spectrum of issues and facilities. Thus, additional issues relating to gas generation, retention and release, flammable gas composition, location of hazards, and the energetics and characteristics of burns must be addressed in closing a USQ. The approach selected to close the USQ involves using expert elicitation methods to define uncertainties associated with these issues. One result of this approach is a tool that allows the analysts to quantitatively predict the effect of control strategies on the safety and operating costs of a given facility configuration. (Sections 7.1 and 7.2 provide additional details on the USQ and closure approach.)

Resolution of the safety issue has been associated with removal of tanks from the FGWL. As noted in Section 1.3, a revision to the FGWL criterion is under review by DOE. Removing a tank from the FGWL will require establishing conditions for any given tank that prevent it from releasing the volume of gas that, if ignited, would result in a pressure above a containment design limit. Achieving this condition would require either mitigation of the existing condition or demonstration, by a preponderance of evidence, that the condition didn't exist in the first place. Information needed to achieve this is given in Section 7.3.

\subsection{SYNOPSIS}

The perceived extent of the flammable gas safety issue has narrowed considerably as our understanding of the problem has improved. The only mechanism that has been demonstrated capable of producing large, spontaneous gas releases is the buoyancy-induced displacement. A buoyant displacement event can release a significant volume (tens of cubic meters) of gas only in tanks with a relatively deep layer of supernatant liquid. Only the DSTs satisfy this condition. It has been determined that there are no known mechanisms for large spontaneous releases in SSTs. This realization significantly reduces the number of tanks that are actually and immediately hazardous:

- The only tank that released large volumes $\left(100-200 \mathrm{~m}^{3}\right)$ of flammable gas $(1-3$ times per year) sufficient to exceed the LFL in the mixed head space and to potentially damage the dome if burned was SY-101 prior to mixer pump installation. No other tank has approached this kind of behavior.

- $\quad$ Only the five other DSTs on the FGWL have demonstrated spontaneous release of significant volumes (tens of cubic meters) of flammable gas. These releases are not sufficient to exceed the LFL in the mixed head space but could result in damage to tank equipment such as HEPA filters if bumed as a plume. 
- There are 40-50 tanks that contain flammable gas and are subject to small (a few cubic meters) spontaneous releases. Additional evaluation and characterization is needed to properly classify these tanks.

- The remaining 120-130 tanks present only an operational hazard due to potential accumulation of gas within equipment due to small releases induced by local waste disruption. About $\mathbf{5 0}$ of these contain so little waste that even this hazard may be minimal.

Waste characterization, via sampling, needs to focus on selected tanks to determine the amount and composition of stored gas, and continuous gas monitoring should be conducted on those tanks containing a significant volume of stored gas.

The understanding of the physical mechanisms for gas generation, retention, and release provide a sound basis to support the controls that were specified in the standing order. As uncertainty is reduced by waste sampling and characterization, study of monitoring data, laboratory experiments, and theoretical analysis, the controls based on a graded tank hazard classification will be implemented. The technical issues need to be sufficiently well understood to describe flammable gas behavior, and this will aid closure of the flammable gas safety issue. 


\subsection{GAS GENERATION}

An understanding of gas generation is important to operation of the waste tanks for several reasons. First a knowledge of the overall rate of generation is needed to verify that any given tank has sufficient ventilation to ensure that flammable gases are maintained at a safe level within the dome space. Results of laboratory tests and tank sampling have shown the current ventilation systems to be capable of handling the steady state release of gas. Understanding the mechanisms for production of the various gases is important so that future waste operations do not create conditions that promote the production of hydrogen, ammonia, and nitrous oxide. Studying the generation of gases also provides important data for the composition of the gas mixture, which in turn is needed to assess the flammability characteristics. Finally, information about generation of gases, including the influence of organic constituents and temperature, will aid in assessing the future behavior of the waste during interim storage, implementation of controls, and/or mitigation.

The project has already evaluated the effects of radiation on the generation of gases (Meisel et al. 1993) and the thermal degradation of the organic species (Barefield et al. 1995, 1996) through studies of synthetic waste mixtures. The more recent focus of the project has been on testing actual tank waste samples (Bryan et al. 1996; Person 1996). The status of the knowledge of gas generation has been summarized by Pederson and Bryan (1996). This section provides a brief overview of the current understanding of laboratory efforts on gas generation, gas phase reactions, gas solubilities, the composition of the slurry gas mixture, and the kinetics of generation.

\subsection{STUDIES USING SIMULATED WASTES}

Gas generation results from the radiolysis of water and the thermal and radiolytic transformation of the organic compounds in the waste. The soluble organic complexants are transformed into oxidized, soluble molecules that are retained in the waste and into several gases: hydrogen, ammonia, nitrogen, nitrous oxide and methane.

Since the actual waste is very complex in nature, containing many organic complexants as well as a multitude of organic decomposition products, it was necessary to design a simpler system (waste simulants) for these studies. Various temperatures and dose rates were used to probe the thermal and radiolytic activation parameters of gas generation reactions. The waste simulants were not intended to exactly duplicate the actual waste for gas generation but were used to probe for gas generation reactions. Waste simulants are used to determine chemical mechanisms for gas generation reactions with organic complexants. 


\subsubsection{Thermal Generation}

Thermal pathways for generation of flammable gas and fragmentation pathways for chelators have been investigated at the Georgia Institute of Technology. The mechanism of hydrogen generation from chelators such as HEDTA and EDTA involves extensive fragmentation of those molecules. Aluminate and nitrite ions are thought to be important in initiating the decomposition (Barefield et al. 1995, 1996). Formaldehyde is proposed as an important hydrogen-producing species, a byproduct of several fragmentation steps. Other aldehydic aging products such as glyoxylate are also important sources of hydrogen (Pederson and Bryan 1996). Figure 2-1 shows the normalized concentrations versus time for the HEDTA breakdown. Figure 2-2 shows the relative gas generation from the same molecule.

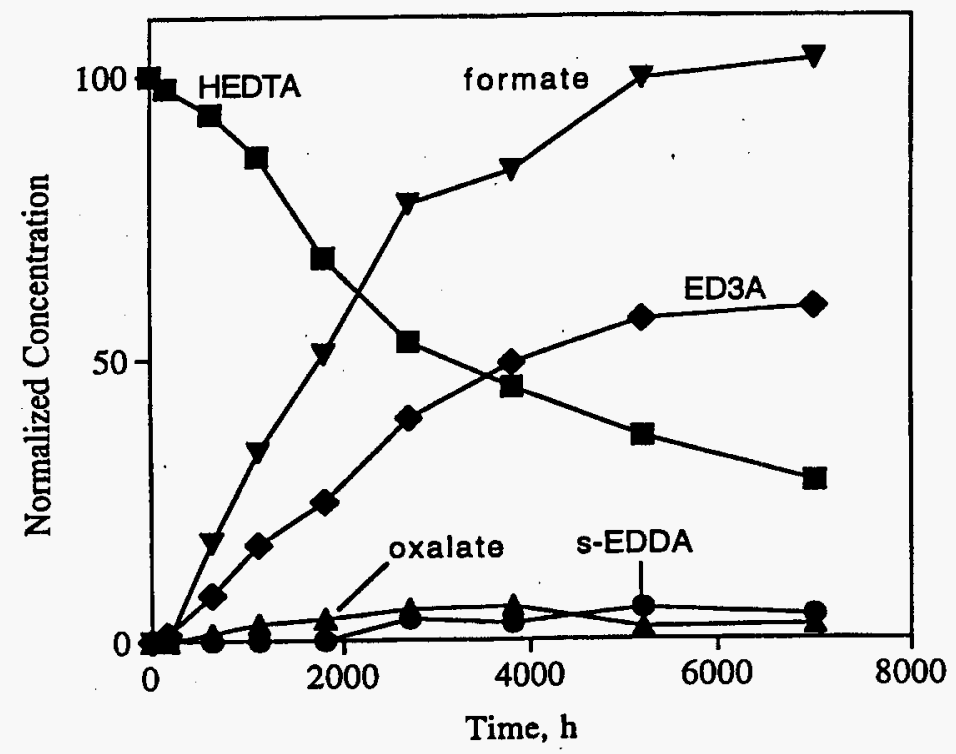

Figure 2-1. Thermal Consumption of HEDTA and Appearance of Fragments as a Function of Time (test at $90^{\circ} \mathrm{C}\left[194^{\circ} \mathrm{F}\right]$ with argon cover gas; concentrations given in units normalized to initial HEDTA concentration [HEDTA initial $=100$ ]; values shown are the average of two tests performed under identical conditions) (figure adapted from Barefield et al. [1996]). 


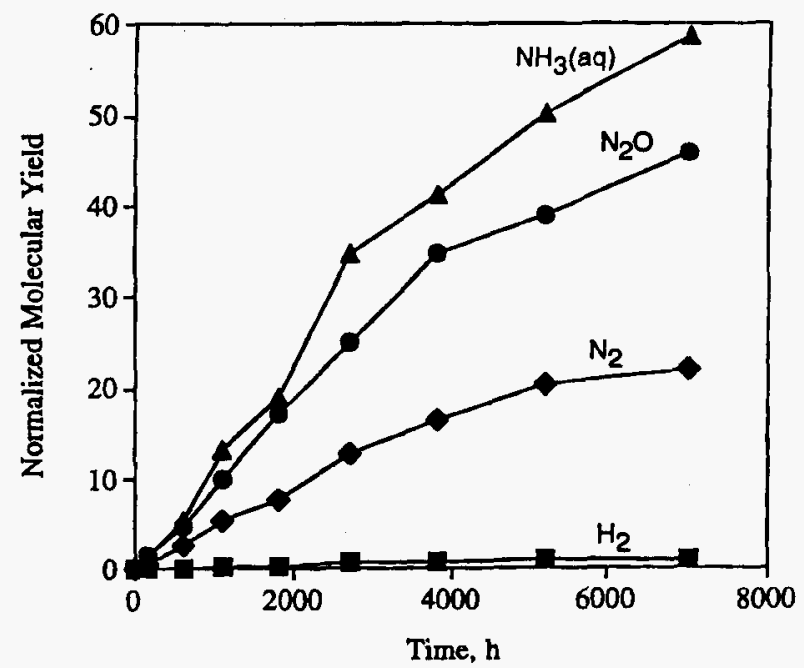

Figure 2-2. Thermal Generation of Hydrogen, Nitrogen, Nitrous Oxide, and Ammonia as a Function of Time (test at $90^{\circ} \mathrm{C}\left[194^{\circ} \mathrm{F}\right]$ with argon cover gas; concentrations in units normalized to initial HEDTA concentration [HEDTA initial $_{\text {i }}=100$ ]; values shown are the average of two tests under identical conditions) (figure adapted from Barefield et al. [1996]).

In brief, breakdown products of HEDTA include the sodium salts of ethylenediaminetriacetic acid (ED3A), glycine, asymmetric ethylenediaminediacetic acid (u-EDDA), symmetric ethylenediaminediacetic acid (s-EDDA), ethylenediaminemonoacetic acid (EDMA), imidodiacetic acid (IDA), formic acid and acetic acid (Barefield et al. 1995, 1996). Formaldehyde, as already mentioned, is a key intermediate producing hydrogen.

The gaseous products of the thermal reaction in Figure 2-2 are predominantly nitrogen-containing substances. Reactions involving the nitrite ion lead to formation of most of the nitrogencontaining gases (nitrogen, nitrous oxide, and ammonia). This feature was demonstrated by using $\mathrm{N}$-15-labeled nitrite ions. The aluminate ion catalyzes the decomposition. The reactions of active nitrogen oxides with organic radicals form several compounds including oximes ( $\mathrm{RCH}=\mathrm{NOH}$ ) 
that can be hydrolyzed to form an aldehyde plus hydroxylamine. Further reactions of hydroxylamine lead to formation of molecular nitrogen, nitrous oxide, and ammonia.

In long-term aging of HEDTA in simulated waste mixtures, ammonia is produced in higher molar quantities than any other gas. A comparison of yields versus the change in HEDTA for two temperatures is shown in Table 2-1.

Hydrogen formation by thermal reactions has been shown to be enhanced under aerobic conditions. Figure 2-3 compares hydrogen generation in tests with argon and air cover gases (Barefield et al. 1996). Hydrogen yields increased significantly in the presence of air, and nitrogenous product yields were lower, resulting in significant changes in relative decomposition product concentrations.

Table 2-1. Comparison of Yields from Reaction of HEDTA in Simulated Waste (from Barefield et al. [1996]).

\begin{tabular}{||c|c|c|c|c|c||}
\hline Temp. $\left({ }^{\circ} \mathrm{C}\right)$ & $\mathrm{H}_{2} / \Delta$ HEDTA & $\mathrm{N}_{2} / \Delta$ HEDTA & $\mathrm{N}_{2} \mathrm{O} / \Delta$ HEDTA & $\mathrm{NH}_{3} / \Delta$ HEDTA & $\Sigma$ N/ $\Delta$ HEDTA \\
\hline \hline 90 & 0.016 & 0.30 & 0.60 & 0.77 & 2.57 \\
\hline 120 & 0.017 & 0.17 & 0.58 & 0.67 & 2.17 \\
\hline
\end{tabular}

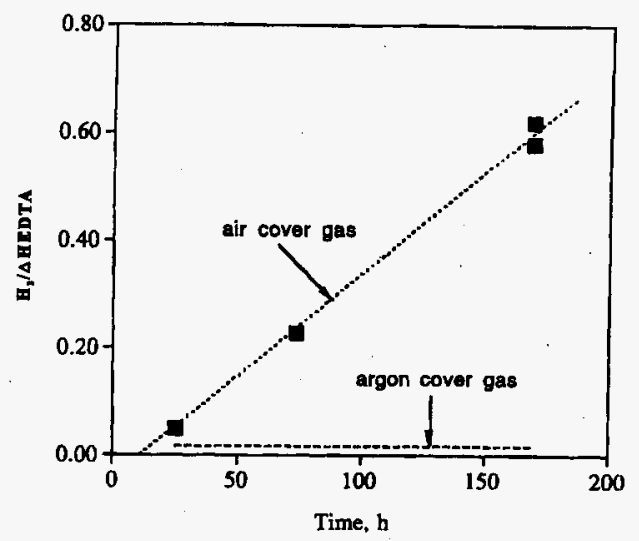

Figure 2-3. Hydrogen Yield in Thermal Reactions per Molecule HEDTA Consumed Versus Time for Tests with Air and with Argon as Cover Gases at $90^{\circ} \mathrm{C}$ (figure adapted from Barefield et al. [1996]). 


\subsubsection{Radiolytic Reactions}

Radiolytic reactions also result in gas generation. Hydrogen is produced by the radiolysis of water and radiolytic reactions involving organic solutes from simulated Hanford waste mixtures. Hydrogen atoms are formed directly from the radiolysis of water. Molecular hydrogen results from the reaction of two hydrogen radicals in the reactive spur and by the abstraction of a hydrogen atom from an organic solute. This reaction system has been investigated in simulated wastes by Meisel et al. $(1991,1992,1993)$, who focused on the reactions that provided hydrogen. One of the principal outcomes of the study was the correlation between the density of $\mathrm{C}-\mathrm{H}$ and $\mathrm{N}-\mathrm{H}$ bonds in simulated waste mixtures and the radiolytic yield of hydrogen. Figure 2-4 shows the dependence of the hydrogen yield on the organic solute. The G-value for production of hydrogen $\left(\mathrm{G}\left(\mathrm{H}_{2}\right)\right.$, molecules $\left./ 100 \mathrm{eV}\right)$, is a direct measure of $\mathrm{C}-\mathrm{H}$ and $\mathrm{N}-\mathrm{H}$ bond concentration; $\eta_{x-\mathrm{H}}$ equals the number of $\mathrm{C}-\mathrm{H}$ or $\mathrm{N}-\mathrm{H}$ bonds in molecule; $[\mathrm{RH}]$ is the molar concentration of organic chelator in simulated waste; $\mathrm{G}\left(\mathrm{H}_{2}\right)=0.031$ molecules $/ 100 \mathrm{eV}$ for waste simulant with no organics present.

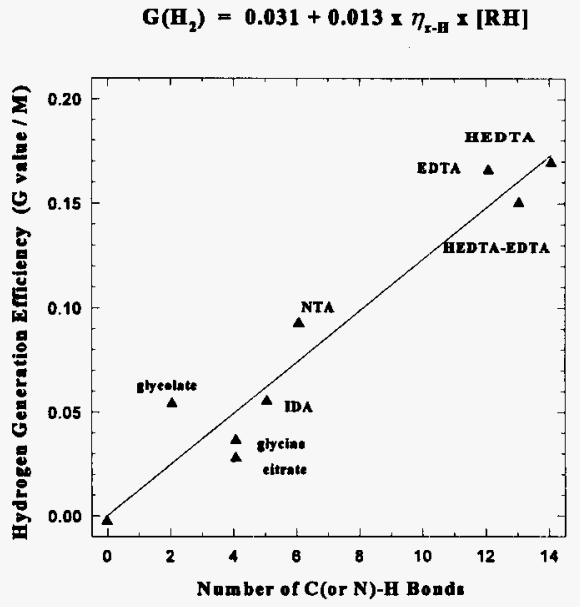

Figure 2-4. Molar Efficiency of Hydrogen Generation for Chelators Using Simulated Tank 241-SY-101 Waste (these experiments were performed at ambient temperatures) (Meisel et al. 1991). 
The hydrogen yield is lowest in the absence of the organic compounds and systematically increases as the number of carbon-hydrogen bonds increase. Although subtle differences between the rates of aging of the organic complexants are obscured in this correlation, the dependence of the hydrogen yield on the availability of organic hydrogen is unmistakable.

Using oxygen as a cover gas also had a marked effect on the distribution of gaseous products in aging studies dominated by radiolytic reactions (Camaioni et al. 1995, 1996; Person 1996). Although the mechanism responsible for this behavior is not well understood, it is clear that oxygen is consumed by the transient molecules in the waste and that the yield of hydrogen increases as a consequence of its presence.

The technical investigations of simulated waste have also established that there are very strong synergisms between the radiolytic and thermal processes. Molecules with small numbers of hydrogen atoms that have modest reactivity in radiolytic processes are often very reactive thermally. All of the aldehydes, particularly formaldehyde, and the alcohols, particularly sodium glycolate, react rapidly in thermal processes in the alkaline media. Hydrogen production from formaldehyde, which is produced by the thermal and radiolytic fragmentation reactions of the complexants, is an especially important source of hydrogen.

\subsection{STUDIES USING ACTUAL WASTE}

Two studies were conducted to measure gas evolution from actual waste core samples. Gas generation was evaluated from samples of the convective layer of Hanford tank SY-103 (Bryan et al. 1996) and a core composite sample from SY-101 (Person 1996). The changes in the gas generation rates as a consequence of changes in temperature, radiation dose rate, presence or absence of oxygen, and dilution with concentrated sodium hydroxide solution were studied to gain perspective on the principal reaction parameters.

Thermal and self-irradiation gas generation rates for the convective layer of tank SY-103 were determined at 60 to $120^{\circ} \mathrm{C}\left(140\right.$ to $\left.248^{\circ} \mathrm{F}\right)$. The results of the thermal reactions are shown in Figures 2-5 and 2-6 and Table 2-2.

The rates of thermal generation of the gases could be investigated because the rates of the selfradiolysis reaction of the wastes were slow at temperatures greater than $60^{\circ} \mathrm{C}$. The rates of formation of the gases exhibit different temperature dependencies with nitrous oxide generation favored at high reaction temperatures and hydrogen generation favored at temperatures, similar to those at which wastes are stored. 


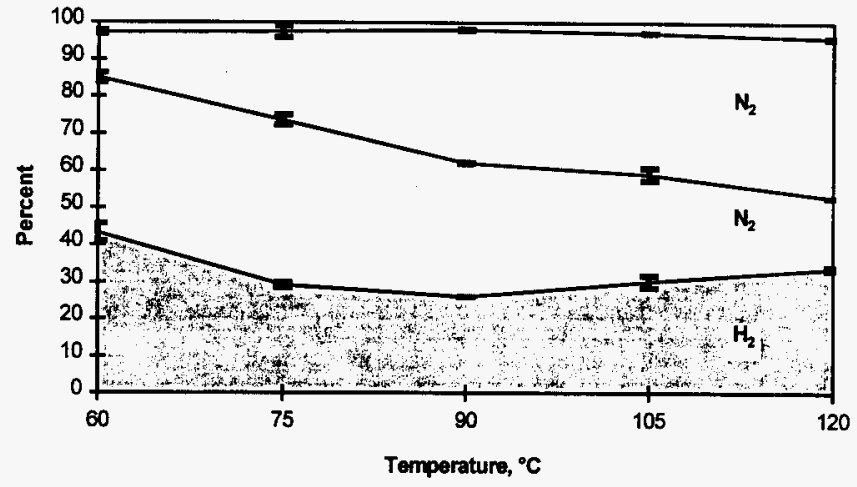

Figure 2-5. Composition of Major Products as a Function of Temperature from Gas Generation from Tank 241-SY-103 (Bryan et al. 1996).

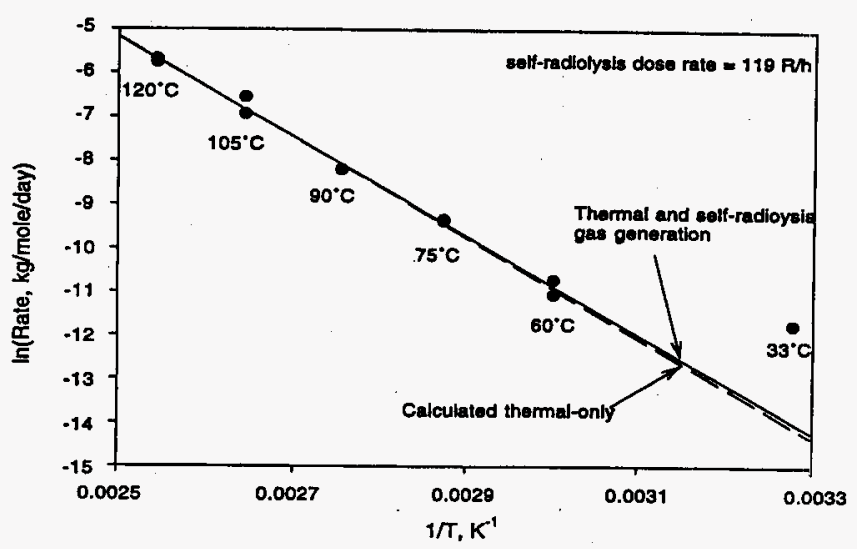

Figure 2-6. Arrhenius Plot of Total Gas Generation Rates for Convective Layer of Tank 241-SY-103 in Thermal Reactions (dashed line represents gas generation corrected for self-irradiation). 
Table 2-2. Pre-Exponential Factors and Activation Energies for Thermal Gas Generation Corrected for Gas Generation from Self-Radiolysis (Bryan et al. 1996).

\begin{tabular}{|c|c|c|c|}
\hline \multicolumn{4}{|c|}{$\begin{array}{l}\text { Pre-Exponential Factors }(\mathrm{mol} / \mathrm{kg}-\mathrm{d}) \text { and Energies of } \\
\text { Activation }(\mathrm{kJ} / \mathrm{mol}) \quad\left(\text { rate }=\mathrm{A}_{\text {exp }}[-\mathrm{Ea} / \mathrm{RT}]\right)\end{array}$} \\
\hline Gas & \multicolumn{3}{|c|}{$\begin{array}{c}\text { Thermal Activation } \\
\text { Parameters }\end{array}$} \\
\hline $\mathrm{H}_{2}$ & $\begin{array}{l}\mathrm{E}_{2} \\
\mathrm{~A}\end{array}$ & $\begin{array}{l}= \\
=\end{array}$ & $\begin{array}{l}91.3 \pm 9.0^{(u)} \\
1.4 \mathrm{E}+09\end{array}$ \\
\hline $\mathrm{N}_{2}$ & E, & $\begin{array}{l}= \\
=\end{array}$ & $\begin{array}{l}83.7 \pm 10.2 \\
1.1 \mathrm{E}+08\end{array}$ \\
\hline $\mathrm{N}_{2} \mathrm{O}$ & $\begin{array}{l}\mathrm{E} \\
\mathrm{A}\end{array}$ & $\begin{array}{l}= \\
=\end{array}$ & $\begin{array}{l}116.7 \pm 9.4 \\
5.5 \mathrm{E}+12\end{array}$ \\
\hline Total gas & $\begin{array}{l}\mathrm{E} \\
\mathrm{A}\end{array}$ & $\begin{array}{l}= \\
=\end{array}$ & $\begin{array}{l}96.3 \pm 6.3 \\
1.2 \mathrm{E}+10\end{array}$ \\
\hline
\end{tabular}

Thermal and self-irradiation gas generation results reported by Bryan et al. (1996) were based on total gas generation from samples heated at 60 to $120^{\circ} \mathrm{C}$. An assumption was made that radiolytic gas generation contributes much less than the thermal generation at and above $60^{\circ} \mathrm{C}$. While this assumption is basically correct, the data were further analyzed to determine the small contribution to gas generation from the self-radiolysis of the radioactive samples (Pederson and Bryan 1996). The radiolytic contribution was subtracted from the total gas generation, yielding the "thermal-only" gas generation for these test samples. The self-irradiation dose rate in tank SY-103 convective layer samples for the specific experimental configuration that was used was calculated at $119 \mathrm{R} / \mathrm{h}$, mainly from ${ }^{137} \mathrm{Cs}$ beta decay, with most of the remainder due to ${ }^{90} \mathrm{Sr}$ (Bryan et al. 1996). In the actual waste tank, the self-irradiation dose rate was calculated to be $444 \mathrm{R} / \mathrm{h}$, about three-fourths of which derived from ${ }^{137} \mathrm{Cs}$ gamma decay (Bryan et al. 1996).

Overall rates of gas generation were found to follow standard Arrhenius behavior over the temperature range 60 to $120^{\circ} \mathrm{C}$. These results are shown in Figure 2-6 along with additional data taken later at $33^{\circ} \mathrm{C}$ (the approximate temperature of SY-103). The best fit of the ln (initial rate) versus the inverse of absolute temperature for the 60 to $120^{\circ} \mathrm{C}$ data was used to estimate the activation energy for gas generation (solid line in the figure). As discussed above, high-temperature gas generation(above $60^{\circ} \mathrm{C}$ ) was dominated by thermal processes, and the effect of the radiolytic gas generation was small. However, the gas generation measured for the radioactive waste sample at $33^{\circ} \mathrm{C}$ showed a significant deviation from the value expected for thermal-only gas generation. The difference between the measured rate of gas generation at $33^{\circ} \mathrm{C}$ and the extrapolated value was attributed to the enhanced gas generation due to self-radiolytic processes.

The radiolytic contribution for gas generation was expected to be approximately constant over the limited temperature range of these samples $\left(33\right.$ to $\left.120^{\circ} \mathrm{C}\right)$. This allowed the radiolytic 
contribution measured at $33^{\circ} \mathrm{C}$ to be subtracted from the total gas generation measured for the high-temperature samples $\left(60\right.$ to $120^{\circ} \mathrm{C}$ ). The best fit of the gas generation data now corrected for the radiolytic contribution is shown as the dashed line in Figure 2-6. The difference in the slopes of the solid line (data from total gas generation) and the dashed line (data from thermalonly gas generation after correction for radiolytic component) is small. Even though the radiolytic contribution is small at high temperature (above $60^{\circ} \mathrm{C}$ ), it should be pointed out that the self-radiolysis contribution to total gas generation is significant at tank temperatures $\left(32^{\circ} \mathrm{C}\right)$ and indeed is approximately five times greater than the thermal process at that temperature $\left(32^{\circ} \mathrm{C}\right)$. Radiolytic gas generation yields were determined for SY-103 convective layer samples using an external radiation source. The results are presented in Table 2-3. The average $\mathrm{G}(\mathrm{H} 2)$ value for 60 and $75^{\circ} \mathrm{C}$ is $0.14 \pm 0.02$ molecules $/ 100 \mathrm{eV}$.

Although the comparisons are indirect, the results from the experimental program and the tank waste are similar, as summarized in Table 2-4. The total calculated hydrogen gas generation from these waste samples is $2.0 \times 10^{-6} \mathrm{~mol}\left(\mathrm{H}_{2}\right) / \mathrm{kg} /$ day. Hydrogen production of $2.3 \times 10^{-6}$ $\mathrm{mol} / \mathrm{kg} /$ day was reported within SY-103 using gas composition data for grab samples from the head space and information on the gas flow rates and head space volume (Wilkins 1995). The agreement between these two investigations is excellent and confirms that the amount of hydrogen generated thermally at tank temperature $\left(31.7^{\circ} \mathrm{C}\right)$ is small; about $20 \%$ of the amount generated by the wastes in SY-103 as a consequence of thermal chemistry.

Independent experiments were carried out with a core composite sample from SY-101 (Person 1996). The tests were performed in the approximate temperature range of 65 to $100^{\circ} \mathrm{C}(149$ to $212^{\circ} \mathrm{F}$ ) with helium or $30 \%$ oxygen in helium as the cover gas. Additional tests were performed with the waste sample diluted by approximately 50 vol\% with $2.5 \mathrm{M}$ sodium hydroxide solution.

The results in Figure 2-7 show that overall rates of gas generation from SY-101 waste samples were remarkably similar to results from SY-103 wastes. The total gas generation rates for SY-101 for the first 10 days of tests at $100^{\circ} \mathrm{C}\left(212^{\circ} \mathrm{F}\right)(0.75 \mathrm{~m}-\mathrm{mole} / \mathrm{kg} /$ day $)$, for example, are statistically indistinguishable from the kinetic data from SY-103 interpolated to that temperature

Table 2-3. G-Values in Radiolytic Reactions of Waste from SY-103 at $5300 \mathrm{R} / \mathrm{h}$ (Pederson and Bryan 1996).

\begin{tabular}{lc} 
Gas & G.Value (molecules $/ 100 \mathrm{eV})$ \\
\cline { 2 - 3 } Hydrogen & $0.14 \pm 0.02$ \\
Nitrogen & $0.53 \pm 0.03$ \\
Nitrous Oxide & $0.033 \pm 0.009$ \\
Ammonia & (a)
\end{tabular}

(a) Not determined in this experiment. 
Table 2-4. Comparison of Gas Generation Rates Estimated from Laboratory Studies Using Small Test Samples with Rates Estimated from Tank 241-SY-103 Observations (Pederson and Bryan 1996).

\begin{tabular}{||l|c|c|c|}
\hline \multirow{2}{*}{$\begin{array}{c}\text { Contribution to Gas } \\
\text { Generation }\end{array}$} & \multicolumn{3}{|c|}{$\begin{array}{c}\text { Gas Generation Rate } \\
\text { (mol/kg-day) }\end{array}$} \\
\cline { 2 - 4 } & Hydrogen & Nitrous Oxide & Nitrogen \\
\hline \hline Thermal at 31.7 ${ }^{\circ} \mathrm{C}$ & $3.1 \times 10^{-7}$ & $5.4 \times 10^{-8}$ & $4.9 \times 10^{-7}$ \\
\hline Radiolytic at 444 R/h & $1.63 \times 10^{-6}$ & $3.84 \times 10^{-7}$ & $6.17 \times 10^{-6}$ \\
\hline Sum & $1.9 \pm 0.1 \times 10^{-6}$ & $4.4 \pm 0.1 \times 10^{-7}$ & $6.7 \pm 0.1 \times 10^{-6}$ \\
\hline In-tank (Wilkins 1995) & $2.3 \pm 0.2 \times 10^{-6}$ & not determined & not determined \\
\hline
\end{tabular}

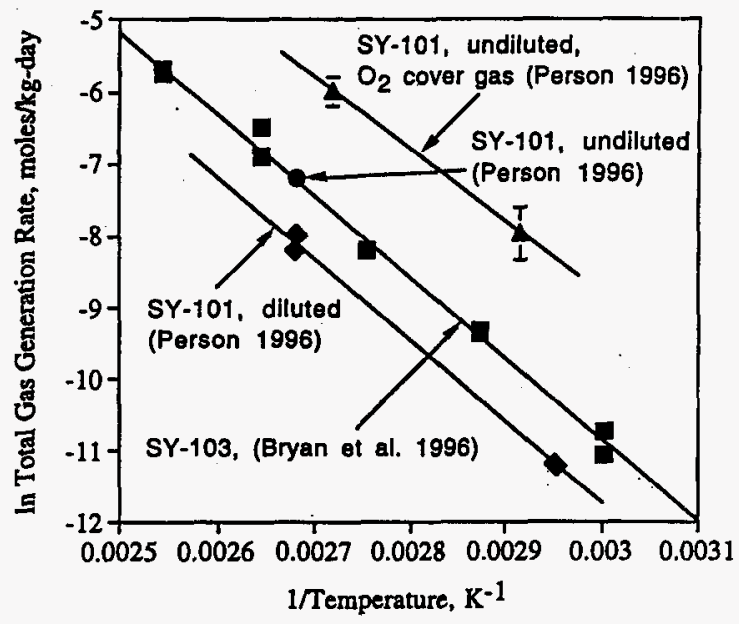

Figure 2-7. Comparison of Total Gas Generation from a Tank 241-SY-101 Core Composite and a Tank 241-SY-103 Convective Layer Sample (Pederson and Bryan 1996). 


\subsection{GAS PHASE REACTIONS}

Gas phase reactions and decompositions are of minor importance. The rates of chemical reactions involving nitrogen, nitrous oxide, hydrogen, and ammonia in the gas phase under thermal and combined thermal and radiolytic conditions were evaluated to assess how reactions between gases trapped in bubbles in Hanford tank wastes may lead to altered gas product distributions depending on how long the bubbles remain trapped. Tests were conducted with dried simulated waste solids present, moist simulated wastes present, and no simulated wastes present. Specific reactions studied included the following: 1) nitrous oxide decomposition with nitrogen and oxygen as primary products; 2 ) nitrogen and hydrogen reactions with ammonia as the primary product; 3 ) nitrous oxide and hydrogen reactions with ammonia, nitrogen, and nitrogen dioxide as the primary products; and 4) ammonia decomposition with nitrogen and hydrogen as the primary products. Tests were performed at 60 to $150^{\circ} \mathrm{C}\left(140\right.$ to $\left.302^{\circ} \mathrm{F}\right)$ and gamma radiation doses of 0 or $10^{7} \mathrm{R}$. The latter corresponds to approximately one year of radiation exposure in SY-101 (Bryan and Pederson 1995; Pederson and Bryan 1996).

Thermally activated nitrous oxide decomposition was not observed at temperatures up to $150^{\circ} \mathrm{C}$ unless simulated waste solids were present for catalysis. The radiolytic reaction is slow; only about $0.9 \%$ of the nitrous oxide initially present will decompose per year. Thermal and radiolytic reactions of nitrous oxide with hydrogen are also very slow. For example, products of decomposition included nitrogen, oxygen, water, oxides of nitrogen, and ammonia. The results for a mixture of $30 \mathrm{~mol} \%$ nitrogen, $30 \mathrm{~mol} \%$ nitrous oxide, $30 \mathrm{~mol} \%$ hydrogen, and $10 \mathrm{~mol} \%$ ammonia at $1,000 \mathrm{R} / \mathrm{h}$ indicate that about $2.2 \%$ of the nitrous oxide is consumed each year (Bryan and Pederson 1995; Pederson and Bryan 1996).

Thermal and radiolytic reactions of nitrogen and hydrogen also appear to be of minor importance under typical Hanford waste storage conditions. A very small quantity of ammonia was produced by thermally activated reactions, with or without simulated wastes present, at rates negligible compared with other ammonia-producing reactions (Bryan and Pederson 1995; Pederson and Bryan 1996). Thus the secondary reactions of the insoluble gases are insignificant processes that do not alter the composition of the waste in any important way.

Ammonia in the gas phase decomposed slowly by radiolysis. The radiolytic decomposition was accelerated in the presence of moist simulated waste solids, suggesting that the rate of decomposition is faster in the condensed phase. It is estimated that $0.35 \%$ of the ammonia initially present will be decomposed within one year. Such losses will be more than offset by the production of ammonia in complexant degradation reactions (Pederson and Bryan 1996).

\subsection{GAS SOLUBILITIES}

Dissolution in the liquid phase is one way gases are retained in Hanford wastes. Gas solubilities are generally lower in concentrated electrolyte solutions than in pure water, but models developed to predict gas solubilities in electrolyte solutions, in general, are not suited to handle the 
high salt concentrations and high degree of complexity typical of Hanford wastes. The solubilities of ammonia, oxygen, nitrogen, hydrogen, methane, and nitrous oxide were determined as a function of temperature in simulated waste mixtures to enable better estimates of the quantities of dissolved gases in actual wastes. Only ammonia and, to a lesser extent, nitrous oxide have significant solubilities (Norton and Pederson 1994, 1995).

The experimental results for oxygen, nitrogen, hydrogen, methane, nitrous oxide, and ammonia in simulated waste mixtures and the Schumpe ion interaction model (Hermann et al. 1995) were employed to define Henry's Law constants $\mathrm{K}_{\mathrm{H}}$ for the mother liquor of the wastes in-SY-101 (Reynolds 1992). These constants are shown in Table 2-5 and are defined as

$$
\mathbf{K}_{\mathbf{H}}=\mathbf{m}_{\mathbf{i}} / \mathbf{P}_{\mathbf{i}}
$$

where $\mathrm{m}_{\mathrm{i}}$ is the concentration of the particular gas dissolved in the liquid phase in moles per kilogram solvent, and $P_{i}$ is the partial pressure of that gas in atmospheres. Schumpe ion interaction parameters (Hermann et al. 1995) were modified by Norton and Pederson (1995) to account for changes in solubility parameters with temperature. Table 2-6 shows values of dissolved gas calculated for SY-101 wastes assuming all are in equilibrium with trapped gases based on the newly determined Henry's Law constants.

Screening tests were performed with two slurry simulant mixtures to determine whether ammonia sorbed onto tank solids in significant quantities. Henry's Law constants were determined as a function of temperature for the decantate (no solids) and the complete simulant and were found to be indistinguishable. Although ammonia sorption onto solid surfaces may well occur, the amount adsorbed appears to be a very small fraction of the total ammonia inventory.

Table 2-5. Henry's Law Constants for Mother Liquor of Tank 241-SY-101 Calculated Using Schumpe Model (Hermann et al. 1995) with Modified Gas Interaction Constants (Norton and Pederson 1995).

\begin{tabular}{|c|c|c|c|c|c|c||}
\hline Temp. ${ }^{\circ} \mathrm{C}$ & $\begin{array}{c}\mathrm{K}_{\mathrm{H}}{ }^{(\mathrm{a})} \\
\text { Oxygen }\end{array}$ & $\begin{array}{c}\mathrm{K}_{\mathrm{H}} \\
\text { Nitrogen }\end{array}$ & $\begin{array}{c}\mathrm{K}_{\mathrm{H}} \\
\text { Hydrogen }\end{array}$ & $\begin{array}{c}\mathrm{K}_{\mathrm{H}} \\
\text { Methane }\end{array}$ & $\begin{array}{c}\mathrm{K}_{\mathrm{H}} \text { Nitrous } \\
\text { Oxide }\end{array}$ & $\begin{array}{c}\mathrm{K}_{\mathrm{H}} \\
\text { Ammonia }\end{array}$ \\
\hline 20 & $1.52 \mathrm{E}-05$ & $4.79 \mathrm{E}-06$ & $2.32 \mathrm{E}-05$ & $6.34 \mathrm{E}-06$ & $5.83 \mathrm{E}-04$ & 10.56 \\
\hline 35 & $1.21 \mathrm{E}-05$ & $3.94 \mathrm{E}-06$ & $2.15 \mathrm{E}-05$ & $4.93 \mathrm{E}-06$ & $3.85 \mathrm{E}-04$ & 5.67 \\
\hline 50 & $1.03 \mathrm{E}-05$ & $3.48 \mathrm{E}-06$ & $2.09 \mathrm{E}-05$ & $4.17 \mathrm{E}-06$ & $2.78 \mathrm{E}-04$ & 3.23 \\
\hline
\end{tabular}


Table 2-6. Estimated Quantity of Gas Dissolved in Entire Tank 241-SY-101 Wastes.

\begin{tabular}{||c|c|c|c|c|c|c|}
\hline $\begin{array}{c}\text { Temperature } \\
{ }^{\circ} \mathrm{C}\end{array}$ & $\begin{array}{c}\text { Oxygen } \\
(\mathrm{SCF})\end{array}$ & $\begin{array}{c}\text { Nitrogen } \\
(\mathrm{SCF})\end{array}$ & $\begin{array}{c}\text { Hydrogen } \\
(\mathrm{SCF})\end{array}$ & $\begin{array}{c}\text { Methane } \\
(\mathrm{SCF})\end{array}$ & $\begin{array}{c}\text { Nitrous Oxide } \\
(\mathrm{SCF})\end{array}$ & $\begin{array}{c}\text { Ammonia } \\
(\mathrm{SCF})\end{array}$ \\
\hline \hline 20 & 6.1 & 6.0 & 25.3 & 0.084 & 541 & $4.4 \mathrm{E}+06$ \\
\hline 35 & 4.8 & 4.9 & 23.5 & 0.066 & 357 & $2.4 \mathrm{E}+06$ \\
\hline 50 & 4.1 & 4.3 & 22.8 & 0.055 & 258 & $1.4 \mathrm{E}+06$ \\
\hline
\end{tabular}

\subsection{DETERMINATION OF IN-TANK GAS COMPOSITION}

Pasamehmetoglu et al. (1994) analyzed a large body of gas composition data and provided a conservative estimate for the composition of gases released during a GRE. The results are shown in Table 2-7. Hydrogen makes up less than one-third the total gas volume of SY-101. The concentrations of nitrogen and nitrous oxide are similar, and ammonia is the fourth largest component.

In-tank gas composition data were collected by mass spectrometry analysis of grab samples from the head space of various Hanford tanks (Table 2-8). A wide variation was noted in the ratio of hydrogen to nitrous oxide, from a high of $33 \pm 19$ for AW-101 to a low of $0.40 \pm 0.17$ for $\mathrm{U}-105$. The origins of these differences are being investigated. Knowledge of the nitrous oxide concentration is important for evaluating the flammability behavior of the gas mixture since it does not always participate in the deflagration (see Section 4.4).

Table 2-7. Estimates of the Composition of Gases

Released from Tank 241-SY-101

(Pasamehmetoglu et al. 1994).

\begin{tabular}{||l|c|}
\hline \multicolumn{1}{|c|}{ Component } & Estimated Mol\% \\
\hline \hline Hydrogen & 29 \\
\hline Nitrous Oxide & 24 \\
\hline Ammonia & 11 \\
\hline Nitrogen & 33 \\
\hline Methane & 0.4 \\
\hline Carbon Monoxide & 0.3 \\
\hline Water & 2.4 \\
\hline
\end{tabular}


Table 2-8. Hydrogen-to-Nitrous-Oxide Ratios Calculated from Mass Spectrometry Analyses of Dome Space Grab Samples.

\begin{tabular}{|c|c|c|c|c|c|}
\hline $\begin{array}{c}\text { Tank } \\
\text { Number }\end{array}$ & $\begin{array}{l}\mathrm{H}_{2} / \mathrm{N}_{2} \mathrm{O} \\
\text { Ratio }^{(a)}\end{array}$ & $\begin{array}{c}\text { Standard } \\
\text { Deviation }\end{array}$ & $\begin{array}{c}\text { No. of } \\
\text { Samples }\end{array}$ & $\begin{array}{c}\text { Avg Temp } \\
{ }^{\circ} \mathrm{C}^{(\mathrm{b})}\end{array}$ & $\begin{array}{c}\text { Watch List } \\
\text { Type }^{(c)}\end{array}$ \\
\hline AN-103 & 15 & 2 & 2 & 45 & $\mathrm{H}_{2}$ \\
\hline AN-104 & 7 & 1.1 & 8 & 49 & $\mathrm{H}_{2}$ \\
\hline AN-105 & 6.9 & 4.4 & 13 & 45 & $\mathrm{H}_{2}$ \\
\hline AW-101 & 33 & 19 & 14 & 40 & $\mathrm{H}_{2}$ \\
\hline SY-101 & 1.48 & 0.9 & 28 & 49 & $\mathrm{H}_{2}$ \\
\hline SY-103 & 2.5 & 1.5 & 12 & 38 & $\mathrm{H}_{2}$ \\
\hline A-101 & 6.3 & 0.6 & 10 & 66 & $\mathrm{H}_{2}$, organic \\
\hline AX-101 & 9.6 & 1.3 & 9 & 56 & $\mathrm{H}_{2}$ \\
\hline AX-103 & 1.2 & 0.2 & 7 & 43 & $\mathrm{H}_{2}$ \\
\hline BY-106 & 1.2 & 0.2 & 4 & 51 & $\mathrm{FeCN}$ \\
\hline BY-109 & 9.4 & 5.2 & 3 & not available & none \\
\hline S-107 & 7.6 & not available & 1 & not available & none \\
\hline S-110 & 9.1 & 1.8 & 2 & not available & none \\
\hline S-111 & 5.5 & 0.7 & 2 & 35 & $\mathrm{H}_{2}$, organic \\
\hline S-112 & 3.5 & 0.7 & 2 & 31 & $\mathrm{H}_{2}$ \\
\hline SX-102 & 3.5 & 1.9 & 7 & 66 & $\mathrm{H}_{2}$, organic \\
\hline SX-103 & 4.2 & 1.1 & 12 & 78 & $\mathrm{H}_{2}$, organic \\
\hline SX-105 & 5.4 & not available & 1 & 83 & $\mathrm{H}_{2}$ \\
\hline SX-106 & 2.7 & 1.5 & 13 & 44 & $\mathrm{H}_{2}$, organic \\
\hline SX-109 & 2.8 & 0.2 & 2 & 66 & $\mathbf{H}_{2}$ \\
\hline TY-302B & 0.13 & 0.02 & 3 & not available & none \\
\hline U-103 & 0.81 & 0.13 & 10 & 31 & $\mathrm{H}_{2}$, organic \\
\hline U-105 & 0.40 & 0.17 & 8 & 33 & $\mathrm{H}_{2}$, organic \\
\hline U-107 & 0.74 & 0.18 & 14 & 28 & $\mathrm{H}_{2}$, organic \\
\hline U-108 & 1.08 & 0.22 & 15 & 32 & $\mathrm{H}_{2}$ \\
\hline \multicolumn{6}{|c|}{$\begin{array}{l}\text { (a) Pederson and Bryan (1996). } \\
\text { (b) Temperature data taken from Hanlon } 1996 . \\
\text { (d) Watch list types include flammable gas }\left(\mathrm{H}_{2}\right) \text {, ferrocyanide }(\mathrm{FeCN}) \text {, and organic } \\
\text { tanks; "none" indicates the tank is not included on a watch list (Hanlon 1996). }\end{array}$} \\
\hline
\end{tabular}

The RGS enables the composition of gases trapped in Hanford wastes to be determined without dilution by air. Waste samples were extracted from AW-101, the first tank to be sampled using this device. The major species found were nitrogen, ammonia, hydrogen, and nitrous oxide. Nitrogen made up more than $50 \mathrm{~mol} \%$ of the gases found; hydrogen was the next most abundant 
product; nitrous oxide made up less than $8 \%$ of the total gas within the sludge layer and less than $2 \%$ of the gases in the supernatant liquid (Shekarriz et al. 1996). The remainder consisted of methane and other hydrocarbons.

Retained gas samples were taken from A-101, AN-103, AN-104, and AN-105; analyses are under way. Initial observations are in reasonable agreement with the work done on simulated and real wastes.

\subsection{KINETICS OF GAS GENERATION}

Although flammable gas generation rates in SY-101 and SY-103 are well established through laboratory studies and in-tank observations, the rates for many other tanks are not known. Equations were developed to estimate the rate of hydrogen generation from tank wastes as a function of temperature and waste composition (Hopkins 1994; Graves 1994). The newly measured kinetic gas generation parameters from actual waste samples enable these quantities to be estimated independently. Tank SY-103 waste was chosen as the benchmark from which to estimate generation rates in other tanks because the kinetic information for this tank is based on well-established analytical measurements and statistical evaluations.

The modified expression (Pederson and Bryan 1996) estimates the thermal component of hydrogen generation from a given waste based on SY-103 behavior:

Thermal rate in waste $\mathrm{X}=$ thermal rate in SY-103

$x \%$ total organic carbon (TOC) in waste $\mathrm{X} / \%$ TOC in SY-103

$\mathrm{x} \% \mathrm{Al}$ in waste $\mathrm{X} / \% \mathrm{Al}$ in $\mathrm{SY}-103$

$x \exp \left[-91 \pm 9 \mathrm{~kJ} / \mathrm{mol} / \mathrm{R}\left(1 / \mathrm{T}_{\mathrm{x}}-1 / \mathrm{T}_{\mathrm{SY}-103}\right)\right]$

The baseline rate for $\mathrm{SY}-103$ is $3.5 \times 10^{-7} \mathrm{~mol} / \mathrm{kg} / \mathrm{day}$ at $31.7^{\circ} \mathrm{C}\left(89.1^{\circ} \mathrm{F}\right)$ with $\mathrm{TOC}=0.74 \mathrm{wt} \%$ (convective layer) and $\mathrm{Al}=2.8 \mathrm{wt} \%$.

The estimated radiolytic yield of hydrogen, based on laboratory data for SY-103 wastes and a correlation developed by Meisel et al. (1993) is

$$
\mathrm{G}\left(\mathrm{H}_{2}\right)=0.031+0.15 \times \text { TOC molecules } \mathrm{H}_{2} / 100 \mathrm{eV}
$$

The radiolytic hydrogen generation rate from a given waste based on SY-103 behavior is $\begin{aligned} & \text { Radiolytic rate } \\ & \text { in waste } X\end{aligned}=\left[\begin{array}{c}\text { radiolytic rate } \\ \text { in SY-103 }\end{array}\right]\left[\begin{array}{l}\frac{\text { dose rate in waste X }}{\text { dose rate in SY-103 }}\end{array}\right]\left[\begin{array}{l}\frac{0.031+0.15 \times \text { TOC in waste X }}{0.031+0.15 \times \text { TOC in SY-103 }}\end{array}\right]$

The baseline radiolytic hydrogen generation rate for tank SY-103 is $1.63 \times 10^{-6} \mathrm{~mol} / \mathrm{kg}$-day for a dose rate of $444 \mathrm{R} / \mathrm{hr}$ (Pederson and Bryan 1996). The TOC content in SY-103 is $0.74 \mathrm{wt} \%$. 
The total rate of hydrogen generation is the sum of the thermal and radiolytic processes. While these expressions provide qualitative guidance about the rates of hydrogen generation in the Hanford tanks, it is evident that they will need to be modified to be applied quantitatively for predicting hydrogen generation. Factors such as the nature of the organic compounds (for example, sodium glycolate provides hydrogen but sodium oxalate does not) are not considered in the TOC parameter, and the synergisms between the radiolytic and thermal reactions are not considered in the present analysis.

Agnew (1996) assessed the disposition of soluble organic complexants in the waste tanks. Fortyseven tanks had TOC contents greater than $0.64 \%$. Of these, 20 are FGWL tanks; the remaining five have TOC values ranging from 0.36 to $0.56 \mathrm{wt} \%$. More analysis is needed to determine the fraction of the TOC that contributes to hydrogen generation.

Significant differences exist in composition among Hanford waste tanks. As a result, gas generation behavior is expected to vary considerably. Most of the technical work has focused on chelator and chelator fragments, which dissolved in the liquid fraction. Other wastes contain solvents that are largely insoluble in the liquid fraction and may decompose by totally different pathways. Laboratory gas generation studies using actual waste mixtures that represent different waste classes would significantly enhance our ability to estimate gas generation behavior in Hanford wastes.

\subsection{ACTIVITIES REMAINING TO UNDERSTAND GAS GENERATION}

Information is needed on the types of gases and the rates at which they are produced to describe the behavior of the tanks. Tests need to be applied to tank waste samples representing carefully selected waste types to validate the concepts derived from the work on simulants and to achieve a predictive capability for the key types of wastes.

The rates at which gases are produced can be obtained by holding the sample under controlled conditions (gamma or thermal energy) while measuring the quantities of gases evolved as a function of time. The data can be used to perform

- $\quad$ engineering estimates of the steady state ventilation requirements of the waste tanks

- assessments of the changes in gas evolution from the wastes over long periods of time

- $\quad$ evaluations of the fuel value of the gases for combustion and explosion level analysis

- analyses to determine the effect of variations in waste constituent concentrations and $\mathrm{pH}$ on gas evolutions from the wastes

- analyses for changes in gas evolution with changes in waste storage and processing conditions that mimic waste temperature and radiation dose rate of actual waste. 
Results from these experiments will contribute to the preponderance of evidence needed to remove tanks from the FGWL.

Additional testing using both SST and DST waste types is needed, as follows:

Double Shell Tanks: Among the DSTs, those determined to be most critical for gas generation measurements were the SY farm tanks SY-101 and SY-103. Gas generation tests have already been concluded on these two tank wastes (Person 1996a; Bryan et al. 1996).

The AN tank farm wastes are next in priority for gas generation testing because of their history of gas releases and retained gas volumes. All AN tanks on the FGWL (AN-103, -104, and -105) contain primarily double-shell slurry or double-shell slurry feed and are considered to be similar with respect to information gained from gas generation testing. Tank AN-105 is judged to be the most important of the AN tanks to investigate for gas generation because it has exhibited measured gas releases in excess of $25 \%$ of the LFL, it has a Gas Characterization System (GCS) installed that provides detailed information on head-space gas concentrations, and it has been sampled using the RGS. The GCS and RGS data will complement the gas generation test data by providing gas composition information from an independent source. Tank AN-105 has been core-sampled, and tests in the 222-S Laboratory will begin in FY 1997.

Waste tank AW-101 has also experienced a measured gas release that exceeded $25 \%$ of the LFL, has a GCS installed, and has been sampled using the RGS. For these reasons it is rated next in priority for gas generation measurements. Due to the relatively high $\mathrm{H}_{2} / \mathrm{N}_{2} \mathrm{O}$ ratio measured for AW-101 waste (see Table 2-8), this waste type was judged to be different enough from the SY and AN waste to warrant a separate study. The sample material for testing is available at PNNL; testing is scheduled to begin in FY 1997 after the S-102 experiments have been completed.

Single-Shell Tanks: Among the SSTs on the FGWL, the tanks in the U, SX, and S tank farms were considered to be the most important for study for gas generation. These tanks were chosen because they are known to generate and store significant quantities of gas. Because of their similarity, a significant number of tanks can be represented by a few tests.

The U tanks are important due to their relatively high potential to exceed the LFL in the dome space due to stored gas, the low $\mathrm{H}_{2} / \mathrm{N}_{2} \mathrm{O}$ concentration ratio $(\leq 1)$ as measured in the head space, and their similarity in noncomplexed waste type. Tank $\mathrm{U}-105$ is scheduled for an SHMS E+ (similar to the GCS) in FY 1997; tank U-103 is scheduled for RGS sampling in FY 1997. The ability to obtain gas composition information from an independent source in addition to gas generation data places these tanks ahead of the other $U$ tanks for gas generation testing. Testing on waste from a $U$ farm tank is planned for FY 1998.

The SX and S tanks were grouped together because of their moderate $\mathrm{H}_{2} / \mathrm{N}_{2} \mathrm{O}$ ratio (2.7 to 5.4). The SX and S tanks have a variable fill history that includes double-shell slurry feed, noncomplexed, and dilute complexed waste types. Due to the variability in waste types, at least 
two wastes should be tested for gas generation. Gas generation tests on waste from S-102 have been started and should be completed in FY 1997.

While the use of waste simulants has helped establish a quantitative description of gas generation, they do not adequately mimic the complexity of actual waste. The relationship between key organics and flammable gas generation in actual waste can be probed further by spiking specific organic complexes into samples of actual waste. The spiked actual wastes can be probed thermally and radiolytically to determine the activation parameters for specific organic complexes under actual waste conditions. The effect of oxygen on hydrogen generation and the fate of organics under actual waste conditions could be probed as well.

These priorities are general guidelines. It is important to maintain flexibility so that project changes can be accommodated. The tank priorities given are not as important as the overall need to obtain more data from actual tank wastes. Given a choice, the ones described above have first priority; however, data from other tanks may also be valuable in assessing the generation of gases from the tank wastes. 


\subsection{GAS RETENTION}

The most significant aspect of the flammable gas safety issue is gas retention. If all of the gas that is generated is released, the problem is reduced to the steady state, or chronic situation, which can be managed through appropriate ventilation. It is the retention of gas that led to the issue in SY-101 in which the episodic releases exceeded the lower flammability limit for hydrogen in air. The amount of gas stored in that tank had been estimated to be as high as 820 cubic meters (STP) (Brewster et al. 1995).

The variety of waste types (slurry, saltcake, sludge, etc.) provides a range of physical conditions that yield different means by which gases can be retained within the waste. An understanding of these mechanisms is critical not only to the flammable gas safety issue but also to future tank operations such as salt-well pumping, waste transfers, and sluicing/ retrieval. Recent laboratory studies on simulated and actual waste samples have provided a framework by which to classify the retention mechanisms by waste type (Gauglitz et al. 1994, 1995, 1996), and this work is reviewed in this section.

Finally, the most significant accomplishment in understanding gas retention in Hanford tanks has been the direct measurement of the free gas void fraction in several tanks with the VFI and the RGS. The results of these direct measurements will also be reviewed in this section.

\subsection{GAS BUBBLE RETENTION MECHANISMS}

Retained bubbles provide the primary mechanism for storing large quantities of flammable gases in tank waste that could be released rapidly. The principal mechanisms of bubble retention can be grouped into three categories: bubbles retained by the strength of the waste material, bubbles retained by capillary forces, and bubbles retained by direct attachment to particles (armored bubbles, bubble attachment, and aggregates, respectively). In layers of materials, bubble retention is dominated by the waste strength and capillary forces; armored bubbles play a minor role. ${ }^{(1)}$

A detailed description of these mechanisms has been presented by Gauglitz et al. (1994, 1995, 1996). In addition, the general character of these mechanisms has been described in the literature, although the associated applications are quite different from gas-bubble retention in waste tanks. Chhabra (1993) gives a discussion of bubbles in non Newtonian fluids, and also reviews the specific situation of spheres (bubbles) retained by the strength of a fluid possessing a yield stress (Ch. 3, Sec. IV-B). Dullien (1992) provides a general discussion of the capillary

(1) In a separate study, frothing tests of SY-103 waste were conducted to probe the ability of waste particles to armor bubbles. In waste tanks, this effect potentially leads to smaller, shielded bubbles that are not easily released to the head space. The presence or absence of organics or surfactants within the waste should affect the ability of particles to armor bubbles. A report will be released soon showing that the addition of waste particles made only a small change to the froth stability of an SY-103 waste sample. 
behavior of nonwetting fluids (bubbles) in particulate materials, and also provides a specific review of the mechanics and literature on capillary trapping (Ch. 5, Sec. 5.3.6.2).

The distinction between yield strength and capillary force retention depends on a Bond number (Gauglitz et al. 1994, 1995, 1996). This dimensionless group contains two parameters, a ratio of gravitational force to surface tension force and a ratio of waste strength force to surface tension force, which are shown below:

$$
\begin{aligned}
& \frac{\text { Gravitational Force }}{\text { Surface Tension Force }}=\frac{\Delta \mathrm{pghD}_{\text {particla }}}{4 \gamma} \\
& \frac{\text { Strength Force }}{\text { Surface Tension Force }}=\frac{\tau, D_{\text {particle }}}{4 \gamma}\left(\frac{A_{2}}{A_{1}}\right)
\end{aligned}
$$

The surface tension force in these dimensionless parameters reflects the resistance the bubble experiences as it seeks to move between particles. Hence, the appropriate length scale is the pore-throat diameter. For beds of packed particles, the median pore-throat diameter is roughly one-third the particle diameter (Dullien 1992). The actual pore-throat diameter (which is a distribution of sizes) can vary by an order of magnitude depending on the particle packing. For the purpose of this scaling analysis, the pore-throat diameter is approximated as the particle diameter, $\mathrm{D}_{\text {particle }}$. In the first dimensionless parameter, $\Delta \mathrm{p}$ is the density difference between the settled solids and the liquid, $g$ is the gravitational acceleration, and $h$ is the depth below the top of the settled solids. In the second parameter, the constant $A_{2} / A_{1}$ is a ratio of areas that resulted from the original scaling analysis, and $\tau_{s}$ represents the shear strength of the material. Although it is expected that tensile and shear strengths are important in the growth of bubbles, the two measures of strength are commonly directly related (see Gauglitz et al. [1995] for a discussion of tensile and shear strength measurements).

The two parameters described above define the transition between two regimes of bubble retention. Figure 3-1 shows both particle-displacing bubbles that are retained by yield strength forces and interstitial-liquid-displacing bubbles that finger between the particles composing the particulate media (see Gauglitz et al. [1995, 1996] for further discussion).

When particle-displacing bubbles grow in a deformable material such as a bentonite clay or actual waste sludge, the dominant factors controlling their growth are surface tension forces, which seek to keep the bubbles round, and the strength of the material that the bubble must overcome to displace the particles. A detailed description of this process is given in Gauglitz et al. (1995, 1996). Simple scaling of the relative importance of sludge strength to surface tension gives the following dimensionless group that governs bubble growth in deformable materials: 


$$
\frac{\text { Strength Force }}{\text { Surface Tension Force }}=\frac{\tau_{\mathrm{s}} \mathrm{D}_{\text {particle }}}{\gamma}
$$

where $D_{\text {particle }}$ is the bubble diameter. In this case, the surface tension $(\gamma)$ force is related to the bubble size, so that the bubble diameter, $D_{\text {particle }}$ is the appropriate length scale. Again, for this scaling, the strength of the material was chosen to be represented by the shear strength. This simple scaling assumes that the particles composing the waste are sufficiently small (small Bond number) that the bubbles never finger between the particles. As reported in Gauglitz et al. (1995), the shear and tensile strengths of bentonite clay sludges decrease with increasing gas bubble content, a detail this simple scaling analysis neglects.

Figure 3-2 shows the bubble shapes that are expected in fine-particulate materials where surface tension or waste strength dominates. When surface tension dominates, the bubble shape is round. When the waste strength dominates, the bubbles grow by displacing the weakest material adjacent to the bubble. In this case, if any small nonuniformity exists in the material the bubbles will follow that path and evolve into some dendritic shape. Though the overall shape may be dendritic, surface tension will dominate on a sufficiently small scale, and the interface between the gas and waste should be smoothly curved.

Figure 3-3 shows the different regimes of bubble retention, and the solid curve denotes the transition between interstitial liquid-displacing bubbles and particle-displacing bubbles. The

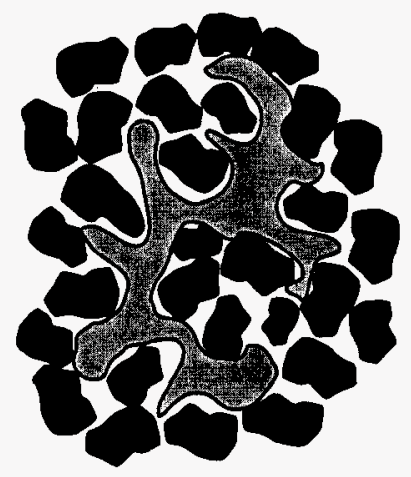

Dendritic-Shaped Bubble Fingering Between Particles

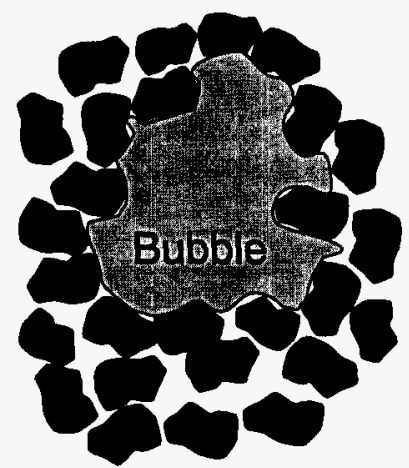

Bubble Displacing Particles

Figure 3-1. Schematic of Bubble Displacing Particles and a Dendritic Bubble Fingering Between Waste Particles. 

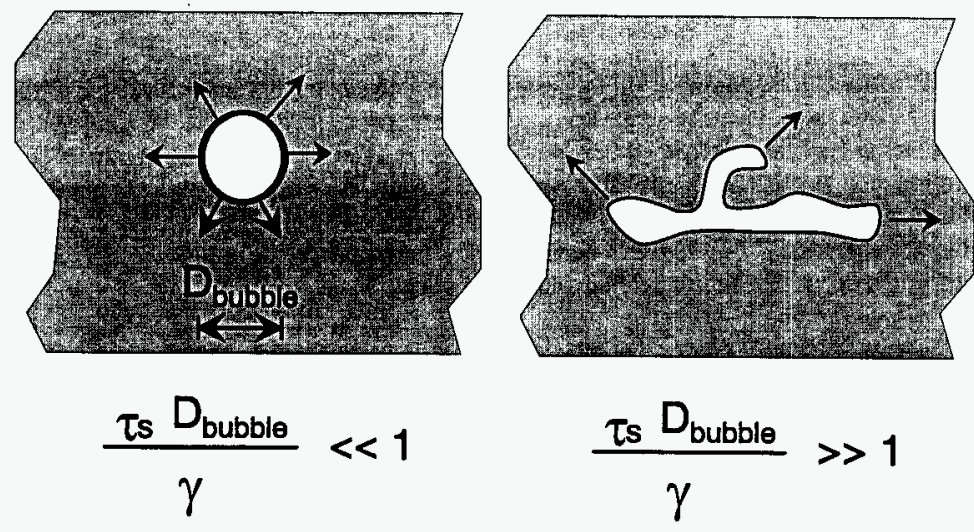

Figure 3-2. Bubbles Displacing Waste When Surface Tension Dominates $\left(\tau_{s} D_{\text {buble }} / \gamma \ll 1\right)$ and When Waste Strength Dominates $\left(\tau_{s} D_{\text {bubble }} / \gamma \gg 1\right)$.

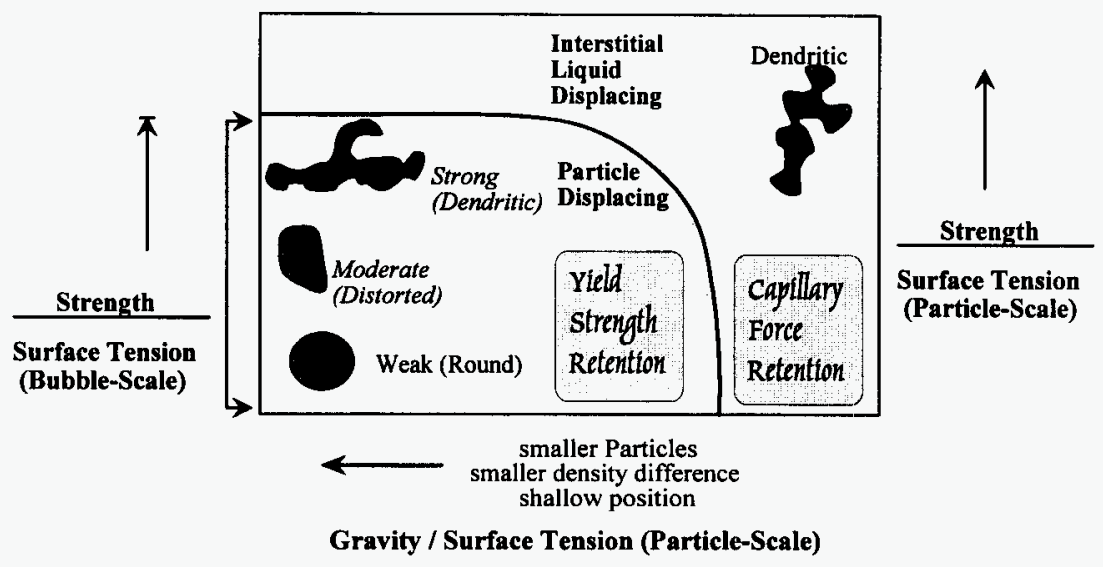

Figure 3-3. Location of Different Bubble Retention Regirnes. 
particle-displacing bubbles are retained by yield strength forces, and the interstitial liquiddisplacing bubbles are retained by capillary forces. The particle-displacing region within the solid curve of Figure 3-3 is further subdivided. The figure also shows the characteristic shape of bubbles in the different areas of the plot.

\section{Effect of Waste Strength on Bubble Release}

As retained bubbles grow, they eventually connect and provide a flow path for gas to be continuously released, unless they are released by some other mechanism such as a buoyant displacement. Figure 3-4 shows two situations of individual bubbles and connected bubbles. When the void fraction is small, the bubbles are separated. As the individual bubbles grow or more bubbles nucleate between previously existing bubbles, a connected path will eventually form. This pathway is likely to be very tortuous, particularly when considering the threedimensional character of the connections. While many aspects of the bubble growth process will affect the connection between bubbles, percolation theory offers a framework to understand the minimum void fraction above which bubbles begin to connect (Stauffer 1985).

The connecting of separate objects and the conductivity of the connected paths were studied with percolation theory (Stauffer 1985). The situation of growing round bubbles is most closely associated with site percolation, which describes the connection of objects that occupy volume, such as bubbles. The percolation threshold, which occurs at a specific fraction of an occupied site, represents the void fraction above which a continuous path forms.

The percolation threshold has been calculated for a number of three-dimensional lattices, and values have been reported as follows: diamond, 0.428 ; simple cubic, 0.312 ; and body-centered cubic, 0.245 (Stauffer 1985). These values are equivalent to the void fraction of bubbles above which a continuous path exists. Although a range of values was reported, it suggests that the bubbles will not connect until a moderate void fraction is reached. Finally, it is expected that bubbles of different shapes will form a percolating path at different void fractions. The more long and slender bubbles shown in Figure 3-1 are expected to connect at a lower void fraction because long and skinny objects connect more easily.

\subsection{RESULTS FOR BUBBLE RETENTION IN ACTUAL WASTES}

Understanding the mechanisms of stored gas retention has a direct bearing on understanding the quantities of gas retained and on possible gas release mechanisms. The approach to quantifying bubble retention mechanisms has been to investigate the behavior of retained bubbles in waste simulants and in actual waste. Studies with simulants were used to provide a general picture of the range of expected behavior and how this behavior scales with waste properties. The actual waste behavior is then compared with the simulant behavior to highlight similarities and differences. 


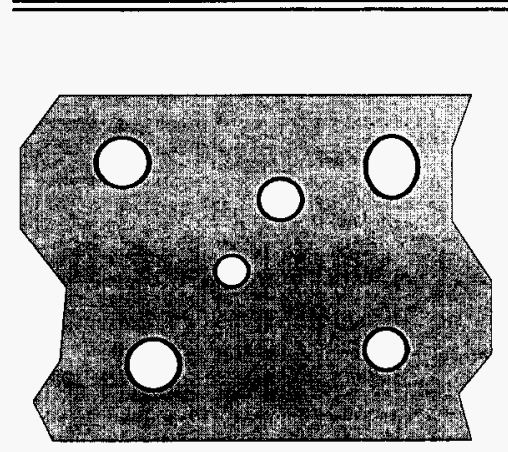

Individual Bubbles

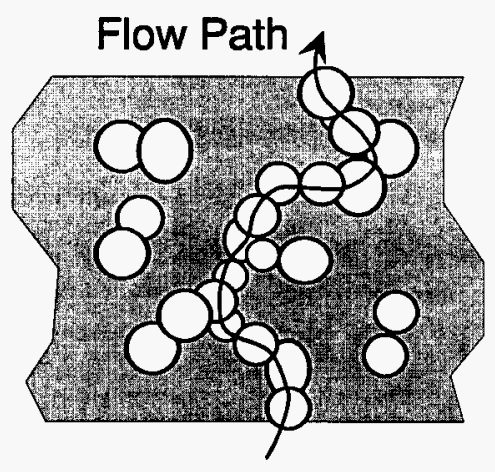

Connected Bubbles

Figure 3-4. Bubble Growth and the Formation of a Connected Pathway of Bubbles.

This section compares available actual waste results with simulant results for bubble shapes and maximum retention. The shape of retained bubbles appears to be directly related to the mechanisms of bubble retention. Competition between the forces acting on the bubbles governs the shape and behavior of the bubbles and the retention mechanism. Although the range of behavior is large, distinct regimes of bubble retention behavior occur, and the regimes can be used to classify bubble retention mechanisms.

Figure 3-5 shows the observations for clay, glass beads, several wastes, and bubble retention mechanisms. The central graph has the three dimensionless groups that determine the mechanism of bubble retention on three of the axes. The solid curve of the plot indicates the transition between particle-displacing bubbles and interstitial liquid-displacing bubbles. The square symbols overlaying this curve are data for the location of the transition as reported by Gauglitz et al. (1995) for glass bead simulants. Surrounding this plot are images of retained bubbles (Bredt and Tingey 1996; Bredt et al. 1995; Gauglitz et al. 1994, 1995, 1996).

The dimensionless groups shown on the axes of the plot contain several experimental parameters. Although it is difficult to measure every parameter or every experiment, it is possible to make reasonable estimates. Each retained bubble image has an arrow showing the approximate location on the plot, which provides a quantitative expression of the bubble retention mechanism. In most cases, the exact positions cannot be determined, and the arrows point to circular regions on the graphs to indicate this uncertainty.

In each location on the plot, the images of retained bubbles in actual waste and simulants are quite similar. Starting on the left side of the plot for sludges (particle displacing bubbles), the stiff sludge from S-102 shows slit-shaped bubbles that are visually equivalent to the slit-shaped 

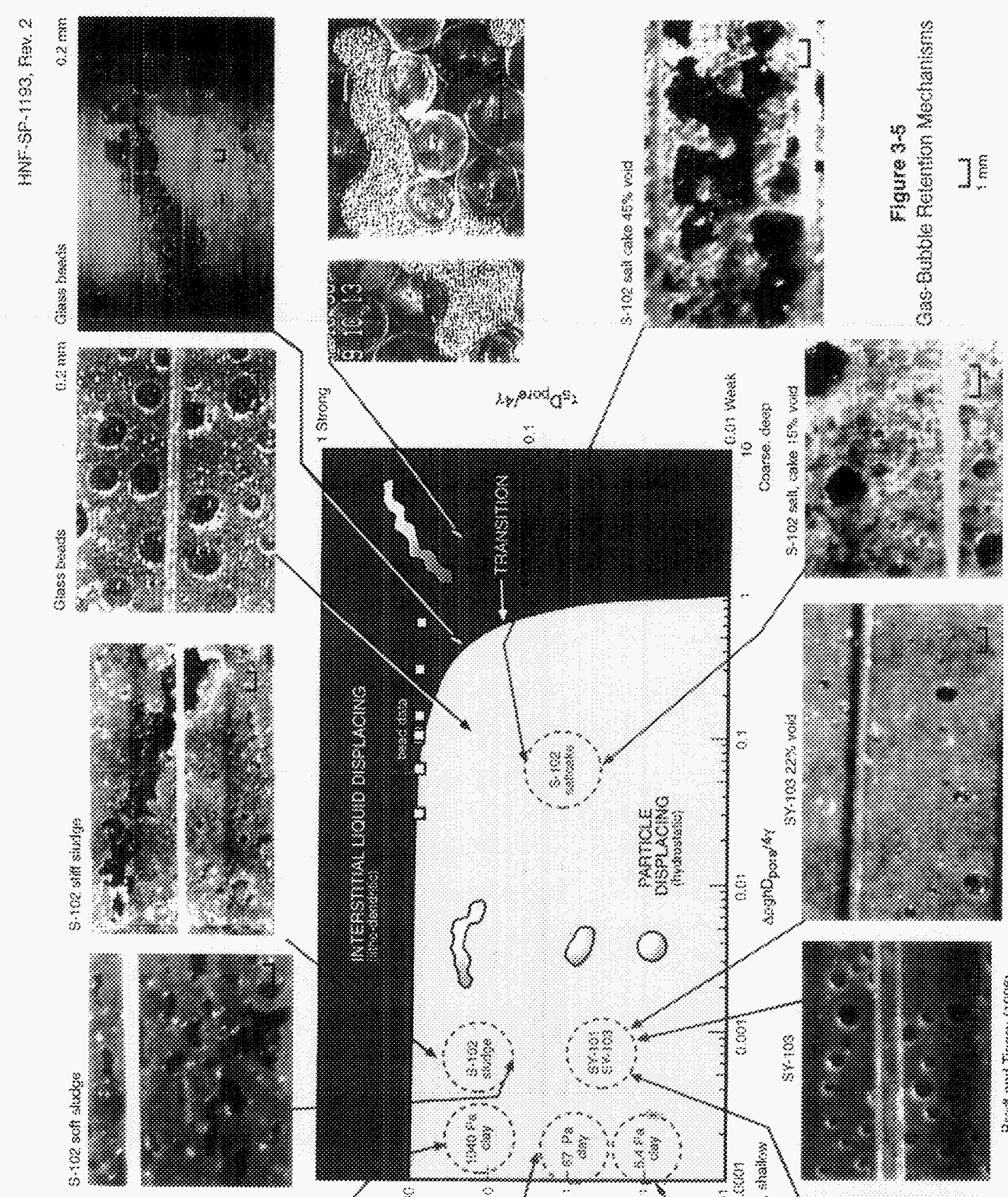
THIS PAGE INTENTIONALLY LEFT BLANK 
bubbles observed in the $1,040-\mathrm{Pa}$ bentonite clay. For the softer sludge from $\mathrm{S}-102$, the retained bubbles were distorted from spherical but were not as slit-shaped as the stiffer sludge, behavior that lies between that of the round bubbles seen in the 67-Pa bentonite clay and the slit-shaped bubbles observed in 1040-Pa bentonite clay. The SY-103 waste samples studied in this work and by Bredt and Tingey (1996) and the SY-101 waste sample studied by Bredt et al. (1995)(1) were all weak materials with very fine particles. Although the original waste samples were of moderate strength, they were composites prepared for laboratory testing, and the strength had been degraded. Because these samples would pour relatively easily, they are located in the lower left region of the plot corresponding to weak particle-displacing bubbles. The round bubbles observed in all these actual waste samples correspond to the round bubbles observed in the weak bentonite clays (6.7 to $67 \mathrm{~Pa})$.

Tank S-102 saltcake samples show bubble retention in actual waste with a distinctly particulate character. The images of bubbles in S-102 saltcake show bubbles displacing the particles, which is expected for small samples with a shallow depth. In the case of $15 \%$ void, the retained bubbles in S-102 are distorted from spherical but are qualitatively similar to the image of bubbles displacing $0.2-\mathrm{mm}$ beads. At the higher void fraction of $45 \%$, the bubbles in S- 102 saltcake appear more dendritic. This may be because this sample is close to the transition between particle-displacing and interstitial liquid-displacing bubbles (farther to the right on the plot in Figure 3-5). It may also be the strength of the sample affecting the bubble shape (farther upward on the plot in Figure 3-5). The final image is a dendritic bubble in a 1-mm bead pack that has displaced the interstitial liquid. Although there are good reasons to believe that saltcake waste such as the S-102 samples will retain interstitial-liquid-displacing (dendritic) bubbles, this prediction could not be confirmed since existing laboratory studies used samples that are too small ( $h$ too small on $\mathrm{x}$-axis) to observe this behavior.

\subsubsection{Mechanism of Retention and Maximum Retention}

The maximum retention of gas bubbles also provides information on the mechanism of bubble retention. Figure 3-6 compares the observed maximum gas void fraction results for the actual waste to bentonite clays. The strength of the actual waste samples was estimated independently from waste behavior during core extrusions and in sample transfers, and the range bars represent the variation in these estimates. The tank S-102 sludge-like material and the SY-103 composite samples were clearly fine-particle materials and can be compared to the bentonite clays. The S-102 saltcake samples, while clearly particulate in character, retained particle-displacing bubbles, so these results are included in this comparison with the sludge-like materials.

(1) The video images of bubbles in SY-101 waste were from experiments that continued those of Bredt et al. (1995). Although similar, the specifics of the experiments differ, and the details have not been reported before. The primary difference was that the SY-101 sample was maintained at hot cell temperature rather than actual tank temperature. 


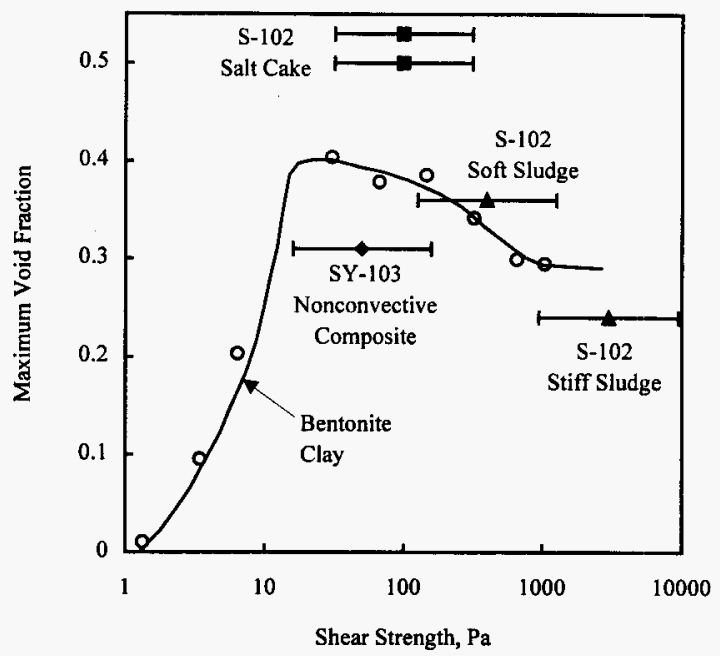

Figure 3-6. Comparison of Maximum Retention in Actual Waste Samples (closed symbols) with Results for Bentonite Clay Simulants (open circles) (Gauglitz et al. 1996).

The actual waste materials show a wide range of maximum retention, spanning from $20 \%$ void for the stiff S-102 sludge to about 50\% void for the S-102 saltcake. This range is somewhat larger than bentonite clay results. The $20 \%$ void in the stiff S- 102 sample, although lower than bentonite clay results, agrees with the trend of decreasing maximum retention with increasing strength. (Slit-shaped bubbles are expected to form a connected path at a lower gas fraction than when round bubbles form a connected path.) Because the stiff S-102 sample retained slit-shaped bubbles, which are similar to the bubbles in the $1,040-\mathrm{Pa}$ bentonite clay, the lower maximum retention was expected. The $45 \%$ to $50 \%$ maximum retention for the $\mathrm{S}-102$ saltcake samples, although greater than the bentonite clay results, are reasonably similar to the simulant. The bubbles retained in the saltcake samples were less round than those in bentonite clay, probably because of the strength or the particulate character of the S-102 saltcake.

The laboratory measurements for maximum retention for actual single-shell waste samples and the bentonite clay show higher values than are generally believed to exist in the actual waste tanks. This implies that there are release mechanisms in the actual tanks (specifically those without continuing level rise) that are not represented in the relatively small and rapid laboratory experiments. 


\subsubsection{Effect of Liquid Removal (salt-well pumping) on Maximum Retention}

Many SSTs contain saltcake waste that has had, or will have, the interstitial liquid drained by salt-well pumping. For saltcake waste that has particle sizes sufficiently large to behave like a permeable medium, it is expected that the drained waste will not be capable of retaining gas bubbles. Gas retention in sludge-like or very fine-grained saltcake materials, on the other hand, probably will be unaffected by salt-well pumping because interstitial liquid will not drain from these fine-particled materials. Experimental results have been obtained for maximum gas retention as a function of the fraction of the waste initially saturated with liquid in 1-mm glass bead packs and water (Gauglitz et al. 1996). These results show, as expected, that as liquid is drained from the waste its ability to retain gas is greatly reduced. The data indicate that the volume of retained gas at maximum retention is roughly proportional to the fractional liquid saturation within the vertical bead pack column and suggest that SST waste that has been drained, presumably by salt-well pumping, is not likely to retain gas bubbles in the drained regions of the waste. In complementary laboratory and modeling studies of salt-well pumping, it has been shown that the process of draining also releases trapped gas, as expected (Peurrung et al. 1996).

\subsection{ESTIMATION OF RETAINED GAS VOLUME}

Closure of the USQ and resolution of the safety issue will require evaluation of the flammable gas hazard in each tank. This assessment can most effectively be carried out by determining the volume of gas retained and the fraction of the retained gas that can be released, and then assessing how rapidly it might enter the head space and be dispersed by ventilation. Changes in waste level indicate variation in the stored gas volume (in the absence of evaporation, leaks, or waste additions). Therefore, knowledge of the gas volume and its vertical distribution allows the use of waste level history to estimate the gas volume over time.

The stored gas volume can be determined most accurately from local void fraction measurements. Where it can be used, the VFI resolves the void profile in detail with measurements about every $30 \mathrm{~cm}$ (12 in.). The in-situ gas volume stored in the nonconvective layer can be calculated from the void fraction profiles. To compute the standard gas volume, the effective pressure and temperature at which the gas is stored are calculated from the void fraction profile, densities, and measured temperature profile. The uncertainty in the gas volumes determined from these measurements generally is less than $25 \%$.

The void fraction of two or three 48-cm (19-in.) segments in a push-mode core can be obtained with the RGS. However, the uncertainty in the vertical void profile is higher with only two or three measurements. The RGS is also the only instrument currently available to measure the waste gas composition in situ. In addition, $\mathrm{X}$-ray analysis also provides more information about the size, number, and shape of the gas bubbles in the waste.

The retained gas volume can also be estimated from the BPE method in those tanks in which it can be applied. This method is based on the correlation of waste level measurements with 
barometric pressure fluctuations, given sufficiently accurate and frequent level data. The cumulative surface level rise also provides an indication of trapped gas volume, provided the initial gas volume, liquid evaporation, leaks, or additions are known. The BPE and surface level rise methods are discussed in Section 5. Both of these indirect methods require an estimate of the effective pressure at which the gas is stored; this requires data on the vertical distribution of the stored gas, which can be provided by VFI or RGS measurements.

In DSTs, a significant volume of gas (up to $20 \%$ of the total standard volume) may be stored in the floating crust layer, but there is as yet no means available to measure it directly, and its uncertainty is quite high. The crust layer is assumed to have an average void fraction of $25 \pm 8 \%$, which is a conservative estimate of the gas content necessary for it to float (Brewster et al. 1995). The crust volume is calculated from the thickness estimated from temperature profiles, core samples, and other available evidence. The estimated crust gas volume can be checked by comparing the total gas volume computed with the BPE method with the volume calculated from VFI data. The difference may indicate whether the crust gas volume is over- or under-estimated.

\subsubsection{Void Fraction Instrument}

The VFI is designed to measure the volume fraction of free (undissolved) gas, or void, at specific locations in a tank. The VFI does not determine gas composition, and its response is very nearly independent of gas composition. The measurement is made by compressing the waste captured in a sample chamber of known size with nitrogen gas. The sample chamber is mounted on a rotating arm that is deployed vertically through a riser by means of a crane. Figure 3-7 is a sketch of the VFI deployed in a tank.

Once below the waste surface and any crust layer, the arm is rotated 90 degrees to become horizontal and is lowered to the desired depth in the tank with the cover of the sample chamber open. At the measurement location the cover is closed to capture a sample, and the waste is compressed with nitrogen gas by opening a valve between the connecting line and the source. Lowering the chamber with the cover open replaces the previous sample with fresh waste. The void fraction is calculated from the initial and final pressures and temperatures and known system volumes. The VFI can make measurements at a radius of $76 \mathrm{~cm}$ ( $30 \mathrm{in}$.) about the riser center about every 30 to $60 \mathrm{~cm}$ (12-24 in.) of elevation.

The VFI has been used in two risers each in SY-101, SY-103, AW-101, AN-105, AN-104, and AN-103. It has performed as designed in all tests and had no significant problems. The initial testing program in SY-101 and SY-103 is documented in Stewart et al. (1995), Brewster et al. (1995), and Shepard et al. (1995). The results of the entire testing program for all six tanks are given in detail in Stewart et al. (1996a).

Table 3-1 contains a summary of all the void fractions, gas volumes, and other quantities relating to gas volume for each of the six tanks. The first section tallies the input data derived from other sources that directly impact the volume calculation; the second section summarizes the mean 


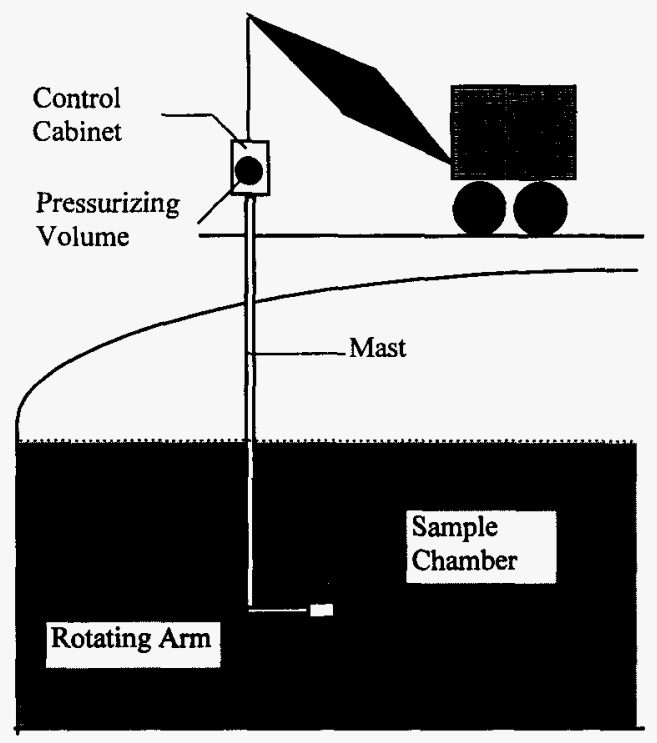

Figure 3-7. Void Fraction Instrument Deployed in a Tank.

void fraction, in situ volume, and effective pressure in the nonconvective layer; and the next portion shows quantities that apply to the entire tank, including the effective pressure ratio and degassed level. The last part of the table summarizes the standard volume (at $1 \mathrm{~atm}$ and $15^{\circ} \mathrm{C}$ ) in each of the three major waste layers and for the entire tank. In all cases, the values are assumed to follow a normal distribution, and uncertainties represent one standard deviation.

\subsubsection{Retained Gas Sampler}

The RGS is a modified version of the universal core sampler designed to be absolutely leak-tight (Cannon and Knight 1995). RGSs are loaded into the drill string during a normal push-mode core sampling event. After capturing a waste sample and recovering it from the drill string, the sampler is X-rayed to determine whether a full sample was captured and then carried to the 222$\mathrm{S}$ laboratory. In the laboratory, the sample is extruded into an extraction vessel, where the waste gas is removed for analysis by a combination of stirring, vacuum pumping, and heating. Samples of the gas are taken at each stage of the extraction process and sent to PNNL for mass spectrometry. 
Table 3-1. Void Fraction and Volume Summary.

\begin{tabular}{|c|c|c|c|c|c|c|}
\hline & AN-103 & $\overline{A N-104}$ & AN-105 & $\overline{A W-101}$ & SY-101 & SY-103 \\
\hline $\begin{array}{l}\text { Input Data } \\
\text { Waste Level }(\mathrm{cm}) \\
\text { Solids Level }(\mathrm{cm}) \\
\text { Dome Volume }\left(\mathrm{m}^{3}\right) \\
\text { Crust Thickness }(\mathrm{cm}) \\
\text { Conv. Dens. }\left(\mathrm{kg} / \mathrm{m}^{3}\right) \\
\text { NC Density }\left(\mathrm{kg} / \mathrm{m}^{3}\right)\end{array}$ & $\begin{array}{c}884 \pm 5 \\
378 \pm 29 \\
1712 \pm 20 \\
92 \pm 10 \\
1530 \pm 50 \\
1800 \pm 50\end{array}$ & $\begin{array}{c}979 \pm 4 \\
410 \pm 25 \\
1323 \pm 18 \\
40 \pm 10 \\
1440 \pm 30 \\
1590 \pm 40\end{array}$ & $\begin{array}{c}1041 \pm 7 \\
450 \pm 18 \\
1066 \pm 21 \\
30 \pm 10 \\
1430 \pm 30 \\
1590 \pm 40 \\
\end{array}$ & $\begin{array}{c}1040 \pm 7 \\
280 \pm 39 \\
1070 \pm 30 \\
64 \pm 10 \\
1430 \pm 30 \\
1570 \pm 30\end{array}$ & $\begin{array}{c}1019 \pm 5 \\
n / a \\
1159 \pm 22 \\
102 \pm 10 \\
1600 \pm 30 \\
1700 \pm 43\end{array}$ & $\begin{array}{c}691 \pm 3 \\
345 \pm 23 \\
2503 \pm 13 \\
20 \pm 10 \\
1470 \pm 30 \\
1570 \pm 50\end{array}$ \\
\hline $\begin{array}{l}\text { Nonconvective Layer } \\
\text { Mean Void }(\%) \\
\text { In-situ Volume }\left(\mathrm{m}^{3}\right) \\
\text { Eff. Pressure Ratio }\end{array}$ & $\begin{array}{c}12.2 \pm 0.4 \\
189 \pm 6 \\
1.92 \pm 0.02\end{array}$ & $\begin{array}{c}5.9 \pm 0.4 \\
99 \pm 6 \\
1.99 \pm 0.02\end{array}$ & $\begin{aligned} 3.8 & \pm 0.6 \\
71 & \pm 12 \\
2.08 & \pm 0.03\end{aligned}$ & $\begin{array}{c}4.7 \pm 0.5 \\
54 \pm 6 \\
2.13 \pm 0.02\end{array}$ & $\begin{array}{l}n / a \\
n / a \\
n / a\end{array}$ & $\begin{aligned} 6.2 & \pm 2.0 \\
88 & \pm 28 \\
1.70 & \pm 0.03\end{aligned}$ \\
\hline $\begin{array}{l}\text { Whole Tank } \\
\text { In-situ Volume }\left(\mathrm{m}^{3}\right) \\
\text { Eff. Pressure Ratio } \\
\text { Degassed Level }(\mathrm{cm})\end{array}$ & $\begin{array}{c}291 \pm 34 \\
1.59 \pm 0.08 \\
838 \pm 5\end{array}$ & $\begin{array}{c}148 \pm 22 \\
1.67 \pm 0.10 \\
955 \pm 4\end{array}$ & $\begin{array}{c}107 \pm 30 \\
1.72 \pm 0.13 \\
1024 \pm 8\end{array}$ & $\begin{array}{c}142 \pm 36 \\
1.47 \pm 0.10 \\
1027 \pm 7\end{array}$ & $\begin{array}{c}164 \pm 43 \\
1.32 \pm 0.11 \\
1010 \pm 5\end{array}$ & $\begin{array}{c}114 \pm 57 \\
1.55 \pm 0.10 \\
669 \pm 8\end{array}$ \\
\hline $\begin{array}{l}\text { Std. Volume }\left(\mathrm{m}^{3}\right) \\
\text { Crust } \\
\text { Convective Layer } \\
\text { Nonconvective Layer } \\
\text { Whole Tank }\end{array}$ & $\begin{array}{l}91 \pm 31 \\
10 \pm 15 \\
363 \pm 12 \\
464 \pm 36\end{array}$ & $\begin{array}{c}39 \pm 16 \\
11 \pm 17 \\
197 \pm 12 \\
247+26\end{array}$ & $\begin{array}{c}30 \pm 14 \\
7 \pm 26 \\
148 \pm 24 \\
185 \pm 44\end{array}$ & $\begin{array}{l}63 \pm 22 \\
32 \pm 34 \\
115 \pm 12 \\
210 \pm 47\end{array}$ & $\begin{array}{c}100 \pm 34 \\
33 \pm 31 \\
84 \pm 12 \\
217 \pm 52\end{array}$ & $\begin{array}{c}20 \pm 12 \\
6 \pm 33 \\
150 \pm 46 \\
176+79\end{array}$ \\
\hline
\end{tabular}

During sample extraction in a hot cell, the RGS is loaded into the extruder and sealed to the extraction vessel. Then the entire contents of the sampler are pushed into the extraction vessel, which is a vacuum system that uses a mercury displacement pump to draw the gas released from the waste into sample collection bottles located outside the cell wall. System temperatures and pressures are continuously monitored and recorded during the extraction process. The collection bottles are then sent to PNNL for composition analysis.

The PNNL mass spectrometer is used for identifying and quantifying all the gas species present in the sample collection bottles. Ammonia concentration measurements are made separately because this gas is difficult to analyze accurately with the sample collection system used for the mass spectrometer. Lithium and bromide concentrations are measured to determine the magnitude of contamination of the sample by the hydrostatic head balancing fluid used in the push-mode sampling process. The overall performance of the RGS has met or exceeded design expectations. Four DSTs, AW-101, AN-105, AN-104, and AN-103, and one SST, A-101, have been successfully sampled (Shekarriz et al. 1996). 


\subsubsection{Consistency of BPE and VFI Gas Volumes}

The VFI provides an accurate assay of the void fraction profile in the liquid and nonconvective layers but it cannot be used in the crust layer. Therefore, the gas volume stored in the crust can only be imperfectly estimated. Also, the VFI is only operated under two risers per tank and therefore potentially misses major maldistributions in gas content. However, all the gas in the tank responds to changes in barometric pressure, so the BPE method can potentially measure the total gas volume if its distribution is known.

Since the VFI data provide an accurate gas distribution for the BPE volume calculation the two methods can be applied together as a consistency check on the total gas volume. Close agreement of the total gas volume computed by the BPE method with that derived from the local VFI data provides some assurance that VFI measurements did not miss any large amount of gas in the nonconvective layer due to maldistribution, and that the crust gas volume estimate is reasonably accurate.

Table 3.2 compares the in-situ gas volume computed from the local void fractions measured by the VFI with the in-situ volume computed with the BPE method from the measured barometric pressure response. The effective pressure for the BPE calculation was derived from the VFI void profile and crust gas volume estimate. In all cases, the VFI gas volume lies well within the standard deviation of the BPE calculation. The BPE volume falls outside the standard deviation of the VFI calculation only in AW-101 and AN-103. This comparison tends to confirm that the stored gas volumes derived from the VFI data and the estimated crust volumes are correct within the stated uncertainty bounds. It is not intended to validate the BPE method in general, though it is a first step toward that goal for DSTs.

\subsection{ACTIVITIES REMAINING TO UNDERSTAND GAS RETENTION}

Gas retention testing on actual tank wastes is needed because these data are essential for estimating the potential physical hazard of the tank wastes. An understanding of the amount of gas that is retained in the solid waste is necessary to evaluate the hazard. It is necessary to test actual waste to verify that the retention behavior predicted from simulant studies can be applied with an acceptable level of confidence.

Table 3.2. Barometric Response Comparison.

\begin{tabular}{|c|c|c|c|c|c|c|}
\hline $\begin{array}{c}\text { In-Situ } \\
\text { Volume (m) }\end{array}$ & AN-103 & AN-104 & AN-105 & AW-101 & SY-101 & SY-103 \\
\hline VFI & $291 \pm 34$ & $148 \pm 22$ & $107 \pm 30$ & $142 \pm 36$ & $164 \pm 43$ & $114 \pm 57$ \\
\hline BPE & $328 \pm 70$ & $133 \pm 43$ & $94 \pm 39$ & $102 \pm 44$ & $154 \pm 69$ & $91 \pm 63$ \\
\hline VFI - BPE & -37 & 15 & 13 & 40 & 10 & 23 \\
\hline
\end{tabular}


The current understanding of gas retention mechanisms is based on laboratory experiments with simulants and real waste samples, and the methods for testing gas retention are well developed (Gauglitz et al. 1996). In the standard bubble experiment, bubble growth is obtained by applying a vacuum to the waste sample following a few days of sample irradiation to generate a small initial fraction of retained gas. As summarized in the preceding sections, bubble retention measurements have been made on waste from DSTs SY-101 and SY-103 and SST S-102. Still, a number of waste types have not been tested, and bubble retention measurements are needed on these additional waste types.

All these bubble retention experiments used relatively small apparatuses where it is not possible to apply hydrostatic or lithostatic pressures typical of tank conditions. Also, gas generation rates were greatly accelerated over those expected under actual tank conditions. This creates uncertainty about the applicability of these results to actual tank conditions. A large-scale, long-term experiment must be performed in the near future to validate the current model and verify that meaningful results are obtained with accelerated bubble growth.

The two tank wastes of highest priority for FY 1997 testing are AN-103 and S-106. The standard bubble retention experiment (bubble growth by applying a vacuum following irradiation) will be conducted on samples from these tanks because they will provide the most valuable data for understanding gas bubble retention and release. Tank AN-103 was selected because it has a large void fraction based on direct measurement and because the waste type is double-shell slurry, differing from the complexant concentrate of the SY farm tanks. This double-shell tank exhibits slurry growth similar to some SSTs, and very few large spontaneous releases have been noted, which is consistent with increased gas retention. Tank S-106 was selected for similar reasons; analysis of the waste level rise and the effect of barometric pressure variations show a potential large void fraction. The waste type is noncomplexed waste, which is different than that for the SSTs tested in FY 1996 (S-102, a double-shell slurry feed). Some additional high priority waste tanks include $\mathrm{AW}-101$, because it contains double-shell slurry feed, differing from the complexant concentrate waste type of the SY-farm tanks; and U-103, because little is known about U-farm SSTs.

While it is possible to bound the total in-situ gas volume in most tanks, we cannot predict where the gas is stored with any certainty, and this increases the uncertainty in the estimated gas volume at STP conditions. Our ability to predict the distribution of gas within the tanks needs to be improved through modeling and direct measurements. Only in situ measurements of gas fraction with the RGS or VFI can provide these data. The VFI has provided accurate gas volume measurements in all the FGWL DSTs (Stewart et al. 1996a), but only the RGS can be operated in SSTs. An aggressive program is needed to operate the RGS in selected tanks suspected to store large volumes of gas. Since the analysis provided in Table 3-1 shows that a significant amount of gas can be held with the crust layer, additional considerations need to be given toward a better way to directly measure the gas retained within the crust.

Once a reasonably accurate in-situ gas volume and its distribution have been determined from VFI or RGS measurements, changes in gas retention can be monitored with surface level 
response and BPR. Volume changes before and after the measurement can be calculated from changes in the surface level. This does not depend on the location of the gas but assumes that leaks, additions, evaporation, and similar effects are negligible (or known). Major changes in the gas elevation can then be determined from the BPE in-situ volume since it is sensitive to the vertical gas distribution, provided sufficiently precise level measurements are available at least daily. Only the Enraf buoyancy gauge is able to provide sufficient precision at this time.

Recent analyses (Whitney et al. 1996) show that the BPE method may also provide information on some waste properties (potentially yield strength and pore size). However, this can only be achieved with highly precise surface level measurements recorded automatically on an hourly schedule. Such readings are available only with an automatic Enraf buoyancy gauge. More Enraf gauges need to be installed on high-priority tanks, and all of them urgently need to be set up to record data automatically.

Our inability to measure gas volume in stabilized tanks must be remedied before the safety issue can be resolved. In tanks that have been stabilized by salt-well pumping, the free liquid level lies beneath the solids level. In some cases we doubt that trapped gas response is correctly reflected by the solid surface level, and we believe that a measurement of the free liquid level would be more appropriate. However, the current method of measuring the interstitial liquid level with a neutron detector in a LOW is so imprecise that it cannot be used to compute gas volume. There is also good reason to believe that the liquid level in a LOW does not represent the level elsewhere in the waste. Currently, the RGS is the only available method for measuring retained gas volume, composition, and distribution in these tanks.

The effects of salt-well pumping on retained gas inventory in SSTs are not understood, although ideal situations have been studied (Peurrung et al. 1996). The retained gas volume is thought to be significantly reduced by salt-well pumping, but the field data are sparse and contradictory. Indications are that sludge tanks do not loose very much gas when salt-well pumped and may even expand in volume as the hydrostatic head is reduced (Caley et al. 1996). The inability to apply the BPE method in these tanks exacerbates the problem. To begin to resolve this issue, future salt-well pumping campaigns need to be appropriately monitored, including a long period after pumping ceases, to correlate any subsidence with potential gas release. Also, the RGS should be used in a tank before and after salt-well pumping to gain a precise measurement of how much gas is removed by the process. The overall understanding of the flammable gas hazard in salt-well pumped tanks could also benefit from a more detailed evaluation of the mechanisms that may affect gas retention. 
HNF-SP-1193, Rev. 2

This page intentionally left blank. 


\subsection{GAS RELEASE}

An assessment of the consequences of a flammable gas deflagration requires information about the amount and rate of gas release. Much of the knowledge gained about gas release derives from the study of gas release events in DSTs. Through an evaluation of the gas monitoring data and waste level history, release fractions and volume distributions have been estimated for the DSTs on the FGWL (Stewart 1996a).

The buoyant displacement gas release mechanism in DSTs (historically been called a "rollover") is relatively well understood based on the consistency and broad agreement of the tank data with models, laboratory studies, and video images of actual release events.

Much effort has been spent in studying the waste forms in SSTs (Stewart 1996b), and, as a result, the number of potential release mechanisms has been considerably reduced. The few remaining plausible mechanisms are discussed in this section along with information about mixing the released gases with the air in the dome space and the flammability behavior of the resulting mixture.

\subsection{RELEASE MECHANISMS: UNDISSOLVED GAS}

The gas release mechanisms currently considered most credible are the buoyancy-induced displacement, percolation of dendritic bubbles, and mechanical disruption. Disruptions include local penetration (for example, core sampling), removal of waste by salt-well pumping or by solids sluicing, addition of liquid that might dissolve surface solids, and severe earthquakes. Only buoyant displacement and seismic disruption appear capable of a rapid release of a major fraction $(\sim 50 \%)$ of the stored gas volume. Dendritic bubble percolation may yield small, though possibly rapid releases. Evidence indicates that disruptions release gas mainly from the region being disturbed. Local penetrations cause only small releases. Salt-well pumping may release a large fraction of stored gas, but the release occurs slowly over the entire campaign of one to two years. Likewise, most proposed retrieval scenarios should release essentially all insoluble retained gas, but the release rate follows the progress of the operation.

\subsubsection{Buoyant Displacement}

Buoyant displacement is an instability event where a portion of the settled solids layer accumulates enough gas to become buoyant with respect to the supernatant liquid above it. When this happens, the buoyant solids rise to the surface, trading places with the liquid. If sufficient mechanical energy is released in the process, the solid-liquid matrix containing the gas is disrupted and some stored gas is released. The amount of energy released increases with the depth of supernatant. It has been found both analytically and experimentally that, for typical tank conditions, the supernatant liquid must be greater than a meter in depth for a significant gas 
release. This condition only exists in certain DSTs. No SSTs are known to have this depth of supernatant. Without sufficient supernatant liquid, the buoyant instability occurs very gently, if at all, and little gas is released.

A series of experiments was conducted to qualitatively demonstrate the differences between buoyant displacement dynamics with relatively deep and shallow overlying supernatant layers (Stewart et al. 1996b). While the small size (27 cm diameter) of the bench-top experiments affects fluid behavior, the simulant physical properties can be adjusted to mimic buoyant displacements qualitatively in a waste tank. The waste simulant was a bentonite clay and water mixture with a small amount of hydrogen peroxide added to generate gas in situ.

The experiments showed that the buoyant displacements were quite energetic with a deep supernatant layer. With the weaker simulant (14 Pa yield stress), this energetic action also produced an immediate and substantial release of gas. For the stronger simulant $(67 \mathrm{~Pa})$ the displacement was also energetic, but the bubbles were not easily released from the clay. Buoyant gobs stayed intact and floated for a while before releasing some of their bubbles. With thin supernatant there was essentially no gas released during or following the buoyant rise of the bubbly solids. For both the weaker and stronger simulants, the bubbly solids did clearly trade places with the liquid. However, this buoyant rise was very lethargic and did not provide sufficient agitation to release any gas from the simulant.

A criterion for gas release can be developed relating the total potential energy available to the energy required to yield the buoyant solids matrix participating in the event. The total stored buoyant energy can be calculated from the work done in raising the participating volume a distance $\mathrm{L}$, given by

$$
E_{b}=\int_{0}^{\ell} F(z) d z
$$

where $F(z)$ is the net buoyant force, neglecting the mass of the stored gas, which is given by

$$
F(z)=\alpha_{0} \rho_{L} V_{0} g \gamma\left(\frac{1+\gamma}{1+\gamma z / L}-k\right)
$$

where $\alpha_{0}$ is the initial void fraction, $\rho_{\mathrm{L}}$ is the supernatant density, $\mathrm{V}_{0}$ is the volume of material participating, and the parameters $\gamma$ and $k$ are given by

$$
\begin{gathered}
\gamma=\rho_{L} g L / P_{A} \\
k=\frac{\alpha_{N B}\left(1-\alpha_{0}\right)}{\alpha_{0}\left(1-\alpha_{N B}\right)}
\end{gathered}
$$


where $P_{A}$ is standard atmospheric pressure and $\alpha_{\mathrm{NB}}$ is the void fraction at neutral buoyancy. The integral in Eq. (4.1) can now be evaluated with the aid of Eq. (4.2) to give the buoyant energy as

$$
E_{b}=\alpha_{0} V_{0} P_{A} \gamma((1+1 / \gamma) \ln (1+\gamma)-k)
$$

We assume that the nonconvective layer has a finite yield strength that must be overcome to release bubbles of gas. The structural and rheological properties of waste are, in general, complex and not yet well known; however, there are some basic features that allow us to estimate yield energy. The energy required to yield a volume of solids is equal to the work done on the volume by an externally applied force in order to deform it to the point of yielding. This is expressed mathematically as

$$
E_{y}=V_{s} \int_{n}^{E_{y}} \tau d \epsilon
$$

Here $\tau$ is the stress applied to the volume, and $\epsilon$ is the strain (relative elongation). The limit of integration is $\epsilon_{y}$ which is the strain at failure. We assume linear-elastic behavior for strain less than $5-10 \%$ and a constant stress over the plastic region up to a strain of 1 . With these assumptions, the energy required to yield the sludge is approximately

$$
E_{y}=\left(1-\alpha_{0}\right) V_{0} \epsilon_{y} \tau_{y}
$$

The ratio of the two energies is given by the ratio of Equations (4.5) and (4.7) as

$$
\frac{E_{b}}{E_{y}}=\frac{\alpha_{0} P_{A} \gamma}{\left(1-\alpha_{0}\right) \epsilon_{y} \tau_{y}}((1+1 / \gamma) \ln (1+\gamma)-k)
$$

Gas release will not occur if the buoyant energy available is less than that required to yield the sludge volume involved. If $E_{b} / E_{y}>\sim 1$, we expect a buoyant displacement to release some or most of the retained gas. Otherwise, we expect little or no gas to be released. But some of the buoyant energy is dissipated in processes other than yielding the rising gob, so more energy is required than just enough to yield. Evaluating the energy ratio given by Equation (4.8) with the conditions of SY-101 gives values ranging from 7-9. The two lab-scale experiments that showed energetic buoyant displacements yielded energy ratios of 2.6 for the 67-Pa simulant and 5.2 for the 14-Pa simulant; the two experiments with shallow supernatant layers had energy ratios less than 1 . While these observations are not sufficient to precisely quantify the relation between gas release and energy ratio, they are consistent with the following criteria: no disruptive buoyant displacement is predicted for $\mathrm{E}_{\mathrm{b}} / \mathrm{E}_{\mathrm{y}}<1$, buoyant displacements with limited gas release might occur for $E_{b} / E_{y}>\sim 2$, and major gas releases can be expected if $E_{b} / E_{y}>\sim 5$. For typical tank conditions, Eq. (4.8) requires the supernatant liquid depth to exceed about $1 \mathrm{~m}$ to allow buoyant displacements and over $3 \mathrm{~m}$ for significant gas release. These conditions currently exist only in the DSTs. 


\subsubsection{Percolation of Dendritic Bubbles}

Percolation describes the situation where dendritic bubbles grow into each other, connect, and rapidly rise until a new equilibrium is reached; or the gas escapes through the waste surface. The vertical extent of a connected dendritic region is limited by the balance of hydrostatic pressure with the capillary pressure and the yield strength of the material. Diffusional and probabilistic arguments would suggest a limited horizontal extent. Gas retained as particle displacing dendritic bubbles potentially causes the largest releases because the solids collapse as the bubble rises. However, calculations indicate these releases are limited to a few cubic meters at most.

Dendritic bubbles may be either particle-displacing or pore-filling as discussed in Section 3 . The dynamics of a percolation gas release from pore-filling or particle-displacing bubbles are different. When a connected region of litho-dendritic bubbles migrates upward, the flow of gas is limited by the rate at which liquid can flow in to replace it. When a particle-displacing bubble network moves, gas flow is not limited by the replacement liquid flow because the bulk waste collapses into the volume the gas had occupied.

Porous media flow calculations reveal that the volumetric flow rate of liquid replacing the gas in a percolating litho-dendritic bubble is very low and independent of pore size when the dependency of bubble height on pore size is included. For typical waste conditions, the flow rate is on the order of $0.003 \mathrm{~m}^{3} / \mathrm{hr}$. This two orders of magnitude less than the most conservative passive breathing rate of about $0.33 \mathrm{~m}^{3} / \mathrm{hr}(0.2 \mathrm{cfm})$. Therefore, the potential releases from porefilling, litho-dendritic bubbles are inconsequential in themselves.

Litho-dendritic bubbles are predicted to exist only in the lower layers of the waste, capped by a layer of particle-displacing bubbles. Therefore, direct release from the litho-dendritic layer to the dome space is not possible. Instead, the gas percolates through the litho-dendritic layer and collects at the bottom of the layer containing particle-displacing bubbles where it eventually escapes by percolation of particle-displacing bubbles.

When particle-displacing bubbles grow in a deformable material, the bubble shape is controlled by surface tension and the strength of the material. If surface tension dominates, the bubble will tend to remain roughly spherical. When the waste strength dominates, the bubble displaces the weakest segment of its surface, following the path of least resistance, and evolves into some dendritic shape. The largest bubble that can remain roughly spherical is given by Eq. (4.9) (Gauglitz et al. 1996).

$$
D_{b}<\frac{\sigma}{\tau_{y}}
$$

Where $\tau_{y}$ is the yield stress, $\sigma$ is the surface tension, and $D_{b}$ is the bubble diameter. The ability of the material to restrain the bubbles buoyancy also limits the size. The largest bubble that will be held by the strength of the waste is expressed as Eq. (4.10) (Stewart et al. 1996b): 


$$
D_{b}<\frac{\tau_{y}}{\rho_{w} g Y_{G}}
$$

where $\rho_{\mathrm{w}}$ is the bulk waste density, and the "gravity yield number," $\mathrm{Y}_{\mathrm{G}}$, is estimated at about 0.2 (Chhabra and Uhlherr 1986).

Figure 4-1 shows the limiting bubble diameters derived from Equations (4.9) and (4.10) plotted versus yield stress for waste density $1800 \mathrm{~kg} / \mathrm{m}^{3}$ and surface tension $0.08 \mathrm{~N} / \mathrm{m}$. The plot represents a map of particle-displacing bubble behavior. The triangular shaded area satisfies both the criteria: the bubbles are round and the waste is strong enough to prevent them from rising. As bubbles grow along the vertical axis, those in relatively strong material, say $\tau_{y}>100 \mathrm{~Pa}$, will first become dendritic, then relax by percolation (see Section 4.2.5). Bubbles in very weak material, say $\tau_{y}<10 \mathrm{~Pa}$, will remain round until they grow to the point that the material can no longer hold them. We conclude that hydrostatic bubble releases are expected only in waste with yield stress less than about $100 \mathrm{~Pa}$, and that the largest individual bubbles will be less than $1 \mathrm{~cm}$ in diameter.

A hydro-dendritic bubble can continue to grow vertically as long as it is neither pinched off nor filled with liquid draining into it. To satisfy this condition, the bubble height must be less than that for which the waste yield strength can bear the hydrostatic pressure difference across the bubble. It turns out that Equation (4.10), the criterion for the maximum diameter of a hydrostatic bubble for a given yield stress, also defines the maximum vertical extent of a hydro-dendritic bubble (Brewster et al. 1996). Referring to Figure 4-1, the maximum hydro-dendritic bubble height in a 500-Pa waste, for example, is just over $10 \mathrm{~cm}$.

Gauglitz et al. (1996) performed experiments which clearly demonstrated gas percolation through a network of hydro-dendritic bubbles in stronger clay simulants. As discussed in Section 3.1.1, the bubbles in one region of the simulant column become dendritic as they expand, then contract as they reach the percolation threshold and discharge part of their gas into an upper region which in turn expands and may discharge upward in an irregular cascade. The contracting bubbles very seldom collapse. The column grows by this process until it becomes quasistationary and releases gas nearly continuously but at varying rates.

A model for hydro-dendritic percolation release was developed by the 29th European Study Group (Brewster et al. 1996). They simulated the process by representing the waste as a set of discrete layers, each of which accumulated gas both from generation and from the discharges of lower layers. Flow from each layer as controlled by a relative permeability which was set to zero below a percolation threshold void fraction $\alpha_{c}$ of $10 \%$ and varied as $\left(\alpha-\alpha_{c}\right)^{2}$ until a critical permeability was reached. At that point the bubble collapsed and discharged a fixed fraction $(70 \%)$ of its gas to the layer above. The results of this model showed the void fraction in all layers hovering about the critical value. However, release from a lower layer often triggered a sort of cascade where all the higher layers would exceed the percolation threshold. Cascades were never observed to begin lower than about halfway down and releases were relatively small. 


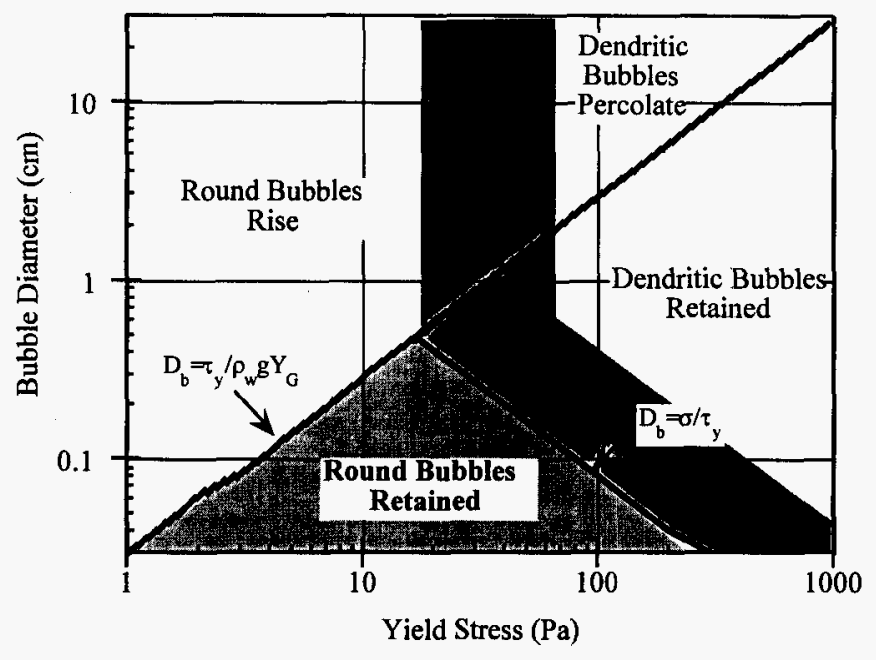

Figure 4-1. Particle-Displacing Bubble Behavior Map.

Further investigation with a similar model (Stewart et al. 1996b) shows that such a cascade typically releases less than $10 \%$ of the gas contained in a column approximately $1-3 \mathrm{~m}$ in diameter. It is believed that this release mechanism is the most probable explanation for the relatively frequent, small releases that have been revealed in recent head-space monitoring data. It should be emphasized, however, that hydro-dendritic percolation offers no pathway for a large, tank-wide gas release.

\subsubsection{Local Disruptions}

Current evidence indicates that, at most, a local disruption will release gas from the material actually disturbed by the penetration. The liquid surrounding a penetration maintains the hydrostatic pressure, and no "pressure sink" to the atmosphere is formed that could scavenge the gas from a wide region. Because of the limited volume of a connected source region described above, local disruptions should not trigger large gas releases when penetrating dendritic bubbles, and no instance has been observed of a penetration such as core sampling triggering a buoyant displacement event in a DST. 
A complete summary of GRE evidence from the tanks' operational history is given in the rotary core sampling safety assessment (LANL 1996a). In 49 core sampling events, only one possible gas release was observed, in A-103 between March 24 and 31, 1986, when the waste level dropped 2.4 inches over one week, bracketing the time lower segment samples were removed. All of these intrusions were in FGWL tanks; 17 were SSTs. Three of the 17 tanks with operating head space gas monitors during these intrusions had small gas releases, estimated at less than 2 $\mathrm{m}^{3}\left(70 \mathrm{ft}^{3}\right)$, and the head space never exceeded $9 \%$ of the LFL.

During 38 liquid observation well installations in SSTs, only one in SX-104 on May 24, 1984, showed a 2.1 inch level drop, but this occurred 1-8 days before LOW installation. However, there was no flammable gas monitoring during these installations. However, ammonia can typically be smelled at $20 \mathrm{ppm}$ and causes discomfort at higher concentrations. No strong ammonia odor was reported during these activities.

The VFI/ball rheometer campaign produced over 50 major penetrations of the waste, all in the highest priority DSTs on the FGWL (Stewart et al. 1996). Though some minor bubbling was observed on the liquid surface of SY-103 (the only tank where a free surface formed during testing), measurable gas releases occurred only in AW-101. Hydrogen monitoring showed a release from the crust layer of about $7 \mathrm{~m}^{3}\left(250 \mathrm{ft}^{3}\right)$ total gas release hydrogen following water lancing under riser $13 \mathrm{~A}$. There were no further releases during ball rheometer operation or lancing through the crust in riser $1 \mathrm{C}$. Shortly after the third VFI traverse began in riser 1C, a release of about $16 \mathrm{~m}^{3}\left(600 \mathrm{ft}^{3}\right)$ occurred.

The mixer pump installation and initial operation in SY-101 can also be cited as an even more significant disruption (Allemann et al. 1994). A slight head-space hydrogen elevation was observed during water lance operation, but there were no well-defined gas releases until highspeed "bumping" (five-minute runs at $1000 \mathrm{rpm}$, twice daily) began July 26, 1993, when release of about $4 \mathrm{~m}^{3}\left(150 \mathrm{ft}^{3}\right)$ occurred. Only brief pump clearing runs were made for the next four months. During this time, there was only one large release of $60 \mathrm{~m}^{3}$ on August 27 that may have been SY-101's last natural release. This pump did not begin mixing the entire tank until October 25 , more than one natural GRE period since Event I. While the tank was being mixed, there were four pump-induced releases in the range of $8-14 \mathrm{~m}^{3}$ but no further large ones.

To further quantify the range of likely behavior, gas release tests were conducted with clay simulants spanning a broad range of strengths. Mixtures of bentonite clay and water were combined with a small amount of hydrogen peroxide (about $0.5 \mathrm{wt} \%$ of the solids layer) to generate oxygen bubbles. The simulant strength ranged from $14 \mathrm{~Pa}$, which poured easily, to $1040 \mathrm{~Pa}$ which was stiff but easily spread with a spatula. For each experiment, the test vessel was filled with a bubbly clay simulant with a void fraction of about 0.2 . In each experiment, the simulant was subjected to three disruptions of increasing intensity. A description of the three disruptions is given below.

- Slow Penetration: A rod was slowly inserted by hand from the top of the simulant to the bottom and then withdrawn over about three seconds. 
- Energetic Penetration: The rod was inserted and withdrawn, by hand, ten times during about a seven second period.

- Vigorous Shaking: The test vessel rocked back-and-forth allowing the vessel to hit the counter as it was rocked. The rocking was done quickly, with about 2 full back and forth motions completed per second, and this shaking was continued for 15 seconds. For each experiment, essentially identical shaking was conducted.

Figure 4-2 shows the experimental results for the percentage of retained gas that was released during the three separate disturbance events. As expected, the amount of gas released decreased as the waste strength increased. The Slow Penetration event released a negligible amount of gas. Energetic Penetration only released significant gas in the very weakest simulant. The gas released by Vigorous Shaking was always greater than the two less energetic disruptions. These shaking experiments also mimic some aspects of how waste would respond to an earthquake. These results show that the gas release fraction decreases with increasing simulant strength. In addition, while we did not do quantitative experiments ranging from slow to energetic shaking, it was apparent that more intense shaking resulted in larger gas releases.

Several other gas release mechanisms of a "disruption" type were once proposed but have been shown not to be credible sources of large, rapid gas releases. These include penetration of a single or few very large bubbles, venting through a fracture, or the uncovering of a gas reservoir by dry-out. See Stewart et al. (1996b) for a complete discussion of these proposed mechanisms.

\subsubsection{Salt-Well Pumping}

Salt-well pumping is believed to ameliorate the flammable gas hazard by reducing the stored gas volume and reconfiguring the waste to prevent large releases of the remainder. However, there is clear evidence that not all the gas is removed in even the most effective campaigns, and we don't understand the process sufficiently to predict its result. The recent data obtained during pumping is unclear, and we cannot yet determine retained gas volumes afterward. Therefore, though saltwell pumping is clearly beneficial, the real effects cannot yet be quantified.

In salt-well pumping, a portion of the interstitial liquid in the waste drains into and is pumped out of a screened well near the center of the tank. Pumping is complete when the liquid level reaches the zone in which capillary forces hold the liquid in place despite gravity. During pumping, the radial liquid profile in the waste has its lowest point at the well screen and its highest points at the tank walls. When the liquid level in the well falls too low to support pumping, the pump is shut off and the interstitial liquid is allowed to seek a uniform level across the tank by gravity and partially refill the well. Then the pump is started, and the well is drained once again. In general the well can be pumped dry much more rapidly than it can be refilled by liquid level equilibration, so salt-well pumping is an intermittent process. 


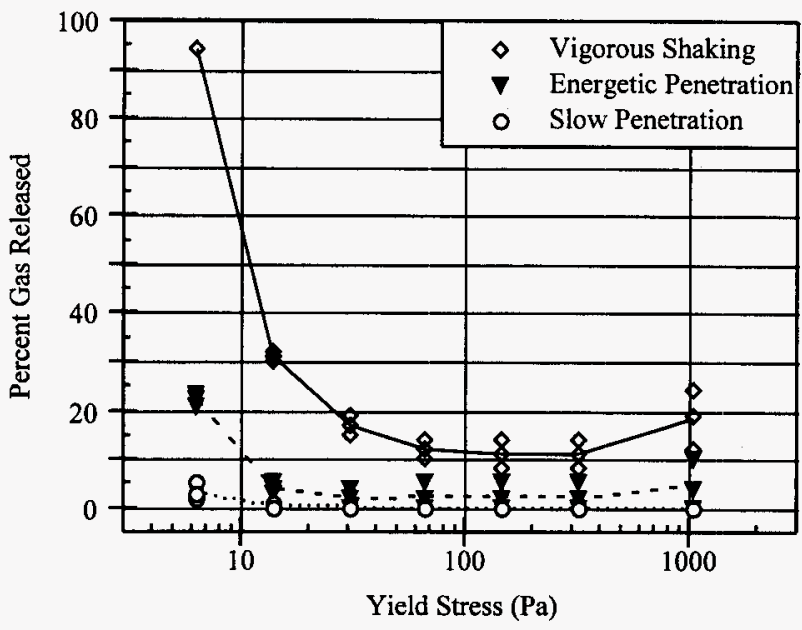

Figure 4-2. Percent of Gas Released as a Result of Disruption.

When liquid drains out of the porous waste, the emptied pores fill with air. Some of the gas already in the pores is exposed to the invading air and is thereby released to the head space by diffusion. Other unexposed gas beneath the interstitial liquid level expands under the decreased hydrostatic head and may migrate upward by percolation to be released at the surface. A substantial amount of the liquid continues to drain, releasing gas while the pump is off or at low speed. There is also a delay between the exposure of retained gas and its transport to and through the head space, due to the limited speed of diffusion. Thus gas releases are not necessarily concurrent with high pumping rates, which is clearly the case in the rather sparse salt-well pumping data.

Caley et al. (1996) summarize the rather sparse head space monitoring data during recent pumping campaigns. The main features of these data are: 1) pumping elevates flammable gas concentrations somewhat above normal background levels though a series of small gas releases; 2) gas release behavior may be somewhat different for sludge tanks versus saltcake tanks; and, 3) gas releases, as evidenced by head space flammable gas concentrations, do not predictably correlate with pumping rate. Beyond these conclusions, the available field data do not give a clear picture of what happens in the waste as the liquid is removed.

Because the exact relationship between gas release and pumping is not immediately evident from gas monitoring data, experiments and modeling studies were performed (Peurrung et al. 1996) to 
gain some insight on the expected behavior. Simulation results indicated that only about half of the interstitial liquid would be drainable, owing to capillary forces, and that all of the drainable liquid would be removed in about 200 days. The maximum insoluble gas release rate was predicted to be $4.2 \mathrm{~m}^{3} /$ day $\left(150 \mathrm{ft}^{3} /\right.$ day) during the first ten days of pumping. The rate quickly fell below less than about $0.6 \mathrm{~m}^{3} /$ day $\left(20 \mathrm{ft}^{3} /\right.$ day) after 25 days pumping. The early maximum in gas release was not observed in the field data.

The soluble gas (ammonia) flux was much larger, with a maximum of $180 \mathrm{~m}^{3} /$ day $\left(6400 \mathrm{ft}^{3} /\right.$ day), and continued at elevated levels (around $23 \mathrm{~m}^{3} /$ day, $800 \mathrm{ft}^{3} /$ day) long after the draining was essentially complete. The high release rates resulted from the extensive moist, unsaturated region produced by pumping, which provides an extremely high wetted surface area for mass transfer of a volatile solute from the liquid to the gas. This predicted ammonia release rate seems very high compared with the current operational experience, however continuous ammonia monitoring has not yet been performed during pumping to allow direct comparison. More recent information on ammonia concentrations implies that the hydrogen release during salt-well pumping could be 10 times, and the ammonia release could be $1 / 15$ or less, that calculated under the current modeling assumptions.

Comparison with laboratory-scale experiment (Peurrung et al. 1996) showed that the simulation model both qualitatively and quantitatively predicted experimental observations of onedimensional insoluble gas release. The predictions of soluble gas behavior under salt-well pumping conditions have not yet been experimentally validated.

Large voids or "caverns" are postulated to form following salt well pumping due to subsidence of the solid column when the partial support of buoyancy is removed with the liquid. Many tanks show deep depressions surrounding salt-well screens and sudden large waste level drops are occasionally observed long after a salt-well pumping campaign ends (Caley et al. 1996). Such level drops could be considered evidence for the collapse of subsurface caverns. If the caverns contained high concentrations of flammable gas, a significant volume could be released in such a collapse. However, a simple diffusion calculation (Stewart 1996b) shows that diffusion of gas through the porous saltcake is quite sufficient to prevent flammable gas buildup in such a cavern. Therefore cavern collapse does not release flammable gas into the tank head space.

Our understanding of salt-well pumping is hampered by the inability to assess the stored gas volume after pumping ends. The barometric pressure method cannot be applied successfully both because the pressure response measurements are doubtful and the model for calculating gas volume is probably not applicable. The RGS is the only means to establish the stored gas volume accurately in stabilized tanks and "before and after" RGS measurements should be performed in the next salt-well pumping campaigns initiated. 


\subsubsection{Earthquakes}

A severe seismic event has the potential to disturb all tank contents, possibly to the point of yielding and allowing a large fraction of the trapped gas to escape rapidly. A conservative model based on linear elastic theory was used (Stewart 1996b) to evaluate the waste motion during the Hanford design basis earthquake (DBE). Elastic assumptions provide a means to characterize induced stresses and absorbed energy for a spectrum analysis. This method requires waste physical and structural property data that are not currently available. Therefore the results are only plausible ranges of effects, not predictions, and they are not intended as a technical basis for a safety analysis.

The DBE spectrum for Hanford used in the model is a 1,000-year earthquake with its "hook" set at $0.35 \mathrm{~g}$. A 100 -year earthquake is a proportional curve with its hook set at $0.20 \mathrm{~g}$. A simple finite element model of waste excitation was used to generate normal stresses. The spectrum excitation was assumed at the base of the tank. Three primary unknowns required to determine natural frequency and response were the modulus of elasticity, Poisson's ratio, and damping.

Two modes of vibration were evaluated: vertical motion due to an excitation applied at the bottom of the tank, and lateral motion due to a rocking spectrum applied at the base. The lateral vibration model includes some adjacent ground structure to account for inherent restraint. The models assume one-dimensional vertical and horizontal vibration.

The magnitude of the calculated induced stresses indicates that most of the waste could potentially yield (i.e., strains would exceed the elastic limit of $\sim 5 \%$ ). Horizontal excitation produces the highest induced stresses. But potential gas releases induced by earthquakes depend only indirectly on the peak stresses. The real issue is how much energy is imparted to the waste compared with the energy required to yield it. Figure 4-3 compares the energy deposited in the waste during 100-year and 1000-year DBEs with the energy required to yield the waste assuming both the elastic yield limit ( $5 \%$ strain) and plastic deformation limit (100\% strain). The conditions represent horizontal excitation and $640 \mathrm{~cm}$ (250 in.) waste depth.

It is clear from the figure that a large earthquake can potentially yield most of the waste. Considering plastic energy absorption, waste with a shear modulus above about $3 \mathrm{kPa}$ might withstand a 100-year DBE, while a modulus of $10 \mathrm{kPa}$ is required for a 1000-year DBE. At $100 \%$ strain the waste yield stress is equal to the shear modulus value.

For a tank whose waste has a yield stress of $500 \mathrm{~Pa}$, typical of DST waste, Figure 4-3 shows that

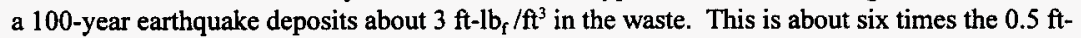
$\mathrm{lb}_{\mathrm{f}} / \mathrm{ft}^{3}$ required to yield the waste assuming plastic energy absorption, and about the same energy ratio as occurred in SY-101's large buoyant displacement events that released up to $50 \%$ of the stored gas (see Section 4.1.1). 


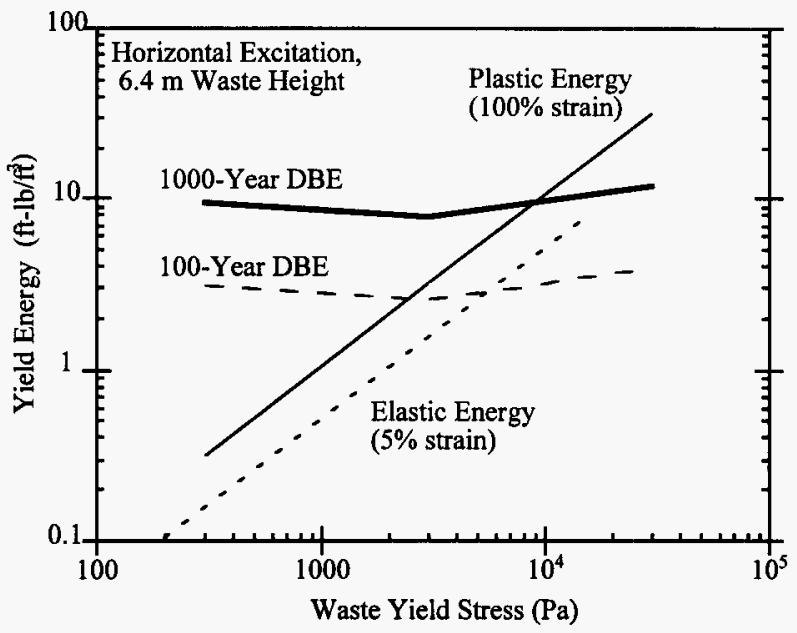

Figure 4-3. Yield Energy Limit-640-cm Height, Horizontal.

For a tank whose waste has a yield stress of $500 \mathrm{~Pa}$, typical of DST waste, Figure 4-3 shows that a 100-year earthquake deposits about $3 \mathrm{ft}-\mathrm{lb}_{\mathrm{f}} / \mathrm{ft}^{3}$ in the waste. This is about six times the $0.5 \mathrm{ft}$ $\mathrm{lb}_{\mathrm{f}} / \mathrm{ft}^{3}$ required to yield the waste assuming plastic energy absorption, and about the same energy ratio as occurred in SY-101's large buoyant displacement events that released up to $50 \%$ of the stored gas (see Section 4.1.1).

Thus, if the analogy holds, a 100-year earthquake might cause a rapid release of $\sim 50 \%$ of the stored gas in a typical DST. For a potentially stronger SST waste with yield stress $1000-1500$ $\mathrm{Pa}$, a 1000-year earthquake is required to deposit the same relative energy for the assumed $\sim 50 \%$ release. At the same time, for a yield stress above about $2500 \mathrm{~Pa}$, yielding in a 100-year earthquake would be incomplete and gas release would be minimal. A 10,000 Pa material would survive a 1000-year event. This result is sketched in Figure 4-4.

We conclude that seismic events have the potential to create large, rapid gas releases in both DSTs and SSTs, though gas releases will be larger in the former. Besides buoyant displacement in tanks with a deep supernatant liquid layer, earthquakes are the only other release mechanism believed to have this potential. However, given the assumptions applied, the results of this analysis must be considered only tentative "ballpark" possibilities, not as formal predictions. 


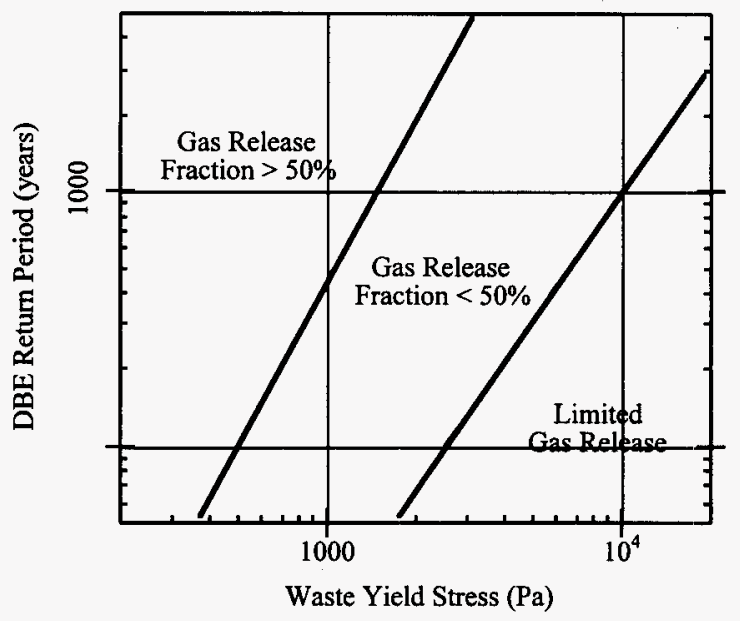

Figure 4-4. Possible Gas Release Fraction Versus Earthquake Severity.

\subsubsection{Observed Gas Releases}

Based on the current understanding of the physics of undissolved gas retention and release in Hanford waste tanks, buoyancy-triggered displacement is the only credible mechanism for a large, rapid, spontaneous gas release. An energetic displacement can only occur with a supernatant liquid layer more than approximately $1-\mathrm{m}$ thick. This condition exists only in DSTs.

The gas release histories of the double-shell tanks derived from waste level history (Stewart et al. 1996a) suggest that SY-101 was unique in releasing 130 to $200 \mathrm{~m}^{3}$ of gas, or 35 to $70 \%$ of its $300-500 \mathrm{~m}^{3}$ retained gas inventory every 100 to 150 days. In contrast, the next highest mean release fraction is $16 \%$ in AW-101 and AN-105. Tanks SY-103, AN-103, and AN-104 release 4 to $10 \%$ of their retained gas on a random schedule. The mean release volumes are $23-26 \mathrm{~m}^{3}$ in tanks AN-104 and AN-105 and $14 \mathrm{~m}^{3}$ in the other three tanks. This information is summarized in Table 4-1. Only the gas releases in tank SY-101 were sufficiently large to make the gas mixture in the tank head space flammable and potentially fail the dome, if burned. 
Table 4-1. Summary of GRE Behavior in Flammable Gas DSTs.

\begin{tabular}{||c|c|c|c|c||}
\hline $\begin{array}{c}\text { Tank } \\
\text { (Watch List } \\
\text { bold) }\end{array}$ & $\begin{array}{c}\text { Waste, Solids, and } \\
\text { Crust Depth } \\
(\mathrm{cm})\end{array}$ & $\begin{array}{c}\text { Gas Release } \\
\text { Vol. (Std m })^{3} \\
(\text { Mean-Max.) }\end{array}$ & $\begin{array}{c}\text { Mean Pre- } \\
\text { GRE Gas Vol. } \\
\left(\text { Std. }^{3}\right)\end{array}$ & $\begin{array}{c}\text { Release } \\
\text { Fraction } \\
(\text { Mean-Max. })\end{array}$ \\
\hline \hline AN-103 & $885 / 380 / 92$ & $14-22$ & 327 & $0.04-0.07$ \\
\hline AN-104 & $980 / 415 / 40$ & $23-75$ & 220 & $0.10-0.30$ \\
\hline AN-105 & $1040 / 450 / 30$ & $26-52$ & 166 & $0.16-0.34$ \\
\hline AN-107 & $975 / 180 / 0$ & none & & \\
\hline AW-101 & $1040 / 280 / 64$ & $14-45$ & 91 & $0.16-0.29$ \\
\hline AW-104 & $1040 / 266 / 0$ & none & & \\
\hline AY-101 & $870 / 80 / 0$ & none & & \\
\hline SY-101 & $1060 / 510 / 100$ & $131-203$ & 394 & $0.34-0.67$ \\
\hline SY-103 & $690 / 345 / 20$ & $14-30$ & 161 & $0.09-0.18$ \\
\hline
\end{tabular}

There is no known mechanism that can create large, sudden, spontaneous gas releases in tanks not subject to buoyant displacement. In fact, only a severe earthquake appears capable of causing a disruption sufficient to release a large fraction of an SSTs stored gas. Fortunately, no earthquakes near the magnitude required to test this theory have occurred during Hanford's recorded history. The relatively rare, small releases accompanying local disruptions have been discussed in Section 4.1.3.

Hydro-dendritic percolation, discussed in Section 4.1.2, may be the mechanism responsible for the most frequent small releases from SSTs. Such releases would be too small to create a detectable waste level drop, but head space gas monitoring data that have become available in the past year reveal many concentration spikes that could be attributed to this mechanism. Many of these occurred during periods of very low barometric pressures during the winter of 1995-1996.

Approximate gas release volumes in SSTs during this period have been estimated by Wilkins (1996) using the transient concentration decay curves. The release volumes are summarized in Table 4-2. The typical small release volumes of 10's of cubic feet of hydrogen and their tendency to cluster around low pressure events is consistent with the percolation mechanism. However, further study is required on a broader range of data before release volumes and rates can be related confidently to specific waste configurations and properties. 
Table 4-2. Hydrogen Releasẹs from SSTs.

\begin{tabular}{||l|c|c||}
\hline Tank & Release Date & $\begin{array}{c}\text { Release Volume } \\
\left(\mathrm{m}^{3} \text { of } \mathrm{H}_{2}\right)\end{array}$ \\
\hline \hline $\mathrm{S}-111$ & $12 / 11 / 95$ & 1.0 \\
\hline $\mathrm{U}-103$ & $12 / 12 / 95$ & 0.5 \\
\hline & $2 / 20 / 96$ & 0.2 \\
\hline $\mathrm{U}-105$ & $12 / 11 / 95$ & 1.4 \\
\hline & $2 / 7 / 96$ & 0.4 \\
\hline & $2 / 20 / 96$ & 0.4 \\
\hline $\mathrm{U}-107$ & $12 / 11 / 95$ & 0.7 \\
\hline & $2 / 20 / 96$ & 0.1 \\
\hline $\mathrm{U}-108$ & $12 / 12 / 95$ & 0.7 \\
\hline $\mathrm{U}-109$ & $12 / 12 / 96$ & 0.4 \\
\hline & $2 / 20 / 96$ & 0.5 \\
\hline
\end{tabular}

\subsection{RELEASE MECHANISMS: DISSOLVED GAS}

Soluble gas, almost entirely ammonia, is retained in solution in the liquid and is released mainly from a free liquid surface, although some is released with bubbles of undissolved gas. Mass transport from a stagnant surface is extremely limited by diffusion through the liquid. Even a thin crust or foam layer bars evolution of ammonia by inhibiting convection. Significant ammonia evaporation occurs only when the liquid surface is strongly disturbed. Such a disturbance is likely in a violent buoyant displacement or seismic event or when liquid waste is transferred to a new tank and during major disruptions involved with retrieval. Salt-well pumping potentially releases large amounts of dissolved gas by exposing a huge surface area of moist, porous solids as the liquid level falls. A catastrophic effervescence release scenario has been proposed but is not credible in Hanford tanks. A detailed discussion of ammonia release mechanisms and the associated flammability hazard is in Palmer et al. (1996).

\subsection{GAS MIXING IN THE HEAD SPACE}

Gases released into the tank head space immediately begin mixing with the existing atmosphere so the flammable gas concentration decreases and the spacial distribution becomes more uniform as a function of time. Predicting the transient concentrations of flammable gases following release is important because hazard is proportional to the volume of gas that is flammable as a function of time. There are two distinct stages to the mixing process: 1) the dilution of the released gas with the ambient head space atmosphere, and, 2) the removal of the gas by 
ventilation with the outside air. The first stage has been investigated by computational modeling and tracer studies and is discussed in Section 4.3.1. The main issue in the second stage is determining passive ventilation rates which is the subject of Section 4.3.2.

\subsubsection{Plume Mixing Studies ${ }^{(1)}$}

Computer modeling of gas mixing was performed before actual tests in S-102. Both the modeling results and subsequent measurements in the dome space showed that complete mixing of the tracer gas occurs in less than an hour after tracer injection. Tracer tests are planned for several more passively ventilated tanks.

Plume-type gas releases were also modeled to evaluate hydrogen concentrations in the head space following release and to evaluate the effects of the presence of other gases on the hydrogen concentrations. A release of $10 \mathrm{~m}^{3}$ of pure hydrogen directly under the riser resulted in less than a $3 \%$ concentration of hydrogen at the riser shortly after the release; and a release at an offset position from the riser resulted in lower hydrogen concentrations at the riser. For a constant volume of hydrogen released, the presence of other gases in the plume has a significant effect in decreasing peak hydrogen concentrations.

Another study addressed the effects of the existing natural and forced convection head space flow field on hydrogen concentrations after a plume-type release of $19 \mathrm{~m}^{3}$ in two minutes. It was found that the existing flow field has little effect on hydrogen concentrations following a local plume-type release. The vent flow rate in a ventilated tank has a negligible effect on peak hydrogen concentrations but exerts a significant influence over dilution time. Only $4-6 \mathrm{~m}^{3}$ of gas was flammable at any instant, and flammability ceased altogether only a few seconds after the release terminated.

None of the computational or experimental studies to date have found or predicted any tendency to stratification where lighter, warmer hydrogen might collect near the top of the dome to create a flammable mixture. Also, it is becoming clear that small plume-type releases are probably flammable only during the actual release.

\subsubsection{Ventilation Rate Studies}

Minor GREs (see Table 4.2) have been seen in the SHMS data in FGWL during large swings in atmospheric pressure that occurred in December 1995 and February 1996. The hydrogen concentration rose rapidly followed by a relatively long period of decreasing concentration that

(1) Taken from Antoniak, Z.I. and K.P. Recknagle, 1996, Modeling of Hydrogen Plume Concentrations in Single-and Double-Shell Tank Domes, letter report TWSFG96.12, Pacific Northwest National Laboratory, Richland, Washington. 
followed an exponential decay. If the dome space is well mixed following a gas release and the background release rate is small relative to the ventilation flow rate, then the head space hydrogen concentration is given by the following expression:

where

$$
\mathrm{C} / \mathrm{C}_{0}=\mathrm{e}^{-1 \mathrm{O} / \mathrm{v}}
$$

$$
\begin{aligned}
& \mathrm{C}=\text { time dependent dome space hydrogen concentration } \\
& \mathrm{C}_{0}=\text { initial dome space hydrogen concentration } \\
& \mathrm{Q}=\text { ventilation rate } \\
& \mathrm{V}=\text { dome space volume } \\
& \mathrm{t}=\text { time after the release }
\end{aligned}
$$

Given the relative hydrogen concentration, the tank ventilation flow rate can be obtained. The model was applied to all the releases observed in the SHMS data identified above (Wilkins 1996). A summary of the application of the mixing model to the SHMS data is shown in Table 4-3.

The ventilation rate for passively ventilated tanks range from $2 \mathrm{cfm}$ to just over $10 \mathrm{cfm}$. These rates are an order of magnitude larger than barometric pressure breathing rates $(0.45 \%$ of the dome tank free volume per day) of $0.1-0.3 \mathrm{~cm}$. The ventilation rate for the actively ventilated tanks of the SX farm are much larger than the passive rates as expected, ranging from 20 to $50 \mathrm{cfm}$. Estimates of the SX farm ventilation rates based on thermal hydraulic analyses using tank temperature data are in reasonable agreement.

These results illustrate that valuable information can be obtained about the residence time and rate of removal of gases released into the tank dome space. Passive ventilation rates have been shown to be much higher than pure pressure breathing. Measurements of dome space concentrations in 134 passively ventilated tanks show that none have concentrations exceeding $25 \%$ of the LFL (see Appendix B). This indicates that passive ventilation is sufficient to effectively mitigate the steady-state flammability hazard in these tanks. 


\section{HNF-SP-1193, Rev. 2}

Table 4-3. Summary of Ventilation Rates.

\begin{tabular}{|c|c|c|}
\hline Tank & Date & $\begin{array}{c}\text { Ventilation Rate } \\
(\mathrm{cfm})\end{array}$ \\
\hline \multirow[t]{2}{*}{ BY -109} & Feb-96 & 35 \\
\hline & Mar-96 & 9 \\
\hline \multirow[t]{4}{*}{$S-111$} & Nov-95 & 2 \\
\hline & Dec-95 & 4 \\
\hline & Dec-95 & 4 \\
\hline & Feb-96 & 4 \\
\hline S-112 & Jan-96 & 4 \\
\hline SX-103 & Dec-95 & 50 \\
\hline \multirow[t]{2}{*}{ SX-104 } & Dec-95 & 30 \\
\hline & Feb-96 & 20 \\
\hline \multirow[t]{2}{*}{ SX-105 } & Dec-95 & 100 \\
\hline & Dec-96 & 40 \\
\hline \multirow[t]{3}{*}{ SX-106 } & Oct-95 & 30 \\
\hline & Dec-95 & 50 \\
\hline & Feb-96 & 35 \\
\hline SX-109 & Dec-95 & 30 \\
\hline \multirow[t]{4}{*}{ U-103 } & Oct-95 & 2.5 \\
\hline & Nov-95 & 7 \\
\hline & Dec-95 & 2 \\
\hline & Feb-96 & 11 \\
\hline \multirow[t]{2}{*}{$\mathrm{U}-105$} & Dec-95 & 9 \\
\hline & Feb-96 & 5 \\
\hline \multirow[t]{2}{*}{$\mathrm{U}-107$} & Dec-95 & 4.5 \\
\hline & Feb-96 & 3 \\
\hline \multirow[t]{3}{*}{$\mathrm{U}-108$} & Oct-95 & 3 \\
\hline & Nov-95 & 4 \\
\hline & Dec-95 & 3 \\
\hline \multirow[t]{3}{*}{ U-109 } & Sep-95 & 4 \\
\hline & Oct-95 & 5 \\
\hline & Dec-95 & 2 \\
\hline
\end{tabular}




\subsection{LEAN COMBUSTION OF GAS MIXTURES IN AIR}

Flammability is fundamental aspect of the flammable gas safety issue. Virtually all analyses of the flammable gas hazard are aimed at estimating the potential for some volume of gas to become flammable in the tank head space. A sound knowledge base for the lower flammability limit under a variety of conditions is essential for these analyses and to close the flammable gas safety issue. As part of an ongoing effort to build such a base, recent experimental studies were performed to determine the combustion characteristics of lean hydrogen, nitrous oxide, ammonia-air mixtures. The focus was on combustion limits, pressure histories and flame speeds of flammable gas mixtures.

The Pittsburgh Research Center of the U.S. Bureau of Mines investigated the flammability of various mixtures of hydrogen nitrous oxide and air (Cashdollar et al. 1992). Flammability data were collected from more than 280 tests in a 120-L spherical chamber. The researchers concluded that below $20 \%$ hydrogen, there is no significant difference in the flammability data for hydrogen-air or 1:1 or 3:2 ratios hydrogen to nitrous oxide in air. At higher hydrogen concentrations, the hydrogen-nitrous oxide-air mixtures are more hazardous, with higher maximum pressures and rates of pressure rise. Therefore, small amounts of nitrous oxide (relative to air) do not appear to have much effect on flammability, but high concentrations of nitrous oxide markedly increase the explosion hazard.

The LFL measured by Cashdollar et al. were the same for the three mixtures (hydrogen-air, 1:1, and $3: 2$ ratios of hydrogen to nitrous oxide in air):

Quiescent conditions, upward propagation Quiescent conditions, downward propagation Turbulent conditions, upward propagation Turbulent conditions, downward propagation
$5 \% \mathrm{H}_{2}$ $8 \% \mathrm{H}_{2}$ $4 \% \mathrm{H}_{2}$ $6 \% \mathrm{H}_{2}$

Tests were performed at an elevated temperature $\left(54^{\circ} \mathrm{C}\right)$ and with added water vapor with no significant effect. Limited tests with ammonia added indicated that each added $1 \%$ ammonia exhibited fuel behavior approximately equivalent to an added $0.5 \%$ hydrogen.

The results demonstrated that nitrous oxide is inert in lean mixtures of hydrogen-air nitrous oxide and reactive in lean mixtures of ammonia-air-nitrous oxide. For mixtures of hydrogen-nitrous oxide-ammonia-air, the reactivity of the nitrous oxide depends on the hydrogen-ammonia ratio. A correlation between the adiabatic, constant pressure, flame temperature of the mixture and the reactivity threshold of the nitrous oxide was made. Nitrous oxide began reacting when the adiabatic flame temperature was between 1,100 and $1,300 \mathrm{~K}$. It was determined that for flame temperatures above this threshold, the presence of nitrous oxide effects the flammability limit, the pressure history, and the flame speed.

Studies at the California Institute of Technology and Los Alamos National Laboratory (Breshears et al. 1996; Ross and Shepherd 1996) with hydrogen-air, hydrogen-nitrous oxide, ammonia-air, 
and ammonia-nitrous oxide were conducted to compare results. Pressure histories, final equilibrium pressures, and burning velocities were measured. The results were in reasonable agreement with previous experiments, taking into consideration the differences in the facilities. It was observed that the nitrous oxide does not always participate in the combustion of hydrogen-nitrous oxide-air mixtures, but participates in the combustion of ammonia-nitrous oxide-air mixtures.

A mixture based on the conservative estimate of the gas release from SY-101 was studied to determine lean flammability and combustion characteristics. The upward propagation limit for the mixture is $8 \%$ fuel content, and the downward propagation limit is $15 \%$ fuel content. The burning velocity varies from $1 \mathrm{~cm} / \mathrm{s}$ at the lean limit to $8 \mathrm{~cm} / \mathrm{s}$ at $18 \%$.

Three other hydrogen-nitrous oxide-ammonia mixtures were examined to find the effect of the nitrous oxide on mixtures rich in ammonia. The nitrous oxide was found to begin participating in the combustion process when the constant pressure adiabatic flame temperature approached $1,100 \mathrm{~K}$. This work suggests the current treatment of nitrous oxide in combustion calculations may be overly conservative and that the lower flammability limits may be somewhat higher.

\subsection{ACTIVITIES REMAINING TO UNDERSTAND GAS RELEASE}

The facts governing passive ventilation rates need to be defined. A knowledge of ventilation rate is necessary to ensure that the head space does not become flammable in the steady state and to determine the dilution time for episodic releases. Ongoing head space tracer studies and analysis of concentration decay transients from gas monitoring data are showing that passive ventilation is much higher than due to pressure breathing alone. However, the effects of diurnal, meteorological, and seasonal temperature variations are not known.

Capability must be developed to predict whether large, spontaneous gas releases will occur in a "new" tank created by transfer of existing waste. Since buoyant displacement is the only mechanism with the demonstrated potential to create a large spontaneous gas release, it is critical to ensure that planned changes in a tank's contents will not make it subject to buoyant displacement. The developing model for prediction of the scale and frequency of these events must be completed as soon as possible.

The relatively frequent small gas releases from SSTs now being observed by head-space gas monitoring need to be examined in the context of the currently understood gas retention and release mechanisms. This will allow the frequency, expected volume, and release rate to be estimated. Also, it has been very difficult to relate the potential for this kind of release to the quantity of gas retained.

These small gas releases enter the head space as a plume that requires a finite time to mix with the head space atmosphere. A portion of the plume is flammable during some mixing period even though the overall head space volume never approaches the lower flammability limit. It is 
very likely that the small plume flammability time is so short that no hazard exists, except for common cause or continuous ignition sources. A predictive model may need to be established as a function of elapsed time for the volume of a small release that is actually flammable, but this need must be evaluated against the needs and benefits of evaluating other items (e.g., source terms) that are major inputs to the overall risk.

Preliminary calculations showed that large earthquakes clearly have a potential for inducing a rapid release of a large fraction of stored gas, and ongoing analyses may confirm this. But other factors have confused the issue. First, such earthquakes are very rare, so the hazard may pose little risk. Second, an earthquake large enough to release gas may also fail the tank dome and cause such widespread collateral damage that the potential consequences of a flammable gas burn do not add to the risk. Finally, there is probably no way to prevent a seismic gas release save removing the waste altogether, which makes evaluation of the hazard questionable. The question whether the earthquake hazard belongs in the "safe storage" category needs to be answered soon.

The gas release processes resulting from salt-well pumping need to be better understood. Theory and computational simulation predict that much of the retained gas in a tank will be released as liquid is removed and that gas releases will approximately follow the pumping rate. Preliminary results also suggest that large volumes of ammonia may evolve from the moist saltcake as the free liquid level recedes and exposes a large gas-liquid interfacial area. However, the limited field gas monitoring data from recent pumping are not consistent with the theory, nor are they consistent from tank to tank. Better head-space gas monitoring, including hydrogen, nitrous oxide, and ammonia and before-and-after in situ measurements with the RGS, are needed, as described in the previous section. We recognize that some tanks may have a significant amount of gas held within a crust layer on top of the waste. Additional evaluations (modeling, laboratory tests, and direct in-tank measurements) must be performed to quantify the releasable amounts of gas from the crust.

Evaluating the consequences of the flammable gas hazard requires an understanding of the combustion process in lean mixtures and a knowledge of ignition source locations, frequencies, and energies, and the structural response of the tanks structure to the resulting pressure pulse. The probability for detonation and potential for flammable gas burns beneath the waste surface also need to be assessed. These issues are being dealt with in the BIO and FSAR. The Flammable Gas Project is developing new knowledge to assist safety analysts in these areas. 
HNF-SP-1 193, Rev. 2

This page intentionally left blank. 


\subsection{EVALUATION METHODOLOGY}

It is desirable that analytical techniques be developed that allow understanding of the tanks' conditions and potential flammable gas hazards based on the information obtained from direct tank sampling and measurement with a goal to extend the analysis to tanks with limited data. For example, the void fraction instrument, which has generated invaluable data, is designed to work in the relatively low-strength waste of the DSTs and is not useful in the drier, high-strength waste of the SSTs. While the retained gas sampler works in the SSTs as will as the DSTs its use is restricted to tanks that can be push sampled. It is not presently adapted to rotary mode sampling. Many of the flammable gas tanks have relatively hard layers that may render them unsuitable for push-mode sampling.

Development of evaluation methods must reflect the current understanding of the flammable gas phenomenon and be verified against real data and measurements. The following sections discuss the historical effort in applying such an evaluation methodology, a critical review of progress to date, and the plans for further development.

\subsection{DEVELOPMENT OF THE EVALUATION METHODOLOGY}

This section provides a brief summary of past work on the method used for evaluating potential FGWL tanks. Criteria for FGWL tanks that were used as part of the evaluation were described by Hopkins (1994). The main focus of the criteria were directed at whether or not a tank's dome space could exceed $25 \%$ of the lower flammability limit of hydrogen in air. In the evaluation process estimates were made of the inventory of flammable gas. Once the inventory is known, an allocated fraction is released to the tank head space and then the resulting condition of interest (concentration, plume size, pressure, etc.) is calculated.

A three-step process was developed to evaluate the flammable gas hazard for each tank against the FGWL criteria:

- When little or no tank-specific information was available, a bounding (worst-case) calculation was made of potential gas releases/concentrations using general information (for example, total waste volume, surface level history, type waste) and information about tank 241-SY-101 and other flammable gas tanks.

- If indirect measures of trapped gas content/releases or head space concentration were available, the information was used to improve the calculations. These results superseded the worst case calculations.

- If direct measures were available, the information was used to further improve the calculations. These results superseded those from the worst-case calculations or indirect measures. 


\subsection{DISCUSSION ON APPLICATION OF THE METHODOLOGY}

The evaluation for potential FGWL tanks considered the release of gas under steady state conditions and for episodic situations. A number of conservative assumptions were made because of a lack of understanding of the physical processes occurring in the tanks. However, it should be noted that the progress made within the last year will enable a refinement of the methodology. The following subsections mainly reflect what had been done in the past.

\subsubsection{Steady State Gas Release}

The steady state situation represents the balance between the gas release rate and the effective ventilation rate for a given tank. The head space sampling program has provided a significant body of data to compare calculated steady-state flammable gas concentration to actual measurements (Appendix B). This comparison showed the calculated methods always overstated the flammable gas concentration, sometimes by more than 500 times. This calculation is affected by the uncertainty in both the rate of generation of flammable gas and the breathing rate of the tank. Because of this extreme conservatism in the calculations and because direct measurements are now available, measurements are always used to determine the steady state or chronic release condition of the tanks.

\subsubsection{Episodic Gas Release}

An estimate must be made of the gas inventory stored in the tank, the fraction of the inventory released in a single event must be applied, and the gas composition and the volume of head space available to dilute the gas must be determined. Two methods were employed to estimate the gas inventory in a tank: 1) the surface level rise method which uses the long-term change in tank surface level from the time the tank was filled to the present, and 2) the barometric pressure effect method, which is based on the observed correlation of surface level changes with atmospheric pressure. Each method currently relies upon several assumptions that have not been validated, upon corrections based on limited historical data, and on simple physical models.

Once the inventory of gas was estimated, a release fraction was applied uniformly to all tanks regardless of waste configuration. A bounding value of $25 \%$ was chosen. This amount is larger than the calculated release fraction in all tanks except SY-101. It was assumed that the rate of release was rapid with respect to the ventilation rate of the tank; therefore, no time dependence was introduced into the calculation. Subsequent studies (see Section 4) have shown that both these assumptions are conservative and result in overestimating the flammability hazards in the dome space.

Because the composition of the released gas is unknown for most tanks, a bounding composition of $97 \%$ hydrogen and $3 \%$ water vapor was used. This composition assumes all the flammable 
gas is generated by radiolysis of water, a condition which may exist in some cooler, low-organic, SSTs. Recent results from the RGS show that the $97 \%$ hydrogen is probably high; maximum values found were about $75 \%$.

The fraction of trapped gas released may occur over several hours, days, or weeks rather than the time frame used currently (minutes), and its flammability may be lower than estimated. The retained-gas sampler is now being used to determine the composition of trapped gases in tank waste. The fraction of $\mathrm{NH}_{3}$ released by mass transport was assumed to be 0.22 times the amount of trapped gas released. However, the concentration of $\mathrm{NH}_{3}$ in the head space may be limited by other factors.

\subsubsection{Surface Level Rise Method}

Gases generated in the waste may be trapped and cause an increase in the waste volume. This volume is reflected in an increase in the waste level. In principle, the surface level rise method is simple. The level at the time the tank is filled is subtracted from the current level, and the difference between the levels is the volume of trapped gas unless other explanations for differences are available. In practice, this method is very difficult to defend because of the many corrections which were introduced. The corrections address additions to and losses from the tank, and changes in the waste volume caused by intrusions, flushes, equipment installation, recrystallization, condensation, leaks, evaporation, settling, etc. Because some tanks were filled more than once, records for pre-existing gas volumes based on material balance showed discrepancies for some tanks. The basis for many corrections is poorly documented or of such low resolution that the corrections themselves introduce potential error terms larger than the magnitude of the measured surface level rise. Another feature of this method was that anything that increased the estimate was included but anything that decreased the estimate was excluded. Subsequent reviews of the method have concluded that it is not adequate for making quantitative estimates of retained gas.

\subsubsection{Barometric Pressure Effect Method}

Early work on SY-101 showed an inverse correlation between waste level measurements and ambient atmospheric pressure. The interpretation of this relationship is that increased atmospheric pressure compressed the gas trapped in the waste, thereby decreasing the waste level. Using this observed relationship, an algorithm was developed to look at the historical level data with respect to barometric pressure for all tanks and to identify those tanks having a statistical correlation. The algorithm produced results equivalent to $95 \%$ confidence that a flagged tank did indeed have a correlation between barometric pressure and level changes.

Waste level measurements are made to monitor tanks for leaks and intrusions. Four measurement devices are used. Three measure the level of the waste surface (manual tape, Food Instrument Corporation [FIC] conductivity probe, and an Enraf surface buoyancy tapes); the 
fourth uses a neutron probe within a well embedded in the waste to monitor the liquid level (when the liquid level is below a dry waste surface). These devices are used to make level measurements at differing frequencies varying from continuously for some automatic logging devices to quarterly for some manually read devices.

The screening was applied to data from each measurement device in each tank. No assessment was made about data quality. If any data for an SST indicated trapped gas, that tank was flagged by the screening process. This resulted in 58 of 177 Hanford tanks being flagged as potentially containing trapped gas. It included 21 of 25 tanks currently on the FGWL.

The screening method was further developed to provide quantitative estimates of the tank response to pressure changes. The data were averaged over long periods of time, and to ensure that the gas inventory was not underestimated the $75 \%$ response value was used. Large scatter in the data introduced large estimates of the gas inventory even in tanks where the data averaged a "zero response" to pressure changes.

\subsection{REVIEW OF THE METHODOLOGY}

A critical review of the evaluation methods at their current state of development was conducted in May and June of 1996. The following sections provide a summary of the reasons for the review, the documents reviewed, and the review results.

\subsubsection{The Issue of More FGWL Tanks}

WHC, with the support of PNNL, screened all 177 Hanford tanks using the criteria for identifying additional FGWL tanks. As a result of conservative, in-depth analysis, 52 tanks were identified as failing the criteria using the methods just discussed. Twenty-one of these tanks were already on the FGWL. The documentation of the methods and analysis used in analyzing potential FGWL tanks includes the following:

1. Hopkins, J.D., 1994, Criteria for Flammable Gas Watch List Tanks, WHC-EP-0702 Rev. 0, Westinghouse Hanford Company.

2. Whitney P.D., 1995, Screening the Hanford Tanks for Trapped Gas, PNL-10821, Pacific Northwest Laboratory.

3. Hopkins, J.D., 1996, Methodology for Flammable Gas Evaluations WHC-SD-WM-TI-724 Rev. 1, Westinghouse Hanford Company. 
4. Hodgson K.M., R.P. Anantamula, S.A. Barker, K.D. Fowler, D.C. Hedengren, J.D. Hopkins, J.A. Lechelt, D.A. Reynolds, R.E. Stout, and R.T. Winward, 1996, Evaluation of Hanford Tanks for Trapped Gas, WHC-SD-WM-ER-526 Rev. 1, Westinghouse Hanford Company.

WHC recommended to DOE in December 1995 that 25 more tanks be added to the FGWL. A second phase of the analysis, completed in March 1996, expanded the number of candidate tanks for the FGWL to 32. The Tank Waste Remediation System submitted the recommendation to DOE-HQ, who requested that the Chemical Reaction Subpanel of the High-Level Waste Technical Advisory Panel review the recommendation and comment. The subpanel questioned the validity of the models and the quality of the data. As a result, DOE-RL formed a team to review the recommendations.

\subsubsection{Critical Review Results}

A critical review was made of the methodology for evaluating flammable gas tanks, specifically to make a recommendation as to the advisability of adding to the FGWL based on application of the evaluation methodology previously discussed. An interdisciplinary team, technically knowledgeable about tank waste and flammable gas issues, was appointed with members from DOE-RL, WHC, PNNL, LANL, and the Chemical Reaction Subpanel of the High-Level Waste Technical Advisory Panel. Two issues were raised: the criteria that was used to add tanks to the Watch List and the information that was used to make a decision.

Following is the consensus of the review team on adding tanks to the FGWL (Johnson 1996a):

No recommendation should be made or accepted for adding tanks to the FGWL at this time based on the concepts, assumptions, and data central to the analysis and decision logic underlying the proposal for the following reasons:

1. The results of the analysis are not sufficiently definitive:

The models are elementary and do not represent adequately the physical situation of the waste in all tanks. The calculation bases established by the models need to be validated before they are determined to be reliable for volume estimates.

The data currently available are highly variable and lack the precision and accuracy necessary to make estimates of the retained gas.

A physical mechanism responsible for an assumed large spontaneous release of gas, pertaining to waste configuration characteristic of that in the SSTs, is not, at this time, supported by data or conceptual physical models. 
2. The current criteria for the FGWL constitute a simple numerical threshold without additional qualifying conditions. Implementation depends on determining consistently reliable numerical values. Within the context of the potential flammable gas tank conditions and the intrinsic uncertainty in the models and data, the criteria cannot be used equitably for the addition to and removal from the list. At present, it is easy to add tanks to the FGWL, but it is difficult to make the technically authoritative argument, given the existing uncertainty, for removing them when such action is challenged.

3. Tanks for which a significant potential for a radioactive release exists are required to be controlled by the USQ process for flammable gas. These tanks are maintained under the highest level of operational controls. Adding tanks to the FGWL, on the basis of an unproven methodology, will not provide additional safety benefits.

The team also identified concerns about the screening process used to identify tanks containing trapped gas. Approximately $40 \%$ of the tanks were screened using data that lacked the precision and sensitivity to identify gas that might have been present. The team also recommended that the screening process be reexamined to determine whether tanks had been missed and to define more accurately the nature of the screening process (Johnson 1996a).

\subsection{APPROACH FOR UPDATING THE METHODOLOGY}

The current methodology for evaluating tanks for flammable gas conditions needs to be updated to reflect the progress made in understanding the mechanisms of gas generation, retention, and release as demonstrated in the previous chapters of this document.

With respect to the estimation of the steady state concentration of flammable gas, it should be possible to base this value on actual data. As shown in Appendix B there are data for most of the single shell tanks. Considerable data have also been collected with the SHMS for each of the flammable gas watch list tanks. Table 4-3 showed ventilation rates for a variety of single shell tanks. Thus, by application of these data the information about the steady state situation will be greatly improved.

Analysis for the episodic releases in double shell tanks has progressed to where data are now available for stored gas volume, stored gas compositions, dome space concentrations and release fractions for a number of events. This data base will be used to help validate the evaluation methodology. In particular, the barometric pressure effect (BPE) method should be able to give appropriate information for the DSTs because of the data noted and from the data obtained from the RGS and VFI tests where the distribution of gas was measured. 
Application of the BPE method to SST waste still needs more work. A key item is the RGS and the application of it to the various SST waste types. Also additional laboratory evaluations underway will provide valuable data on the gas retention capability of the SST waste types.

Better instrumentation and automatic data logging capabilities are being deployed on the tanks. This will improve both the precision and accuracy of the measurements and any calculations derived from the data. For some evaluation parameters, the data scatter is very wide. Improving the instrumentation used to measure the surface level would greatly reduce data scatter in the BPE. A highly negative ratio of level change to pressure change or a wide range on the standard deviation of the ratio results from poor surface level data due to an imprecise gauge, infrequent readings, or manual readings entered into the Surveillance Analysis Computer System database several hours after being taken. These problems can be solved by installing Enraf gauges on tanks which do not currently have them and connecting the gauges to the Tank Monitoring and Control System for automatic data capture.

It is important to know where the surface level plummet contacts the surface. It is assumed that the level at which the plummet contacts the waste is the average waste height unless the plummet is in a hole. Without recent photographs or videos, there may be considerable uncertainty about where the plummet contacts the waste. Portable television systems have been developed for use in flammable gas tanks; such equipment will aid in the evaluation of the nature of waste surfaces.

Applying a disciplined approach to the updating of the evaluation methodology should enable a better understanding of which tanks may pose significant hazards. A careful reconciliation of all available data for a particular tank needs to be conducted to ensure a consistent understanding of tank conditions. An assessment could then be made concerning the applicability of various models to quantitative evaluation of the flammable gas hazard. Final determination of the flammable gas conditions of a tank must be based on the preponderance of evidence and the best understanding of outlying data. 
HNF-SP-1 193, Rev. 2

This page intentionally left blank. 


\subsection{WASTE CHARACTERIZATION}

Future efforts for characterizing the waste for the flammable gas safety issue will emphasize four areas: 1) retained gas sampling of selected SST waste types, 2) additional gas monitors to obtain data for potential gas releases in selected operations, 3) improved measurements of waste surface level, and 4) selected laboratory evaluations for gas generation and retention.

\subsection{MEASUREMENT OF STORED GAS VOLUME}

The RGS was developed to measure the void volume and composition of gases retained in the waste. It was developed for and has been successfully used in characterizing DSTs using the push mode sampling system. To date, one SST has also been sampled. A total of 39 RGS samples have been obtained, and 28 have been extracted and analyzed.

Whether the RGS can be applied successfully to establish the composition of gas for additional SSTs is more uncertain. Currently, the system is limited to tanks that can be sampled with the push mode system. The approach will be to sample selected tanks of the major waste types and use the results to estimate the volume and composition in the other tanks within a given waste type. Tanks were selected based on a combination of the waste types defined by Brewster and Palmer ${ }^{(1)}$ and those tanks considered to be potential "push mode" tanks. At this time, the list of tanks include the following: 241-S-106, 241-BY-101, 241-BY-109, 241-A-103, 241-SX-106, 241-S-112, 241-S-103, and 241-U-111.

The priorities outlined above are general guidelines. It is important to maintain flexibility so that project changes can be accommodated. The tank priorities given are not as important as the overall need to obtain more data from actual tank wastes. Given a choice in tanks available, the ones described above have first priority. However, data from other tanks may also be valuable in assessing the retention of gases.

\subsection{MEASUREMENT OF HEAD SPACE GASES}

A revision to the approach for conducting continuous gas monitoring of flammable gas tanks was needed because of changes in planned waste intrusive activities (Lentsch 1996) and by a reprioritization of flammable gas monitoring needs developed by Tank Waste Remediation System Engineering, Operations, and Safety Issue Resolution staff. The earlier approach had been transmitted to the DNFSB in August 1996 (Wagoner 1996a); thus this section is a summary of what had been done and is presented here as historical information.

(1) Brewster, M.E., and B.J. Palmer, December 1995, Prioritization of Single-Shell Tanks for Study for Gas Retention and Episodic Release, letter report PNL-WTS122295, Pacific Northwest Laboratory, Richland, Washington. 


\subsubsection{Tank Groupings and Data}

Table 6-1 summarizes the information used to determine monitoring priorities. The waste tanks have been grouped as follows:

- Tanks with the calculated potential to exceed $100 \%$ of the LFL in the head space (Hodgson et al. 1996) caused by gas retention and an episodic release.

- DSTs that receive supernatant from salt-well pumping with the potential for gas retention and episodic release.

- Project tanks (W-320, W-030, W-151, and W-211) with the potential for gas retention and episodic release.

- Aging waste tanks with high radiation source terms for gas generation.

- Other tanks currently equipped with Standard Hydrogen Monitoring Systems (SHMSs).

- Other tanks that are scheduled for salt-well pumping.

The potential percentage of the LFL (\%LFL) that might be observed during an episodic gas release, as determined in Hodgson et al. (1996) is presented for each tank in the table. The calculated \%LFL is based both on the surface level rise method and on the barometric pressure and waste level correlation method. These calculated values should not be taken as a known value; they were used in a comparative mode for potential tank behavior. FGWL tanks are annotated.

Table 6-1 shows the estimated dates of planned waste intrusive activities for each tank. This includes salt-well pumping start dates, push-mode or rotary-mode core sampling dates, and project start dates, such as mixer pump operation or waste sluicing. The table also shows the currently installed gas monitoring systems and the dates when these systems were first installed. Six of the 28 SHMSs have not operated continuously since their installation because of moisture accumulations in the piping. Sample conditioning chillers are being installed on each unit to resolve this problem. 
HNF-SP-1193, Rev. 2

Table 6-1. Waste Tank and Gas Monitor Prioritization (4 sheets).

\begin{tabular}{|c|c|c|c|c|c|c|}
\hline & Tank & $\begin{array}{l}\text { Potential \% } \\
\text { LFL } \\
\text { SL/BPE }\end{array}$ & $\begin{array}{l}\text { Planned } \\
\text { Intrusive } \\
\text { Activities } \\
\text { Start Date }\end{array}$ & $\begin{array}{c}\text { Current Gas } \\
\text { Monitor } \\
\text { Installation } \\
\text { Date }\end{array}$ & $\begin{array}{l}\text { Proposed New } \\
\text { Gas Monitor } \\
\text { (Date) }\end{array}$ & $\begin{array}{c}\text { New } \\
\text { SHMS } \\
\text { Priority }\end{array}$ \\
\hline \multirow{21}{*}{$\begin{array}{l}\text { Tanks > } \\
100 \% \\
\text { LFL } \\
\text { Potential }\end{array}$} & SY-101 & WL 825/572 & NA & $\begin{array}{l}\text { GMS, SHMS } \\
(3 / 92)\end{array}$ & & \\
\hline & AN-105 & WL $743 / 411$ & NA & $\begin{array}{l}\text { GCS, SHMS } \\
(9 / 94)\end{array}$ & & \\
\hline & AN-104 & WL $503 / 246$ & NA & $\begin{array}{l}\text { SHMS (MTI) } \\
(9 / 94)\end{array}$ & & \\
\hline & A-101 & WL $0.99 / 379$ & 12/96 SWP & SHMS (3/95) & SHMS-E+12/96 & 1 \\
\hline & AN-103 & WL $334 / 301$ & NA & SHMS (9/94) & & \\
\hline & U-105 & WL $270 / 129$ & 1/99 SWP & SHMS (3/95) & SHMS-E+9/98 & 2 \\
\hline & AW-101 & WL $231 / 233$ & NA & $\begin{array}{l}\text { GCS, SHMS } \\
(9 / 94)\end{array}$ & & \\
\hline & S-102 & WL $190 / 226$ & 7/97 SWP & SHMS (3/95) & & \\
\hline & S-106 & $187 / 223$ & $\begin{array}{l}\text { 3/98 SWP } \\
\text { 11/96 PMCS }\end{array}$ & & SHMS-E+11/96 & 1 \\
\hline & SX-103 & WL $2 / 216$ & $\begin{array}{l}\text { 4/97 SWP } \\
\text { 3/97 RMCS }\end{array}$ & SHMS (3/95) & SHMS-E+1/97 & 1 \\
\hline & U-102 & $152 / 203$ & 1/99 SWP & & SHMS-E 9/98 & 2 \\
\hline & TX-112 & $66 / 195$ & 9/98 RMCS & & & 4 \\
\hline & S-111 & WL 80/181 & 1/98 SWP & SHMS (3/95) & & \\
\hline & U-108 & WL $179 / \mathrm{nc}$ & $3 / 98$ & SHMS (3/95) & & \\
\hline & U-103 & WL $77 / 161$ & $\begin{array}{l}\text { 1/99 SWP } \\
\text { 10/96 PMCS }\end{array}$ & SHMS (3/95) & & 4 \\
\hline & S-109 & $16 / 145$ & 2/97 SWP & & SHMS-E+11/96 & 1 \\
\hline & BY-105 & $13 / 145$ & $\begin{array}{l}\text { 2/97 SWP } \\
\text { 10/98 RMCS }\end{array}$ & & SHMS-E+11/96 & 1 \\
\hline & S- 107 & $138 / 34$ & 1/98 SWP & & SHMS 10/97 & 2 \\
\hline & AW-104 & $127 / 134$ & $\begin{array}{c}8 / 97 \\
\text { LLCE/PO }\end{array}$ & & SHMS-E 5/97 & $1 \mathrm{~T}$ \\
\hline & $Y-106$ & $123 / \mathrm{NC}$ & 7/97 SWP & SHMS (8/95) & & D \\
\hline & $\mathrm{T}-201$ & $121 / \mathrm{NC}$ & 3/98 RMCS & & & 4 \\
\hline
\end{tabular}


Table 6-1. Waste Tank and Gas Monitor Prioritization (4 sheets).

\begin{tabular}{|c|c|c|c|c|c|c|}
\hline & Tank & $\begin{array}{l}\text { Potential \% } \\
\text { LFL } \\
\text { SL/BPE }\end{array}$ & $\begin{array}{l}\text { Planned } \\
\text { Intrusive } \\
\text { Activities } \\
\text { Start Date }\end{array}$ & $\begin{array}{l}\text { Current Gas } \\
\text { Monitor } \\
\text { Installation } \\
\text { Date }\end{array}$ & $\begin{array}{c}\text { Proposed New } \\
\text { Gas Monitor } \\
\text { (Date) }\end{array}$ & $\begin{array}{l}\text { New } \\
\text { SHMS } \\
\text { Priority }\end{array}$ \\
\hline \multirow{3}{*}{$\begin{array}{l}\text { Tanks > } \\
100 \% \\
\text { LFL } \\
\text { Potential } \\
\text { (contd) }\end{array}$} & U-109 & WL $81 / 118$ & 1/99 SWP & SHMS (3/95) & & \\
\hline & AN-107 & $113 / \mathrm{NC}$ & $\sim 9 / 97 \mathrm{CA}$ & & SHMS-E 6/97 & $1 \mathrm{VV}$ \\
\hline & S-101 & $109 / 47$ & 10/97 SWP & & SHMS-E 7/97 & 1 \\
\hline \multirow{3}{*}{$\begin{array}{l}\text { DST } \\
\text { SWP } \\
\text { Receiver } \\
\text { Tanks }\end{array}$} & AN-101 & $0 / \mathrm{NC}$ & $12 / 96 \mathrm{SWP}$ & & SHMS-E+12/96 & 1 \\
\hline & AP-104 & $0 / \mathrm{NC}$ & $12 / 98 \mathrm{CST}$ & & SHMS-E+ $+9 / 98$ & 2 \\
\hline & SY-102 & $15 / \mathrm{NC}$ & $\begin{array}{c}\text { 8/98 W211 } \\
11 / 98 \text { PMCS } \\
2 / 97 \text { SWP }\end{array}$ & & SHMS-E+12/96 & 1 \\
\hline \multirow{2}{*}{$\begin{array}{l}\text { Project } \\
\text { W320 } \\
\text { Sluicing }\end{array}$} & C- 106 & $0 / \mathrm{NC}$ & $\begin{array}{c}\text { 4/97 W320 } \\
11 / 97 \text { RMCS }\end{array}$ & & SHMS (MTI) 1/97 & 1 \\
\hline & AY -102 & $0 / \mathrm{NC}$ & $4 / 97$ W320 & & SHMS (MTI) 1/97 & 1 \\
\hline \multirow{3}{*}{$\begin{array}{l}\text { Aging } \\
\text { Waste } \\
\text { Tanks }\end{array}$} & AY-101 & $\sim 0 / 5$ & $3 / 97$ W030/80 & & & 4 \\
\hline & AZ-101 & $0 / \mathrm{NC}$ & $\begin{array}{c}\text { 4/99 RMCS } \\
12 / 96 \text { W151 } \\
3 / 97 \text { W030 }\end{array}$ & & SHMS-E $3 / 97$ & 1 \\
\hline & AZ-102 & $11 / \mathrm{NC}$ & $\begin{array}{l}\text { 7/99 PMCS } \\
12 / 96 \text { W030 }\end{array}$ & & SHMS-E 3/97 & 1 \\
\hline
\end{tabular}


HNF-SP-1193, Rev. 2

Table 6-1. Waste Tank and Gas Monitor Prioritization (4 sheets).

\begin{tabular}{|c|c|c|c|c|c|c|}
\hline & Tank & $\begin{array}{l}\text { Potential \% } \\
\text { IFL } \\
\text { SL/BPE }\end{array}$ & $\begin{array}{l}\text { Planned } \\
\text { Intrusive } \\
\text { Activities } \\
\text { Start Date }\end{array}$ & $\begin{array}{l}\text { Current Gas } \\
\text { Monitor } \\
\text { Installation } \\
\text { Date }\end{array}$ & $\begin{array}{l}\text { Proposed New } \\
\text { Gas Monitor } \\
\text { (Date) }\end{array}$ & $\begin{array}{l}\text { New } \\
\text { SHMS } \\
\text { Priority }\end{array}$ \\
\hline \multirow{14}{*}{$\begin{array}{l}\text { Other } \\
\text { tanks with } \\
\text { SHMS }\end{array}$} & SY-103 & WL $79 / 57$ & NA & SHMS 5/92 & & \\
\hline & AX-101 & WL ONC & $\begin{array}{c}\text { 1/97 RMCS } \\
\text { 5/97 SWP }\end{array}$ & SHMS 3/95 & & $\bar{D}$ \\
\hline & AX-103 & WL --- & 10/97 RMCS & SHMS 3/95 & & D Now \\
\hline & SX-101 & WLO/28 & $\begin{array}{l}\text { 1/97 RMCS } \\
\text { 1/99 SWP }\end{array}$ & SHMS 3/95 & & \\
\hline & SX-102 & WL30/93 & $\begin{array}{c}\text { 8/9*7 RMCS } \\
10 / 97 \text { SWP }\end{array}$ & SHMS 3/95 & & \\
\hline & SX-104 & WL6/11 & $\begin{array}{c}\text { 4/97 RMCS } \\
\text { 3/97 SWP }\end{array}$ & SHMS 3/95 & & $\mathrm{D}$ \\
\hline & SX-105 & WL87/- & $\begin{array}{l}\text { 4/98 RMCS } \\
11 / 97 \text { SWP }\end{array}$ & SHMS 3/95 & & \\
\hline & SX-106 & WL67/78 & $\begin{array}{l}\text { 8/97 PMCS } \\
12 / 97 \text { SWP }\end{array}$ & SHMS 3/95 & & \\
\hline & SX-109 & WLO/NC & 10/97 RMCS & SHMS 3/95 & & D \\
\hline & S-112 & WL30/NC & $\begin{array}{l}\text { 10/97 PMCS } \\
\text { 1/99 SWP }\end{array}$ & SHMS 3/95 & & D \\
\hline & U-107 & WL42/87 & $5 / 98$ SWP & SHMS 3/95 & & \\
\hline & $T-110$ & WL32/NC & $\begin{array}{l}\text { 5/98 PMCS } \\
\text { 2/97 SWP }\end{array}$ & SHMS 3/95 & & D \\
\hline & BY-103 & $0 / 26$ & $\begin{array}{l}\text { 11/98 RMCS } \\
\text { 12/96 SWP }\end{array}$ & SHMS 8/95 & & $\mathrm{D}$ \\
\hline & BY-109 & $\sim 0 / 13$ & $\begin{array}{l}\text { 4/97 PMCS } \\
\text { 9/96 SWP }\end{array}$ & SHMS 8/95 & & $\mathrm{D}$ \\
\hline \multirow{4}{*}{$\begin{array}{l}\text { Other } \\
\text { SWP } \\
\text { tanks }\end{array}$} & $C-103$ & $0 / \mathrm{NC}$ & 1/98 SWP & & & 4 \\
\hline & U-111 & 97/NC & $\begin{array}{l}\text { 2/98 PMCS } \\
\text { 9/98 SWP }\end{array}$ & & & 4 \\
\hline & U-106 & $37 / 21$ & $5 / 98 \mathrm{SWP}$ & & & 4 \\
\hline & S-103 & $57 / 72$ & $\begin{array}{c}\text { 12/97 PMCS } \\
\text { 6/98 SWP }\end{array}$ & & & 4 \\
\hline
\end{tabular}


Table 6-1. Waste Tank and Gas Monitor Prioritization (4 sheets).

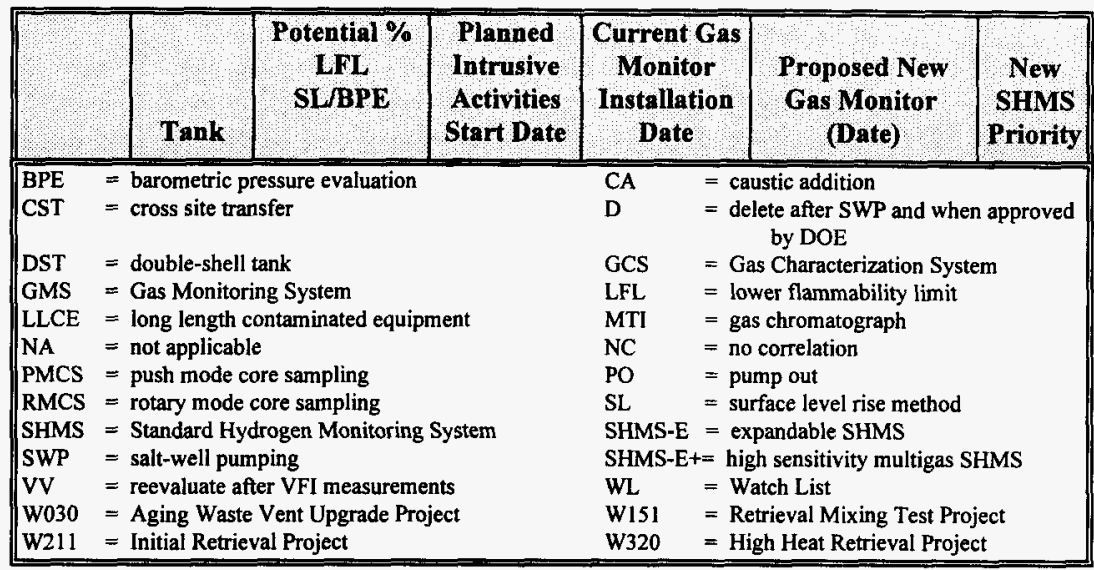

\subsubsection{Gas Monitoring Priority and Criteria Methodology}

The information in Table 6-1 was reviewed for each tank to determine the priority for installing continuous gas monitoring systems. Priorities were assigned as follows:

Priority 1: Monitor required in Fiscal Year 1997

Priority 2: Monitor required but defer installation until Fiscal Year 1998

Priority 3: Monitor required beyond Fiscal Year 1999 for retrieval operations

Priority 4: A new monitor is not required

Priority T: Temporary monitor required for short duration

Priority D: Remove the current monitor.

Criteria were established for determining the priority of continuous monitors for each tank. The criteria are as follows.

- The potential exists for exceeding $100 \%$ of the LFL for the current waste state and planned intrusive work.

- Operations or events are planned that could lead to future gas retention or releases that would exceed $100 \%$ of the LFL.

The criteria for removing a current monitor are as follows: 
- There is no potential to exceed $25 \%$ of the LFL.

- The tank has been interim stabilized.

- Adequate data have been acquired.

- No waste intrusive activities are planned for the tank.

Consideration must be given to the legal ramifications of deleting current monitoring systems on FGWL tanks because Public Law 101-510, "The Wyden Amendment," requires continuous monitoring for releases and/or pressure or temperature changes. During the initial implementation of the Wyden requirements, credit was taken for using SHMSs to check for releases that would occur before a deflagration or release of waste from the tank.

Temporary continuous monitoring was recommended when there was only one planned operational evolution for a limited duration, such as the pump-down of AW-104, with the potential for an episodic gas release. No monitoring was recommended if rotary core sampling was the only planned activity because the rotary truck uses continuous gas monitoring instrumentation similar to an SHMS.

\subsubsection{Prioritization Results}

Priorities are given in Table 6-1. At this time, no tanks are identified as priority 3 tanks. Future retrieval operations will evaluate the need for monitoring systems and will provide them as needed. Currently proposed monitoring systems may be redeployed for retrieval.

Table 6-1 shows the type of gas monitoring systems required when indicated by priority 1 or 2 . To determine the gas composition and release rate, an SHMS (SHMS-E+) with high sensitivity and multi-gas capabilities (Wagoner 1996a) is proposed for ventilated tanks where gases are diluted. This includes the first tank in each tank farm to be salt-well pumped and appropriate double-contained receiver tanks where the potential exists for having gas releases and accumulations greater than $100 \%$ of the LFL. For example, the W-320 Project sluicing tank (241-C-106) received a high sensitivity unit for hydrogen only. The SHMS-E units are designed for modular expansion to the -E+ capabilities if it is necessary after the initial monitoring results are obtained. All SHMS units (normal SHMS, -E, or -E+units) have the capability to collect automatic grab samples if the gas composition exceeds $25 \%$ of the LFL, or manual grab samples for gas composition analysis.

Gas sampling probes with double isolation valves will be installed in all DSTs. Rapid measurements will also be possible using hand-held combustible gas meters during planned operational work or during unplanned events such as an extended loss of ventilation exhauster flow. 
Two cart-mounted SHMS-E+ units will be provided in conjunction with the installed gas sampling probes for continuous but temporary characterization of tank vapor spaces. These units will be used for planned waste transfers or other operational or project evolutions to assess changes in gas generation and retention, for safety assessment purposes, and for operational monitoring.

For tanks in which current gas monitoring systems are proposed for deletion, the deletion would occur after adequate data have been acquired (approximately FY 1998). For tanks that have been salt-well pumped, a determination about monitoring will be made depending on gas measurement data, unless noted otherwise in Table 6-1. When a unit is removed from a tank, the electrical connections, sample lines, and any cabinet foundations will be left in place for possible future use, such as during waste retrieval. The monitors will be relocated to other tanks, kept as spares, or maintained in storage for future use in other applications.

Plans are under way after FY 1997 to integrate the gas monitoring functions of the SHMS-E+ units with the safety interlock functions of the flammable gas monitors provided with salt-well pumping skids. Competitive bids will be sought for single monitoring systems that perform both functions and use the technologies developed with these earlier units. This integration probably will result in additional savings, but the savings will not be available during FY 1997.

\subsubsection{Summary}

Thirteen gas monitoring systems are planned for installation in FY 1997. In FY 1998, four systems will be installed, not counting reductions from integration that is planned with the saltwell pumping flammable gas interlock system. By the end of FY 1998, nine current SHMSs on SSTs may be discharged for redeployment. As additional SSTs are interim stabilized, more SHMSs probably can be redeployed.

Using two cart-mounted SHMS-E+ systems, the installation of gas probes in tanks without continuous gas monitoring systems will allow 15 additional DSTs to be monitored and characterized as needed in the future.

\subsection{WASTE SURFACE LEVEL MEASUREMENTS}

The approach for evaluating all tanks for trapped gas centers around the analysis of the changes in surface level. The presence of stored gas can be inferred from a steady rise in waste level, sudden, large changes in level, and small changes in level that can be correlated to changes in atmospheric pressure. Section 5 outlined the basis for the "barometric pressure effect." Use of past historic waste level data has been plagued with instrument operational problems as well as the detection limit of the instruments. Recent efforts have focused on a new displacement gauge, made by Enraf. Use of these instruments in an automatic mode provide very good level data that can be used with the atmospheric data to provide estimates of the amount of stored gas. The 
FGWL tanks have been equipped with the new Enraf gauges, but not all of them have been placed into the fully automatic mode. This requires connection to the Tank Monitoring and Control System (TMACS). TMACS provides for computer storage of the data. Future efforts will focus on installing the Enraf gauges on additional tanks as well as providing for connection to TMACS.

\subsection{LABORATORY TESTING OF SELECTED WASTE SAMPLES}

A few tests still need to be conducted to complete our understanding of gas generation and retention. These needs were discussed in Sections 2.7 and 3.9. No special core sampling operations are required; the samples can be obtained from existing or planned core samples. 
HNF-SP-1 193, Rev. 2

This page intentionally left blank. 


\subsection{CLOSURE OF THE FLAMMABLE GAS USQ AND SAFETY ISSUE}

\subsection{USQ BACKGROUND INFORMATION}

During 1990, WHC investigated the retention and periodic release of gases in particular waste tanks. It was concluded that the creation, collection, and release of flammable gases was a safety concern that had not been considered adequately in the development of the Authorization Basis. The flammable gas issue was declared a USQ in May 1990 (Lawrence 1990). Since that time, the USQ was expanded to include other flammable gases (Bacon 1996b). Initially the applicability of the USQ to specific SSTs and DSTs and aging waste facilities was not always clearly defined, the USQ was expanded to cover an increasing number of tanks.

Our understanding of the flammable gas phenomenon has increased significantly through tank sampling and characterization, examining monitor data, laboratory experiments, and theoretical modeling and analysis, but some uncertainty still exists about the degree of gas retention and release for individual tanks. The concern about flammable gases in tanks containing radioactive wastes is the possibility of gases igniting which potentially could result in damage to tank structure, injury to personnel in the immediate vicinity, and dispersal of some tank contents to the environment.

On July 30, 1996, the TWRS Plant Review Committee issued a revised USQ for flammable gas USQ TF-96-0433. This USQ determination was prepared in accordance with the DOE Order 5480.21 (1991) to update and consolidate previous USQ determinations related to the generation of flammable gas by high-level waste in Hanford facilities. The USQ determination identified flammable gas hazards and affected facilities and updated information about them. Except for the Authorization Basis associated with SY-101, the USQ determination concludes that flammable gas hazards, the controls to manage them, and the technical bases for these controls are not adequately analyzed and documented. This updated USQ determination has been approved by DOE-RL.

Also on July 31, 1996, the TWRS Plant Review Committee approved a justification for continued operation (JCO) (Grigsby and Leach 1996) that addressed USQ determination TF-960433. The JCO, which is under review by DOE, provides detailed descriptions and data about the flammable gas hazards identified in USQD TF-96-0433 and develops work controls and equipment requirements related to them. TWRS is conducting operations with flammability controls applied to all tanks in accordance with standing orders approved by DOE-RL, which are those given in the proposed JCO. According to Johnson (1996b), TWRS personnel believe that while there is no merit to closing the original USQ on a tank-by-tank basis, closing should occur according to the revised USQ with its expanded and encompassing scope. Johnson summarizes issues related to the previous USQ closure strategy based on the limited definition of the USQ in 1990. Closure of the originally defined 1990 USQ would not result in effective management of the flammable gas hazard for all TWRS facilities. 


\subsection{PATH FORWARD FOR USQ CLOSURE}

The scope of the revised USQ provides a logical and efficient approach to USQ closure. Because the understanding of the flammable gas issue has increased, additional technical uncertainties, defined in the recently revised USQ TF-96-0433, must be resolved. The USQ also defined the scope of TWRS structures and facilities for which the flammable gas hazard has not been fully accounted for in the TWRS Authorization Basis and for which various levels of operational controls appear to be warranted.

A path forward to resolve the flammable gas USQ and the safety issue was initially proposed by Johnson (1996b). The path forward is based on Safety Control Optimization by Performance Evaluation (SCOPE), a previously used and highly successful process (Bergeron et al. 1996). The SCOPE process is based on the systematic application of expert elicitation methods to quantify the technical uncertainty of phenomenological issues related to tank and waste behavior. The process enables cost-effective, consistent decisions about hazard controls for TWRS to be made that take into account conservative viewpoints but do not constrain operations or impose costs that are too burdensome. The use of SCOPE has been approved by DOE (Sohn 1997).

The proposed Path Forward has been recently expanded into a more detailed strategy and has been formally transmitted to RL as a Memorandum of Understanding (MOU). The proposed strategy is based on the facility grouping strategy identified in the recently proposed flammable gas JCO (Grigsby and Leach 1996). Closure of the flammable gas USQ will begin with the group of tanks that are expected to require minimal controls with respect to the flammable gas hazard. The MOU establishes interim milestones and performance agreements for closure of the flammable gas USQ. A description of each major milestone based on the facility grouping approach includes the following:

Submit safety basis documentation to support closure of the flammable gas USQ for JCO facility group 3A; (115) interim stabilized SSTs (August 15, 1997)

- Submit safety basis documentation to support closure of the flammable gas USQ for JCO facility group 3B; (34) non-interim stabilized SSTs (September 30, 1997)

- Submit safety basis documentation to support closure of the flammable gas USQ for JCO facility group 2 SSTs (June 30, 1998)

- Submit safety basis documentation to support closure of the flammable gas USQ for JCO facility group 1 and 2 double-shell and aging waste facility tanks by July 31, 1998.

The completion of safety basis documentation and the submittal of the flammable gas USQ closure packages also supports the Hanford Federal Facility Agreement and Consent Order (TriParty Agreement), (Ecology et al. 1996), milestone M-40-09, "Close All Unreviewed Safety Questions (USQ) for Double-Shell and Single-Shell Tanks" (September 1998). 


\subsection{EVALUATION OF TANKS FOR REMOVAL FROM THE WATCH LIST}

One item needing further development is the process for screening tanks against the FGWL criteria. Methods were developed for screening tanks for gas retention (Whitney 1995), then applying the results to previously determined criteria (Hopkins 1995; Hodgson 1995). However, an evaluation (Johnson 1996a, 1996b) of these methods was performed and areas were identified in which improvements were needed. To implement improvements, a process that builds upon the previous technical work and incorporates recommendations will be required. A summary of process elements is provided here. They apply to tank conditions in storage mode and will determine whether a significant flammable gas risk exists, that is, tanks will be evaluated for an intrinsic flammable gas hazard during the period of time where no active, intrusive operations are taking place. (Active operations, such as sampling and pumping, require a safety authorization basis for that operation that evaluates a complete set of hazards, including the flammable gas hazard. The complete set of hazards for any operation must be shown to present an acceptable risk before receiving authorization to proceed.)

The FGWL identifies tanks with a "serious potential" for "release of high-level waste due to uncontrolled increases in temperature or pressure" caused by a combustion of flammable gas. Only the specific event sequences that could lead to a combustion of flammable gas are considered. The combustion of flammable gases can only result if all or part of the tank head space is at or above the LFL.

Two pathways could lead to a significant volume of flammable gas in the tank head space:

- Persistent, steady-state evolution of gas

- An episodic GRE.

\subsubsection{Steady-State Release of Flammable Gas}

Placing more emphasis on flammable gas data from the head space of tanks will make it easier to identify tanks at risk, because the persistent, steady-state release of flammable gas can lead to the tank head space being above the LFL under the following conditions:

- The gas generation is high

- The ventilation rate (passive or active) is low.

Using estimated bounding parameters, it has been calculated that some tanks may exceed the LFL under steady-state conditions. However, tank measurements have always shown tanks, in the absence of a GRE, to be well below the LFL. Although the potential exists, it is extremely unlikely that any tank would exceed the lower flammability limit solely due to the steady-state 
release of flammable gas. Because flammable gas measurements are available for the head space of all tanks, these will be used as the basis for steady-state evaluations.

\subsubsection{Episodic Gas Release Events}

Improving and enhancing data will also make it easier to identify tanks at risk. After dispersal, an episodic GRE could result in the entire tank dome being above the LFL, it could result in a gas plume that is flammable but disperses to a concentration below the LFL.

To provide a full analysis of a tank with an episodic gas release, both qualitative and quantitative information must be evaluated to gain a consistent picture of what happens in the tank. Once it is clear that available models apply to the tank condition, numeric estimates can be generated. Several factors influence the process of identifying and estimating whether a given tank will exceed the LFL. These factors include the following factors:

- The measured in-situ stored gas volume

- The calculated fraction of stored gas released in an event

- The measured composition of the in-situ stored gas

- The calculated rate of gas released based on such measurements as rate of pressure rise or rate of rise of hydrogen concentration

- The known head space volume

- The calculated degree of mixing and removal of gases from the head space.

The factors can be estimated or measured using direct or indirect measurements. If measurements are not available, then estimates can be used based on analysis of other tanks, simulated wastes, or limiting physical conditions. Because the calculations are complex and are unique to each tank, it is desirable to screen out tanks which have no indication of flammable gas retention.

The movement of the tank waste surface can be used to determine the amount of gas trapped in the waste on a tank-by-tank basis. The movement of the surface when the barometric pressure changes has been correlated. As the pressure increases, the waste is compressed with a movement downward; as the pressure decreases, the waste expands with a movement upward. This method is referred to as the barometric pressure evaluation method. Efforts to validate this method are underway. Where this method is valid, it will be used to estimate the retained gas volume. Direct measures of retained gas by measurement of void fraction or retained gas sampling will be used where available and valid. 
Some of the waste parameters used to estimate the gas retention and release include the following:

- $\quad$ Surface area of the waste being displaced

- Surface level of the waste

- Density of the waste

- Porosity of the waste

- Distribution of the gas throughout the waste

- Composition of the gas

- Amount of gas released in a release event

- Surface level change with barometric pressure change

- Temperature of the waste

- Adjustments to the surface level.

Analyzing tanks for episodic gas release behavior must be based on a total reconciliation of all available data on the tank so that a consistent understanding of tank conditions is achieved. Once it is determined that a tank is a candidate for episodic gas release behavior, the data must be assessed to determine that sufficient quality exists to perform quantitative calculations. Only when the data are deemed to be of sufficient quality will calculations of magnitude for potential GREs be performed. Removal of a tank from the FGWL must be based on the preponderance of information. 
HNF-SP-1193, Rev. 2

This page intentionally left blank. 


\subsection{SUMMARY}

Considerable progress has been made in dealing with the flammable gas safety issue. Early efforts of the project were directed at tank SY-101, which exhibited large episodic releases of flammable gas mixtures. These releases exceeded the LFL of hydrogen in air. A mixer pump was installed in this tank to prevent gas accumulation. This mitigation effort has been successful, and the USQ for this tank has been closed. This report summarizes the current understanding of flammable gas issues and describes activities related to closing the USQ for the remaining tanks.

The efforts of the Flammable Gas Project now show that the magnitude of concern raised by the situation for SY-101 does not apply to the other tanks. Five DSTs do exhibit episodic releases of gas but to a much smaller extent than SY-101. The composition and distribution of stored gas in these five DSTs has been measured with special equipment (VFI, RGS).

It has been determined that there are no mechanisms for large, spontaneous releases of gas from the wastes stored in the SSTs; however, small spontaneous and/or induced releases do occur. Only severe earthquakes are potentially able to induce large, rapid gas releases in SSTs. Results of gas monitoring activities have shown that the spontaneous and/or induced releases are on the order of a few cubic meters. Also, gas monitoring has shown that steady state releases of gas are not a concern; the ventilation systems effectively remove the steady emission of gases. However, episodic releases will require the use of active ventilation systems for some tanks.

Laboratory evaluations regarding the generation, retention and release have now moved from studying waste simulants to performing tests on actual tank wastes in hot cell facilities. Pathways for hydrogen generation have been identified and rates of generation have been determined for waste classified as double-shell slurry/complexed concentrate. Mechanisms for gas retention have been identified and related to waste type. Gas release fractions have been quantified for DSTs, and limiting conditions have been established for SSTs.

Flammability controls (ventilation and monitoring requirements and ignition source controls) are in place for all 28 DSTs and 149 DSTs. Additional, continuous gas monitors are being installed as is improved instrumentation for measuring the level of the waste. A process for closing the USQ has been outlined and efforts are under way to ensure closure by September 30, 1998, which is a TPA milestone. Revised criteria for placing tanks on and removing tanks from the FGWL are under review by DOE. 
HNF-SP-1193, Rev. 2

This page intentionally left blank. 


\subsection{REFERENCES}

Allemann, R.T., Z.I. Antoniak, W.D. Chavala, L.E. Efferding, J.G. Fadeff, J.R. Friley, W.B. Gregory, J.D. Hudson, J.J. Irwin, N.W. Kirch, T.E. Michener, F.E. Panisko, C.W. Stewart, and B.M. Wise, 1994, Mitigation of Tank 241-SY-101 by Pump Mixing. Results of Testing Phases $A$ and B, PNL-9423, Pacific Northwest Laboratory, Richland, Washington.

Agnew, S.F., R. Corbin, J. Boyer, T. Duran, K. Jurgensen, T. Ortiz, B. Young, R. Anema, and C. Ungerecht, 1996, History of Organic Carbon in Hanford HLW Tanks: HDW Model Rev. 3, LA-UR-96-989, Los Alamos National Laboratory, Los Alamos, New Mexico.

Bacon, R.F., 1996a, Revision of Flammable Gas Watch List Criteria, Letter 9652550 to J.E. Kinzer, June 14, 1996, Westinghouse Hanford Company, Richland, Washington.

Bacon, R.F., 1996b, Justification for Continued Operation for Flammable Gas Unreviewed Safety Question, Letter 9653371 to J.E. Kinzer, July 31, 1996, Westinghouse Hanford Company, Richland, Washington.

Barefield, E.K., D. Boatwright, A. Deshpande, F. Doctorovich, C.L. Liotta, H.M. Neumann, and S. Seymore, 1995, Mechanisms of Gas Generation from Simulated SY Tank Farm Wastes: FY 1994 Progress Report, PNL-10822, Pacific Northwest Laboratory, Richland, Washington.

Barefield, E.K., D. Boatwright, A. Deshpande, F. Doctorovich, C.L. Liotta, H.M. Neumann, and S. Seymore, 1996, Mechanisms of Gas Generation from Simulated SY Tank Farm Wastes: FY 1996 Progress Report, PNNL-11247, Pacific Northwest National Laboratory, Richland, Washington.

Bergeron, K.D., D.C. Williams, S.E. Slezak, M.L. Young, C.E. Leach, M.G. Plys, B. Malinovic, J.M. Grigsby, 1996, SCOPE. Safety Controls Optimization by Performance Evaluation: A Systematic Approach for Safety-Related Decisions at the Hanford Tank Waste Remediation System, SAND96-2927, Sandia National Laboratories, Albuquerque, New Mexico.

Bracken, G.J., 1990, Flammable Gas/Slurry Growth Issues, External letter 9001274B to President, WHC, April 2, DOE-RL, Richland, Washington.

Bratzel, D.R., H. Babad, and J.L. Huckaby, 1995, Headspace Gas and Vapor Characterization Summary for 43 Vapor Program Suspect Tanks, WHC-SD-WM-ER-514 Rev. 0, Westinghouse Hanford Company, Richland, Washington. 
Bredt, P.R., S.M. Tingey, and E.H. Shade, 1995, The Effect of Dilution on the Gas Retention Behavior of Tank 241-SY-101 Waste, PNL-10781, Pacific Northwest Laboratory, Richland, Washington.

Bredt, P.R., and S.M. Tingey, 1996, The Effect of Dilution on the Gas Retention Behavior of Tank 241-SY-103 Waste, PNNL-10893, Pacific Northwest National Laboratory, Richland, Washington.

Breshears, W.D., H.A. Fry, and J.L. Lyman, 1996, Interim Progress Report: Gas Flammability Modeling. II. Analysis and Interpretation of Flammability Data for Hydrogen-AmmoniaNitrous Oxide-Air Mixtures, TSA-10-96-503, Los Alamos National Laboratory, Los Alamos, New Mexico.

Brewster, M.E., N.B. Gallagher, J.D. Hudson, and C.W. Stewart, 1995, The Behavior, Quantity, and Location of Undissolved Gas in Tank 241-SY-101, PNL-10861, Pacific Northwest Laboratory, Richland, Washington.

Bryan, S.A., and L.R. Pederson, 1995, Thermal and Combined Thermal and Radiolytic Reactions Involving Nitrous Oxide, Hydrogen, and Nitrogen in the Gas Phrase; Comparison of Gas Generation Rates in Supernate and Solid Fractions of Tank 241-SY-101 Simulated Wastes, PNL-10490, Pacific Northwest Laboratory, Richland, Washington.

Bryan, S.A., and L.R. Pederson, 1996, Thermal and Combined Thermal and Radiolytic Reactions Involving Nitrous Oxide, Hydrogen, Nitrogen, and Ammonia in Contact with Tank 241-SY-101 Simulated Wastes, PNNL-10748, Pacific Northwest National Laboratory, Richland, Washington.

Bryan, S.A., C.M. King, L.R. Pederson, S.V. Forbes, and R.L. Sell, 1996, Gas Generation from Tank 241-SY-103 Waste, PNNL-10978, Pacific Northwest National Laboratory, Richland, Washington.

Caley, S.M., L.A. Mahoney, and P.A. Gauglitz, 1996, Summary of Tank Information Relating Salt Well Pumping to Flammable Gas Safety Issues, PNNL-11335, Pacific Northwest National Laboratory, Richland, Washington.

Camaioni, D.M., W.D. Samuels, S.A. Clauss, J.C. Lenihan, K.L. Wahl, J.A. Campbell, and W.J. Shaw, 1995, Organic Tanks Safety Program FY95 Waste Aging Studies, PNL-10794, Pacific Northwest National Laboratory, Richland, Washington.

Camaioni, D.M., W.D. Samuels, S.A. J.C. Lenihan, S.A. Clauss, A.K. Sharma, K.L. Wahl, and J.A. Campbell, 1996, Organic Tanks Safety Program FY96 Waste Aging Studies, PNL-11312, Pacific Northwest National Laboratory, Richland, Washington. 
Cannon, N.S., and R.C. Knight, 1995, Retained Gas Sampler System Acceptance Test Report, WHC-SD-WM-ATR-137 Rev. 0, Westinghouse Hanford Company, Richland, Washington.

Cashdollar, K.L., G.M. Green, M. Hertzog, C.E. Lucci, R.A. Thomas, and I.A. Zachower, 1992, Laboratory Flammability Studies of Mixtures of Hydrogen Nitrous Oxide and Air, WHC-SD-WM-ES-219 Rev. 0, Westinghouse Hanford Company, Richland, Washington.

Chhabra, R.P., and P.H.T. Uhlherr, 1986, "Static Equilibrium and Motion of Spheres in Viscoplastic Liquids," Encyclopedia of Fluid Mechanics, Vol. 21, N.P. Cheremisinoff, ed., pp.611-633.

Chhabra, R.P., 1992, Bubbles, Drops, and Particles in non-Newtonian Fluids, CRC Press, Boca Raton, Florida.

DOE, 1991, Unreviewed Safety Questions, DOE Order 5480.21, U.S. Department of Energy, Washington, D.C.

DOE-RL, 1996, Recommendation 93-5 Implementation Plan, DOE-RL-94-0001, Rev. 1, U.S. Department of Energy, Richland Operations, Richland, Washington.

Dullien, F.A.L., 1992, Porous Media: Fluid Transport and Pore Structure, Academic Press, San Diego, California.

Ecology, EPA, and DOE, 1996, Hanford Federal Facility Agreement and Consent Order, as amended, Washington State Department of Ecology, U.S. Environmental Protection Agency, and U.S. Department of Energy, Olympia, Washington.

Gauglitz, P.A., L.A. Mahoney, D.P. Mendoza, and M.C. Miller, 1994, Mechanisms of Gas Bubble Retention, PNL-10120, Pacific Northwest Laboratory, Richland, Washington.

Gauglitz, P.A., S.D. Rassat, M.R. Powell, R.R. Shah, and L.A. Mahoney, 1995, Gas Bubble Retention and its Effect on Waste Properties: Retention Mechanisms, Viscosity, and Tensile and Shear Strength, PNL-10740, Pacific Northwest Laboratory, Richland, Washington.

Gauglitz, P.A., P.R. Bredt, J.H. Konynenbelt, D.P. Mendoza, S.D. Rassat, and S.M. Tingey, 1996, Mechanisms of Gas Retention and Release: Results for Hanford Waste Tanks 2412-102 and 241-SY-103 and Single-Shell Tank Simulants, PNNL-11298, Pacific Northwest National Laboratory, Richland, Washington.

Graves, R.D., 1994, Topical Report on Flammable Gases in Non-Burping Waste Tanks, WHC$S D-W M-S A R R-015$, Westinghouse Hanford Company, Richland, Washington. 
Grigsby, J.M., and C.E. Leach, 1996, Flammable Gas/Slurry Growth Unreviewed Safety Question: Justification for Continued Operation for the Tank Farms, WHC-SD-WM-JCO-007 Rev. 0A, Westinghouse Hanford Company, Richland, Washington.

Hanlon, B.M., 1996, Waste Tank Summary Report for Month Ending February 29, 1996. Westinghouse Hanford Company, Richland, Washington.

Harmon, H.D., January 8, 1991a, Safety Measures for Waste Tanks at the Hanford Site, Richland, Washington, External letter 9059124 to R.E. Gerton, DOE-RL, Westinghouse Hanford Company, Richland, Washington.

Harmon, H.D., February 8, 1991b, Watch List for Tanks Which May Have Hydrogen Buildup, External letter 9001478B RI to R.E. Gerton, DOE-RL, Westinghouse Hanford Company, Richland, Washington.

Hermann, C., I. Dewes, and A. Schumpe, 1995, "Chemical Engineering Science," 50:1673.

Hodgson, K.M., 1995, Evaluation of Hanford Tanks for Trapped Gas, WHC-SD-WM-E-526 Rev. 0, Westinghouse Hanford Company, Richland, Washington.

Hodgson, K.M., R.P. Anantamula, S.A. Barker, K.D. Fowler, D.C. Hedengren, J.D. Hopkins, J.A. Lechelt, D.A. Reynolds, R.E. Stout, and R.T. Winward, 1996, Evaluation of Hanford Tanks for Trapped Gas, WHC-SD-WM-ER-526 Rev. 1, Westinghouse Hanford Company, Richland, Washington.

Hopkins, J.D., 1994, Criteria for Flammable Gas Watch List Tanks, WHC-EP-0702 Rev. 0, Westinghouse Hanford Company, Richland, Washington.

Hopkins, J.D., 1995, Methodology for Flammable Gas Evaluations, WHC-SD-WM-TI-724 Rev. O, Westinghouse Hanford Company, Richland, Washington.

Hopkins, J.D., 1996, Methodology for Flammable Gas Evaluations, WHC-SD-WM-TI-724 Rev. 1, Westinghouse Hanford Company, Richland, Washington.

Johnson, G.D., 1996a, Evaluation of Recommendation for Addition of Tanks to the Flammable Gas Watch List, WHC-SD-WM-ER-594 Rev. 0, Westinghouse Hanford Company, Richland, Washington.

Johnson, G.D., August 28, 1996b, Flammable Gas Project: Unreviewed Safety Question Closure Path Forward and Milestone T22-96-119, Letter 9653533.1 to J.K. McClusky, Westinghouse Hanford Company, Richland, Washington. 
LANL, 1996, A Safety Assessment of Push-Mode and Rotary-Mode Core Sampling in Flammable Gas Single Shell Tanks: Hanford Site, Richland, Washington, WHC-SDWM-SAD-035 Rev. 1, Appendix L, Westinghouse Hanford Company, Richland, Washington.

Lawrence, M.J., May 14, 1990, Unreviewed Safety Question--Waste Storage Tanks, Letter to L.P. Duffy, DOE-RL, Richland, Washington.

Lentsch, J.W., October 15, 1996, Flammable Gas Project: Revised Strategy for Continuous Monitoring, Letter 9654881 to S. Marchetti, Duke Engineering Services Hanford, Richland, Washington.

Meisel, D., H. Diamond, E.P. Horowitz, C.D. Jonah, M.S. Matheson, M.C. Sauer, and J.C. Sullivan, 1991, Radiation Chemistry of Synthetic Waste, ANL-91/40, Argonne National Laboratory, Argonne, Illinois.

Meisel, D., C.D. Jonah, M.S. Matheson, M.C. Sauer Jr., F. Barnabas, E. Cerney, Y. Cheng, and T. Wojta, 1992, Radiation Chemistry of High-Level Wastes ANL/CHM Task Force on Gas Generation in Waste Tanks, ANL-92/40, Argonne National Laboratory, Argonne, Illinois.

Meisel, D., C.D. Jonah, S. Kapoor, M.S. Matheson, and M.C. Sauer, 1993, Radiolytic and Radiolytically Induced Generation of Gases from Synthetic Wastes, ANL-93/43, Argonne National Laboratory, Argonne, Illinois.

National Defense Authorization Act for Fiscal Year 1991, Public Law 101-510, Section 3137, "Safety Measures for Waste Tanks at the Hanford Nuclear Reservation," November 5, 1990.

Norton, J.D., and L.R. Pederson, 1994, Ammonia in Simulated Hanford Double-Shell Tank Wastes: Solubility and Effects of Surface Tension, PNL-10173, Pacific Northwest Laboratory, Richland, Washington.

Norton, J.D., and L.R. Pederson, 1995, Solubilities of Gases in Simulated Tank 241 SY-101 Wastes, PNL-10785, Pacific Northwest Laboratory, Richland, Washington.

Palmer, B.J., C.M. Anderson, G. Chen, J.M. Cuta, T.A. Ferryman, and G. Terrones, 1996, Evaluation of the Potential for Significant Ammonia Releases from Hanford Waste Tanks, PNNL-11237, Pacific Northwest National Laboratory, Richland, Washington.

Pasamehmetoglu, K., 1994, Analyses of Gas Composition and Relevant Gas Concentration Measurements for the Release Gas in Tank 24I-SY-101, N6-CN-WT-SA-GR-004, Los Alamos National Laboratory, Los Alamos, New Mexico. 
Pederson, L.R., and S.A. Bryan, 1996, Status and Integration of Studies of Gas Generation in Hanford Wastes, PNNL-11297, Pacific Northwest National Laboratory, Richland, Washington.

Person, J.C., 1996, Effects of Oxygen Cover Gas and NaOH Dilution on Gas Generation in Tank 241-SY-101 Waste, WHC-SD-WM-DTR-043, Westinghouse Hanford Company, Richland, Washington.

Peurrung, L.M., S.M. Caley, E.Y. Bian, and P.A. Gauglitz, 1996, Gas Release During Salt Well Pumping: Model Predictions and Comparisons to Laboratory Experiments, PNNL-11310, Pacific Northwest National Laboratory, Richland, Washington.

Remund, K.M., C.M. Anderson, and B.C. Simpson, 1995, Hanford Single-Shell Tank Grouping Study, PNL-10749, Pacific Northwest Laboratory, Richland, Washington.

Reynolds, D.A., May 4, 1992, Current Understanding of the Composition of Gas from 101-SY, Internal memorandum 7K210-92-310 to C.E. Hansen, Westinghouse Hanford Company, Richland, Washington.

Ross, M.C., and J.E. Shepherd, 1996, Lean Combustion Characteristics of Hydrogen-Nitrous Oxide-Ammonia Mixtures in Air, Part 1, FM 96-4, California Institute of Technology, Pasadena, California.

Shekarriz, A., D.R. Rector, L.A. Mahoney, M.A. Chieda, J.M. Bates, R.E. Bauer, N.S. Cannon, B.E. Hey, C.G. Linschooten, F. J. Reitz, and E.R. Siciliano, 1996, Preliminary Retained Gas Sampler Measurement Results for Hanford Waste Tanks 241-AW-101, 24I-A-101, 24I-AN-103, 241-AN-104, and 24I-AN-105, PNNL 11450, Pacific Northwest National Laboratory, Richland, Washington.

Shepard, C.L., C.W. Stewart, J.M. Alzheimer, G. Terrones, G. Chen, and N.E. Wilkins, 1995, In Situ Determination of Rheological Properties and Void Fraction: Hanford Waste Tank 241-SY-103, PNL-10865, Pacific Northwest National Laboratory, Richland, Washington.

Sohn, C.L., January 13, 1997, Qualified Acceptance of the Memorandum of Understanding (MOU) on the Strategy for Closure of the Flammable gas Unreviewed Safety Question, Letter 96-WSD-356 to H.J. Hatch, Fluor Daniel Hanford, Inc., Richland, Washington.

Stauffer, D., 1985, Introduction to Percolation Theory, Taylor and Francis, London.

Stewart, C.W., C.L. Shepard, J.M. Alzheimer, and G. Terrones, 1995, In Situ Determination of Rheological Properties and Void Fraction in Hanford Waste Tank 241-SY-101, PNL-10682, Pacific Northwest Laboratory, Richland, Washington. 
Stewart, C.W., J.M. Alzheimer, M.E. Brewster, G. Chen, R.E. Mendoza, H.C. Reid, C.L. Shepard, and G. Terrones, 1996a, In Situ Rheology and Gas Volume in Hanford Double-Shell Waste Tanks, PNNL-11296, Pacific Northwest National Laboratory, Richland, Washington.

Stewart, C.W., M.E. Brewster, P.A. Gauglitz, L.A. Mahoney, P.A. Meyer, K.P. Recknagle, and H.C. Reid, 1996b, Gas Retention and Release Behavior in Hanford Single-Shell Waste Tanks PNNL-11391, Pacific Northwest National Laboratory, Richland, Washington.

Wagoner, J.D., August 19, 1996a, Transmittal of Information to Complete Milestone 5.4.3.5.b Letter 96-WSD-161 to J.T. Conway, DNFSB, DOE-RL, Richland, Washington.

Wagoner, J.D., November 1, 1996b, Definition and Declaration of Flammable Gas Unreviewed Safety Question (USQ), Letter 96-WSD-283 to H.J. Hatch, Fluor Daniel Hanford, Inc., Richland, Washington.

Whitney, P.D., 1995, Screening the Hanford Tanks for Trapped Gas, PNL-10821, Pacific Northwest Laboratory, Richland, Washington.

Whitney, P.D., P.A. Meyer, N.E. Wilkins, F. Gao, and A.G. Wood. 1996, Flammable Gas Data Evaluation Progress Report, PNNL-11373, Pacific Northwest National Laboratory, Richland, Washington.

Wilkins, N.E., R.E. Bauer, and D.M. Ogden, 1996, Results of Vapor Space Monitoring of Flammable Gas Watch List Tanks, WHC-SD-WM-TI-797, Westinghouse Hanford Company, Richland, Washington. 
HNF-SP-1193, Rev. 2

This page intentionally left blank. 
HNF-SP-1193, Rev. 2

APPENDIX A

WATCH LIST TANKS 
HNF-SP-1 193, Rev. 2

This page intentionally left blank. 


\section{APPENDIX A: \\ DETERMINATION OF WHICH TANKS WERE TO BE FLAMMABLE GAS WATCH LIST TANKS}

A flammable gas issue was declared an Unreviewed Safety Question (USQ) in March 1990 for tank 241-SY-101. The notification that DOE-RL sent out in May 1990 also referenced other affected tanks as part of the response to DOE Order 5480.5. Tanks that were identified to be "flammable gas tanks" were considered to pose a problem because of observed changes (as noted in a review of plant records, documents, and letters) in the waste surface level, such as sudden drops or a continuous increase in level, or by engineering judgement. This process identified 20 tanks. Subsequently, an analysis based on criteria (level increase, unexplained pressurizations or changes in temperature, surface crust, total organic carbon content, and B-Plant waste in tank) for exhibiting slurry growth identified two more tanks to bring the total to 22 . Tank SX-109 was added to the list of tanks because six of the identified tanks vented through it. Thus the original list of tanks identified for the USQ encompassed 23 tanks.

In November of 1990, "Safety Measures for Waste Tanks at Hanford Nuclear Reservation", Public Law 101-510, Section 3137 became effective. In WHC's response to the requirements of this law, tanks were identified as those that "may have a serious potential for release of high-level waste due to uncontrolled increases in temperature or pressure...." These tanks became known as "Watch List" tanks. At that time watch lists were created for the safety issues of flammable gases, ferrocyanide, organic salt, and high heat load.

As part of the program to deal with the flammable gas safety issue, analyses of tank data indicated that two other tanks (101-AW and 107-U) needed to be added to the Watch List, bringing the current total to 25. The table below provides a listing of the 25 Flammable Gas Watch List tanks. A more comprehensive discussion of how the watch list tanks were identified is given in Harmon (1991). 
HNF-SP-1193, Rev. 2

Table A-1. Flammable Gas Watch List Tanks

\begin{tabular}{||c|c|c||}
\hline \multicolumn{2}{|c|}{ Single-Shell Tanks } & Double-Shell Tanks \\
\hline \hline $101-\mathrm{A}$ & $105-\mathrm{SX}$ & $103-\mathrm{AN}$ \\
\hline $101-\mathrm{AX}$ & $106-\mathrm{SX}$ & $104-\mathrm{AN}$ \\
\hline $103-\mathrm{AX}$ & $109-\mathrm{SX}$ & $105-\mathrm{AN}$ \\
\hline $102-\mathrm{S}$ & $110-\mathrm{T}$ & $101-\mathrm{SY}$ \\
\hline $111-\mathrm{S}$ & $103-\mathrm{U}$ & $103-\mathrm{SY}$ \\
\hline $112-\mathrm{S}$ & $105-\mathrm{U}$ & $101-\mathrm{AW}$ \\
\hline $101-\mathrm{SX}$ & $107-\mathrm{U}$ & \\
\hline $102-\mathrm{SX}$ & $108-\mathrm{U}$ & \\
\hline $103-\mathrm{SX}$ & $109-\mathrm{U}$ & \\
\hline $104-\mathrm{SX}$ & & \\
\hline
\end{tabular}

\section{REFERENCE}

Harmon, H.D., February 8, 1991, Watch List for Tanks Which May Have Hydrogen Buildup, External letter 9001478B R1 to R.E. Gerton, DOE-RL, Westinghouse Hanford Company, Richland, Washington. 


\section{APPENDIX B}

RESULTS OF VAPOR PHASE SAMPLING OF HANFORD SITE PASSIVELY VENTHATED SINGLE-SHELL TANKS

B-1 
HNF-SP-1 193, Rev. 2

This page intentionally left blank. 


\title{
APPENDIX B:
}

\section{RESULTS OF VAPOR PHASE SAMPLING OF HANFORD SITE PASSIVELY VENTILATED SINGLE-SHELL TANKS}

\begin{abstract}
All 134 passsively ventilated single-shell tanks were vapor-phase sampled for flammable gas by the vapor sampling system truck (Bratzel et al. 1995) or by direct measurement on a stream extracted from a tank's headspace using a combustible gas meter (Grigsby and Leach 1996). The results of sampling for each tank shown in Table B-1 along with the date on which the tank was sampled, the type of sampling preformed, and the percent of the lower flammability limit (LFL) obtained.
\end{abstract}

The tank showing the highest LFL percent is $241-\mathrm{C}-103$; the result reported is $13 \%$ of the LFL, well below the action limit of $25 \%$. Tank 241-C-103 has a floating organic layer on its surface and is expected to have relatively higher concentrations of flammable organic vapors and hydrogen. The next highest tank was $241-\mathrm{S}-101$ at $7 \%$ of the LFL. Of the 134 tanks sampled, 27 showed flammable gas concentrations above $1 \%$ of the LFL.

The purpose of this sampling is to understand the steady-state concentration of flammable gas in the tanks under normal operating conditions. There was no attempt made to sample during periods of restricted passive ventilation or gas release events. Although these conditions may occur and would result in elevated flammable gas conditions, it is important to understand that the normal condition for the head space is nonflammable even in tanks that experience passive ventilation only. 
HNF-SP-1193, Rev. 2

Table B-1. Sampling Results for Passively Ventilated Single-Shell Tanks. (5 sheets)

\begin{tabular}{|c|c|c|c|}
\hline Tank No. & Sample Date & Sample IYpe & Total L FL (\%) \\
\hline A-101 & $04 / 09 / 95$ & VSS & 2.5 \\
\hline A-102 & $11 / 10 / 95$ & VSS & 0.93 \\
\hline A-103 & $11 / 09 / 95$ & VSS & 1.38 \\
\hline A-104 & $01 / 14 / 96$ & CGM & 0 \\
\hline A-105 & $01 / 19 / 96$ & CGM & 0 \\
\hline A-106 & $08 / 12 / 96$ & $\mathrm{CGM}$ & 2 \\
\hline AX-101 & $04 / 15 / 95$ & VSS & 0.32 \\
\hline $\mathrm{AX}-102$ & $06 / 28 / 95$ & VSS & 0 \\
\hline AX-103 & $04 / 21 / 95$ & VSS & $<0.31$ \\
\hline AX-104 & $01 / 14 / 96$ & CGM & 0 \\
\hline B-101 & $03 / 26 / 96$ & CGM & 0 \\
\hline B-102 & $04 / 18 / 96$ & VSS & 0 \\
\hline B-103 & $02 / 08 / 95$ & VSS & 0 \\
\hline B-104 & $03 / 26 / 96$ & CGM & 0 \\
\hline B-105 & $06 / 06 / 96$ & CGM & 0 \\
\hline B-106 & $04 / 26 / 96$ & CGM & 0 \\
\hline B-107 & $06 / 06 / 96$ & CGM & 2 \\
\hline B-108 & $04 / 26 / 96$ & CGM & 0 \\
\hline B-109 & $06 / 12 / 96$ & CGM & 0 \\
\hline B-110 & $04 / 26 / 96$ & CGM & 0 \\
\hline B-111 & $03 / 19 / 96$ & CGM & 0 \\
\hline B-112 & $08 / 30 / 95$ & CGM & 0 \\
\hline B-201 & $06 / 04 / 96$ & CGM & 0 \\
\hline B-202 & $06 / 04 / 96$ & CGM & 0 \\
\hline B-203 & $11 / 20 / 95$ & CGM & 0 \\
\hline B-204 & $04 / 26 / 96$ & CGM & 0 \\
\hline BX-101 & $04 / 24 / 96$ & CGM & 0 \\
\hline BX-102 & $06 / 24 / 96$ & CGM & 0 \\
\hline BX-103 & $03 / 26 / 96$ & CGM & 0 \\
\hline BX-104 & $12 / 30 / 94$ & VSS & 0.4 \\
\hline BX-105 & $04 / 24 / 96$ & VSS & 0 \\
\hline BX-106 & $12 / 19 / 95$ & CGM & 0 \\
\hline BX-107 & $11 / 17 / 95$ & VSS & 0.1 \\
\hline
\end{tabular}


Table B-1. Sampling Results for Passively Ventilated Single-Shell Tanks. (5 sheets)

\begin{tabular}{|c|c|c|c|}
\hline Tank Nos & Sample Date & Sample Type & Taul LP $(\%)$ \\
\hline BX-108 & $08 / 29 / 95$ & CGM & 0 \\
\hline BX-109 & $04 / 24 / 96$ & CGM & 0 \\
\hline BX-110 & $10 / 02 / 95$ & CGM & 0 \\
\hline $\mathrm{BX}-111$ & $04 / 24 / 96$ & $\mathrm{CGM}$ & 0 \\
\hline BX-112 & $04 / 16 / 95$ & CGM & 0 \\
\hline BY-101 & $08 / 08 / 96$ & CGM & 0 \\
\hline BY-102 & $11 / 21 / 95$ & VSS & 0.26 \\
\hline BY -103 & $11 / 01 / 94$ & VSS & 0.1 \\
\hline BY-104 & $06 / 24 / 94$ & VSS & 1 \\
\hline BY-105 & $07 / 07 / 94$ & VSS & 0.3 \\
\hline BY-106 & $07 / 08 / 94$ & VSS & 0.2 \\
\hline BY-107 & $10 / 26 / 94$ & VSS & 2.3 \\
\hline BY-108 & $10 / 27 / 94$ & VSS & 3.4 \\
\hline BY-109 & 08/08/96 & CGM & 0 \\
\hline BY-110 & $11 / 11 / 94$ & VSS & 0.4 \\
\hline BY-111 & $11 / 16 / 94$ & VSS & 0.2 \\
\hline BY-112 & $11 / 18 / 94$ & VSS & 0.1 \\
\hline C-101 & $09 / 01 / 94$ & VSS & 1.8 \\
\hline C- 102 & $08 / 23 / 94$ & VSS & 1.2 \\
\hline C-103 & $05 / 24 / 94$ & VSS & 13 \\
\hline C- 104 & $3 / 3 / 94$ & VSS & 0.3 \\
\hline C-107 & $09 / 29 / 94$ & VSS & 0.6 \\
\hline C- 108 & $08 / 05 / 94$ & VSS & 0 \\
\hline C-109 & $08 / 09 / 94$ & VSS & 0.3 \\
\hline C-110 & $08 / 24 / 94$ & VSS & 0.2 \\
\hline C-111 & $09 / 13 / 94$ & VSS & 0.03 \\
\hline $\mathrm{C}-112$ & $08 / 11 / 94$ & VSS & 0.5 \\
\hline C-201 & $08 / 31 / 95$ & CGM & 0 \\
\hline C-202 & $08 / 31 / 95$ & CGM & 0 \\
\hline C-203 & $08 / 29 / 95$ & CGM & 0 \\
\hline C-204 & $06 / 03 / 96$ & CGM & 0 \\
\hline S-101 & $04 / 03 / 96$ & CGM & 7 \\
\hline S-102 & $03 / 14 / 95$ & VSS & 2 \\
\hline
\end{tabular}


HNF-SP-1193, Rev. 2

Table B-1. Sampling Results for Passively Ventilated Single-Shell Tanks. (5 sheets)

\begin{tabular}{|c|c|c|c|}
\hline Tank No. & Sample Date & Sample Type & Fotal L I. ( $\%$ ) \\
\hline S-103 & $05 / 17 / 96$ & CGM & 0 \\
\hline S-104 & $03 / 19 / 96$ & CGM & 0 \\
\hline S- 105 & $12 / 07 / 95$ & VSS & 0.09 \\
\hline S-106 & $05 / 17 / 96$ & CGM & 0 \\
\hline S-107 & $09 / 30 / 95$ & CGM & 4 \\
\hline S-108 & $12 / 06 / 95$ & VSS & 0.09 \\
\hline S-109 & $05 / 17 / 96$ & CGM & 0 \\
\hline$S-110$ & $12 / 05 / 95$ & VSS & 0.45 \\
\hline S-111 & $03 / 21 / 95$ & VSS & 1.1 \\
\hline S-112 & $07 / 11 / 95$ & VSS & 0.1 \\
\hline SX-113 & $08 / 18 / 95$ & CGM & 0 \\
\hline SX-115 & $03 / 08 / 96$ & CGM & 0 \\
\hline $\mathrm{T}-101$ & $07 / 30 / 96$ & CGM & 0 \\
\hline $\mathrm{T}-102$ & $05 / 09 / 96$ & CGM & 0 \\
\hline T-103 & $02 / 15 / 96$ & CGM & 0 \\
\hline T-104 & $2 / 7 / 96$ & VSS & 0 \\
\hline $\mathrm{T}-105$ & $05 / 09 / 96$ & CGM & 0 \\
\hline T-106 & $05 / 09 / 96$ & CGM & 0 \\
\hline T-107 & $12 / 18 / 95$ & VSS & 0.1 \\
\hline$T-108$ & $05 / 09 / 96$ & CGM & 0 \\
\hline $\mathrm{T}-109$ & $05 / 09 / 96$ & CGM & 0 \\
\hline$T-110$ & $08 / 31 / 95$ & VSS & 0.1 \\
\hline$T-111$ & $12 / 20 / 95$ & VSS & 0.2 \\
\hline T-112 & $05 / 09 / 96$ & CGM & 0 \\
\hline T-201 & $07 / 31 / 96$ & CGM & 0 \\
\hline$T-202$ & $08 / 09 / 96$ & CGM & 2 \\
\hline T-203 & $03 / 19 / 96$ & CGM & 0 \\
\hline T-204 & $07 / 31 / 96$ & $\mathrm{CGM}$ & 0 \\
\hline TX-101 & $06 / 14 / 96$ & CGM & 0 \\
\hline TX-102 & $06 / 20 / 96$ & CGM & 0 \\
\hline TX-103 & $06 / 17 / 96$ & CGM & 0 \\
\hline TX-104 & $07 / 23 / 96$ & $\mathrm{CGM}$ & 0 \\
\hline TX-105 & $12 / 21 / 94$ & VSS & 0 \\
\hline
\end{tabular}


HNF-SP-1193, Rev. 2

Table B-1. Sampling Results for Passively Ventilated Single-Shell Tanks. (5 sheets)

\begin{tabular}{|c|c|c|c|}
\hline Tank ro, & Sapple Date & Sample Type & Total L RL $(\%)$ \\
\hline TX-106 & $07 / 23 / 96$ & CGM & 0 \\
\hline TX-107 & $01 / 17 / 96$ & $\mathrm{CGM}$ & 0 \\
\hline TX-108 & $07 / 17 / 96$ & $\mathrm{CGM}$ & 0 \\
\hline TX-109 & $07 / 17 / 96$ & $\mathrm{CGM}$ & 1 \\
\hline $\mathrm{TX}-110$ & $07 / 17 / 96$ & CGM & 0 \\
\hline $\mathrm{TX}-111$ & $10 / 12 / 95$ & VSS & 0.78 \\
\hline TX-112 & $07 / 24 / 96$ & CGM & 0 \\
\hline TX-113 & $06 / 18 / 96$ & CGM & 0 \\
\hline TX-114 & $06 / 18 / 96$ & CGM & 0 \\
\hline TX-115 & $08 / 01 / 96$ & CGM & 0 \\
\hline $\mathrm{TX}-116$ & $3 / 19 / 96$ & $\mathrm{CGM}$ & 0 \\
\hline $\mathrm{TX}-117$ & $03 / 19 / 96$ & CGM & 0 \\
\hline TX-118 & $12 / 16 / 94$ & VSS & 0.3 \\
\hline TY-101 & $04 / 06 / 95$ & VSS & 0 \\
\hline TY-102 & $04 / 05 / 96$ & CGM & 0 \\
\hline TY-103 & $04 / 11 / 95$ & VSS & 0.2 \\
\hline TY-104 & $04 / 27 / 95$ & VSS & 0 \\
\hline TY-105 & $08 / 06 / 96$ & CGM & 2 \\
\hline TY-106 & $08 / 18 / 95$ & CGM & 0 \\
\hline U-101 & $02 / 14 / 96$ & CGM & 1 \\
\hline U-102 & $04 / 30 / 96$ & CGM & 3 \\
\hline U-103 & $02 / 15 / 95$ & VSS & 1.9 \\
\hline U-104 & $05 / 10 / 96$ & CGM & 0 \\
\hline U-105 & $02 / 21 / 95$ & VSS & 0.2 \\
\hline U-106 & $03 / 08 / 95$ & VSS & 1.2 \\
\hline U-107 & $02 / 17 / 95$ & VSS & 1.6 \\
\hline U-108 & $08 / 29 / 95$ & VSS & 1.85 \\
\hline U-109 & $08 / 16 / 95$ & VSS & 2.33 \\
\hline U-110 & $03 / 19 / 96$ & CGM & 2 \\
\hline U-111 & $02 / 28 / 95$ & VSS & 1.1 \\
\hline U-112 & $07 / 03 / 96$ & CGM & 2 \\
\hline U-201 & $08 / 18 / 95$ & CGM & 0 \\
\hline U-202 & $08 / 18 / 95$ & CGM & 0 \\
\hline
\end{tabular}


HNF-SP-1 193, Rev. 2

Table B-1. Sampling Results for Passively Ventilated Single-Shell Tanks. (5 sheets)

\begin{tabular}{|l|c|c|c|}
\hline \multicolumn{1}{|c|}{ Tank No. } & Sample Date & . Sample Type & . Total LrL $(\%)$ \\
\hline U-203 & $08 / 09 / 95$ & VSS & 0 \\
\hline U-204 & $08 / 08 / 95$ & VSS & 0 \\
\hline Note: The date is given in the $\mathrm{mm} / \mathrm{dd} / \mathrm{yy}$ format. \\
\hline
\end{tabular}

\section{REFERENCES}

Bratzel, D.R., H. Babad, and J.L. Huckaby, 1995, Headspace Gas and Vapor Characterization Summary for 43 Vapor Program Suspect Tanks, WHC-SD-WM-ER-514 Rev. 0, Westinghouse Hanford Company, Richland, Washington.

Grigsby, J.M., and C.E. Leach, 1996, Flammable Gas/Slurry Growth Unreviewed Safety Question: Justification for Continued Operation for the Tank Farms, WHC-SD-WM-JCO-007 Rev. 0A, Westinghouse Hanford Company, Richland, Washington. 
HNF-SP-1193, Rev. 2

\section{DISTRIBUTION}

Number of copies

OFFSITE

U.S. Department of Energy

EM-38, Trevion II

12800 Middlebrook Road

Germantown, MD 20874

Harry Calley

Dave Pepson

Ken Lang

1

Argonne National Laboratory

9700 S. Cass Avenue

Argonne, IL 60439

Danny Meisel

1

Harry Babad

2540 Cordoba Court

Richland, WA 99351

1

David O. Campbell

102 Windham Road

Oak Ridge, TN 37830

1

Billy C. Hudson

202 Northridge Court

P.O. Box 271

Lindsborg, KA 67456

1

Thomas S. Kress

102-B Newridge Road

Oak Ridge, TN 37830

1

Thomas E. Larson

2711 Walnut Street

Los Alamos, NM 87544 


\section{DISTRIBUTION (Continued)}

Fauske and Associates, Inc. $16 \mathrm{~W} 070 \mathrm{~W} .83$ rd St.

Burr Ridge, IL 60521

Marty G. Plys

Hans K. Fauske

1

G \& P Consulting. Inc. 3640 Ballard Road

Dallas, OR 97338

Arlin K. Postma

Los Alamos National Laboratory

P.O. Box 1663

Los Alamos, NM 87545

W. L. Kubic K557

K. Pasamehmetoglu K555

C. Unal K575

Nuclear Consulting Services, Inc.

P.O. Box 29151

Columbus, OH 43229-0151

J. Louis Kovach

1

Oak Ridge National Laboratory

P.O. Box 2008

Oak Ridge, TN 37831-6495

Charles W. Forsberg, MS-6495

2

Sandia National Laboratories

P.O. Box 5800

Albuquerque, NM 87185

Dana A. Powers, MS-0744

Scott E. Slezak, MS-0741 
HNF-SP-1193, Rev. 2

\section{DISTRIBUTION (Continued)}

State of Washington - Department of Ecology

Alex B. Stone

1315 W. 4th Avenue

Kennewick, WA 99336

1

Westinghouse Savannah River Company

Savannah River Site 241-121H

Aiken, SC 29802

Susan J. Eberlein

ONSITE

12

U.S. Department of Energy, Richland Operations Office

M. H. Campbell $\quad$ S7-73

K. Chen S7-54

J. M. Gray \$7-54

C. A. Groendyke $\quad$ S7-54

M. A. Hunemuller S7-50

D. H. Irby $\quad$ 57-54

J. K. McClusky S7-54

G. W. Rosenwald S7-54

C. L. Sohn S7-51

Public Reading RoomH2-53

RL Docket File (2) B1-17

Hanford Contractors

S. A. Barker

R2-11

W. B. Barton

R2-11

R. E. Bauer

S7-14

D. R. Bratzel

S7-14

R. J. Cash (3)

S7-14

A. F. Choho

H6-36

R. A. Dodd

S5-07

G. L. Dunford

A2-34

W. M. Funderburke

R2-38

T. C. Geer

R2-38

J. M. Grigsby

R1-49 


\section{DISTRIBUTION (Continued)}

R. C. Hill

R1-51

K. M. Hodgson

H0-34

G. D. Johnson (10)

S7-14

N. W. Kirch

R2-11

J. G. Kristofzski

R2-12

C. E. Leach

R1-49

J. W. Lentsch

S2-48

J. E. Meacham

S7-14

W. H. Meader

S8-05

D. M. Ogden

H0-34

M. A. Payne

S7-84

L. D. Pennington

S7-21

D. A. Reynolds

R2-11

S. H. Rifaey

R1-56

W. E. Ross

S5-07

O. M. Serrano

R2-12

J. P. Sloughter

R2-54

J. S. Schofield

S7-12

E. R. Siciliano

H0-31

L. M. Stock

S7-14

A. M. Umek

S7-81

R. J. Van Vleet

A3-34

D. J. Washenfelder

S7-40

J. R. White

S7-15

J. H. Wicks

R2-50

N. E. Wilkins

R2-11

Central Files

A3-88

EDMC

H6-08

DPC

A3-94

\section{ONSITE}

Pacific Northwest National Laboratory

Z. I. Antoniak

K7-15

J. M. Bates

K7-15

J. W. Brothers

K5-22

S. A. Bryan

P7-25

D. M. Camaioni

K2-44

J. A. Campbell

P8-08

P. A. Gauglitz

P7-41

R. T. Hallen

P8-38 
HNF-SP-1193, Rev. 2

\section{DISTRIBUTION (Continued)}

J. L. Huckaby

K6-80

B. J. Palmer

$\mathrm{K} 7-15$

F. E. Panisko

K8-34

L. R. Pederson

K2-44

A. Shekarriz

K7-15

C. W. Stewart

K7-15

P. D. Whitney

K5-12

Hanford Technical Library

P8-55 
HNF-SP-1193, Rev. 2

This page intentionally left blank. 